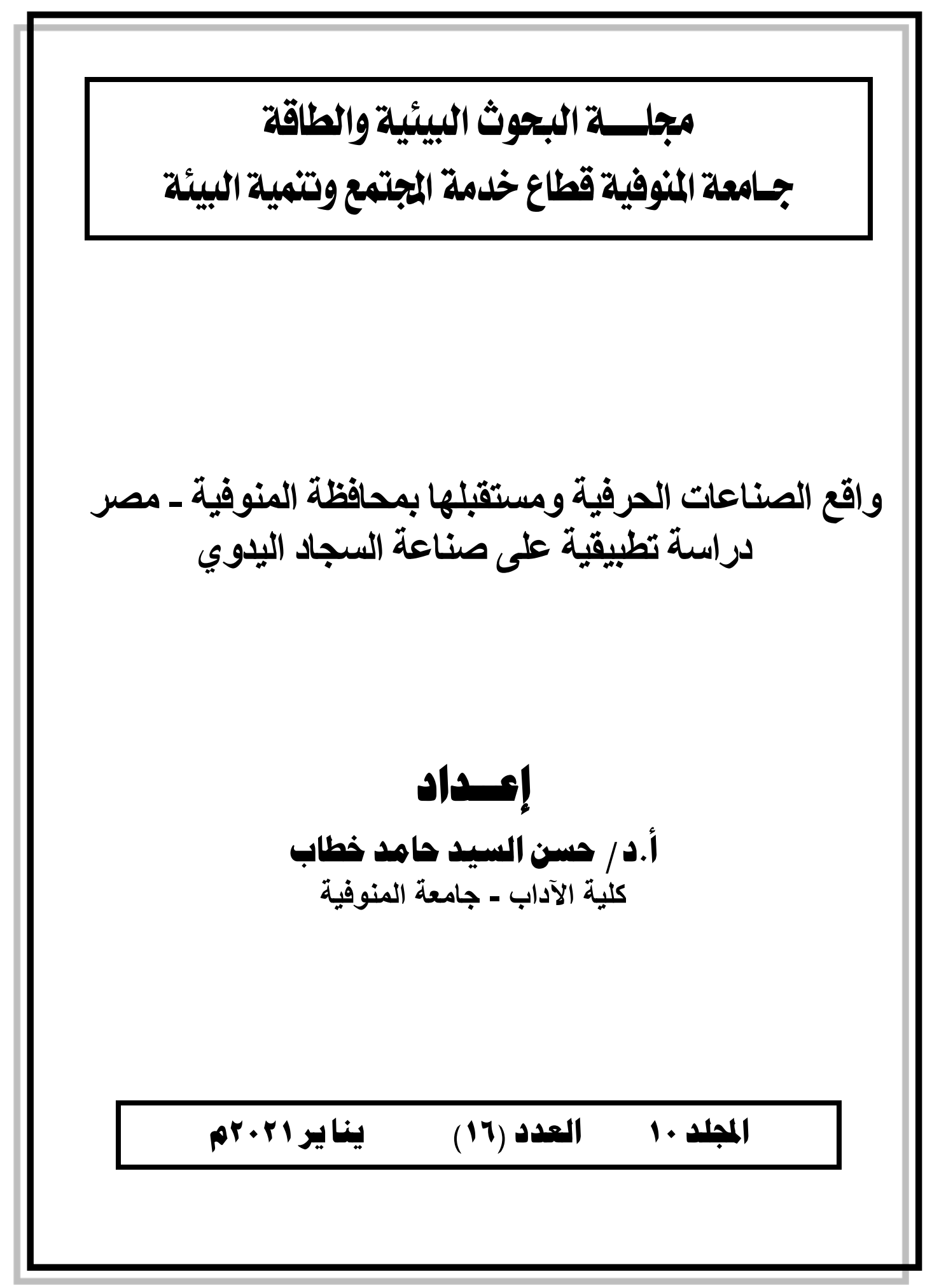


واقع الصناعات الحرفية ومستقبلها بمحافظة المنوفية ـ مصر

\section{واقع الصناعات الحرفية ومستقبلها بمحافظة المنوفية - مصر \\ دراسة تطبيقية على صناعة السجاد اليدوي}

\section{د/ موسى فتحي موسى عتلم}

أستاذ الجغرافيا الاقتصادية المساعد- كلية الآداب - جامعة المنوفية

مقدمة:

تمثل الصناعات الحرفية أحد الحرف المهمة التي يمكن أن تدفع عجلة التتمية في محافظة المنوفية، لاسيما أن المحافظة تمتلك العديد من العوامل المحفزة على نشر تلك الصناعات، بعضها اجتماعي وبعضها اقتصادي وبعضها بيئي، وقد نشأت تلك الصناعات كوسيلة من وسائل توفير فرص العمل وتحسين ظروف المعيشة وتثبيت السكان في أماكن إقامتهم بدلاً

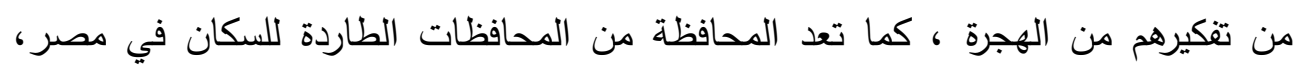
وينخفض نصيب الفرد من الأراضي الزراعية بها بدرجة كبيرة، كما يتسم القطاع الزراعي بعدم قدرته على استيعاب العمالة المتوفرة في المحافظة، بالإضافة إلى انخفاض نصيب

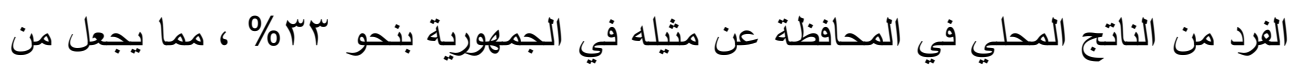

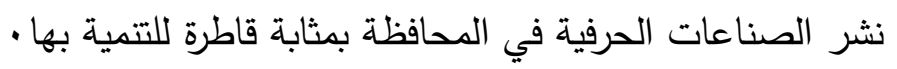
وقد ضمت المحافظة العديد من الصناعات الحرفية يتركز أغلبها في مركز أشمون من فن فئه أمثلتها صناعة السجاد اليدوي الحرير بساقية أبو شعرة التي تعد إحدى العلامات المميزة للصناعات الحرفية بالمحافظة وصناعة التطعيم بالصدف في ساقية المنقدي وصناعة الفخار إنداري بجريس وصناعة منتجات الجريد في شنوان وصناعة النسيج بكفر هلال، وقد استطاعت أن تجذب العديد من الاستثمارات والأيدي العاملة بها ، كما كان لها انعكاسها على أوضاع التتمية بتلك القرى وبعض القرى المجاورة لها، ومن ثم فإن هذه الصناعات يمكن أن تمثل أقطاب تتمية لدورها في تتمية قراها وبعض التجمعات المجاورة عن طريق الانتشار الصناعي

$1 T$.

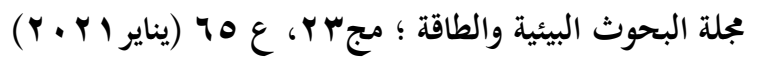


يحاول هذا البحث عرض تطور صناعة السجاد اليدوي وتفسير العوامل المؤثرة فيها ، كما يعرض اقتصاديات صناعة السجاد بمنطقة الدراسة، ويدرس مشكلاتها، ويعرض الدور التتموي للصناعة ، وينتهي ببيان بعض المقترحات لتنمية هذه الصناعة . مصادر بيانات البحث:

اعتمد البحث على بعض البيانات الإحصائية المنشورة وغير المنشورة ، بالإضافة إلى الدراسة الميدانية لصناعة السجاد اليدوي بمركز أثمون ، من خلال التركيز على عمل قاعدة بيانات لكافة مدخلات الصناعة ومخرجاتها ومشكلاتها ومستتبلها عن طريق استمارة استبيان تم تطبيقها مع عينة ممثلة للعاملين وأصحاب الورش بهذه الصناعة . كما تم مقابلة العديد من أصحاب ورش ومصانع السجاد والعاملين بالصناعة، ومقابلة مسئول التتمية بالقرية والمركز، بالإضافة إلى بعض المصادر التي وفرت بيانات محدودة عن الصناعة مثل مركز معلومات ساقية أبو شعرة ومركز معلومات مركز أشمون وإدارة

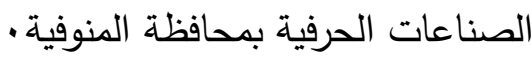

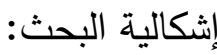

من الإشكاليات التي يطرحها البحث ويحاول تقديم إجابات وحلول لها: O كيف يمكن استغلال الواقع الاقتصادي والاجتماعي للسكان في المحافظة في نشر الصناعات الحرفية؟ - ت الص

كيف يمكن جعل هذا النموذج من الصناعات الحرفية في المحافظة بمثابة أقطاب تتمية لها كيف يمكن الاستفادة من الجامعات باعتبارها بيت الخبرة لإقليمها والمؤسسات التنفيذية

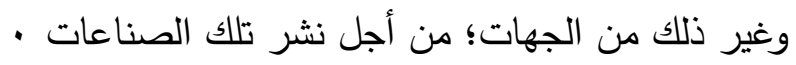
كيف يمكن وضع خريطة استثمارية لتتمية الصناعات الحرفية في المحافظة؟ 
واقع الصناعات الحرفية ومستقبلها بمحافظة المنوفية ـ مصر

محتويات البحث .

يتألف البحث من العناصر الآتية:

مقدمة عن صناعة السجاد اليدوي ومنطقة الدراسة .

• تطور صناعة السجاد اليدوي بمنطقة الدراسة .

• العوامل المؤثرة في صناعة السجاد بمنطقة الدراسة •

اقتصاديات صناعة السجاد بمنطقة الدراسة •

الآثار التنموية لصناعة السجاد بمنطقة الدراسة ـ .

بعض مشكلات صناعة السجاد بمنطقة الدراسة .

• آفاق تتمية صناعة السجاد بمنطقة الدراسة . .

(1) مقدمة عن صناعة السجاد اليدوي ومنطقة الدراسة •

تمثل صناعة السجاد اليدوي بساقية أبو شعرة إحدى الصناعات التي ذاع صيتها داخل

المحافظة وخارجها، في ظل عمل نسبة كبيرة من سكان القرية بهذه الصناعة ، حيث

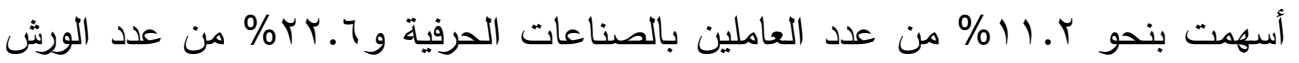

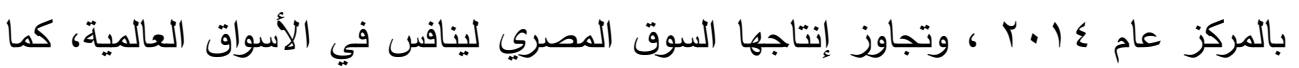

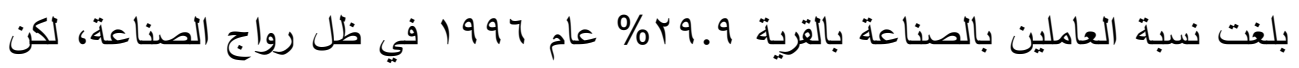

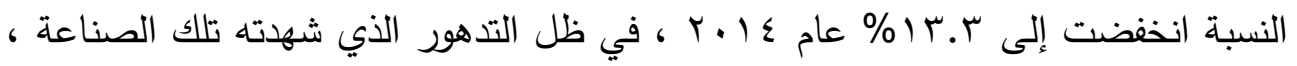
وبالرغم من ذلك فإن نسبة العاملين بالصناعة بها تتفوق على متوسط المركز والمحافظة .

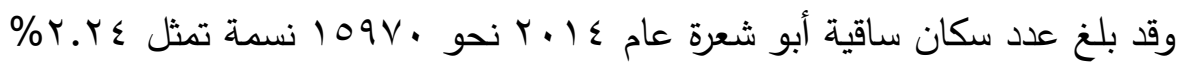

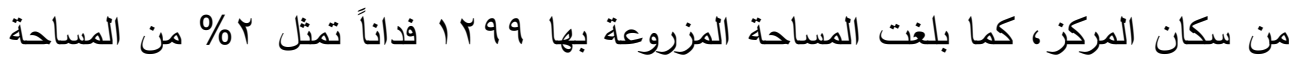

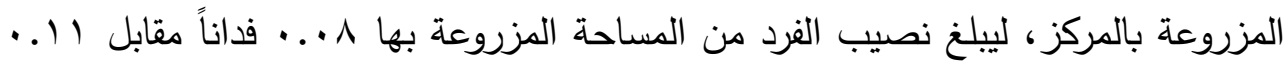
فداناً لنصيبه في المركز عام ع ا ـ. ، كما تتسم القرية بسيادة الحيازات القزمية بها، الأمر 
الذي يجعل انتشار صناعة السجاد في القرية بمثابة حل للكثير من مشكلاتها الاقتصادية والاجتماعية (مركز المعلومات ودعم اتخاذ القرار بمحافظة المنوفية، والنسب من حساب (الباحث)

كما أسهمت صناعة السجاد بساقية أبو شعرة في زيادة الوزن النسبي للمركز من

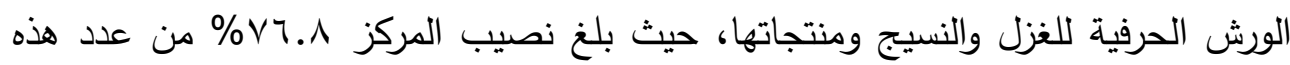

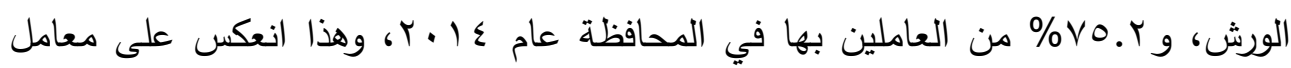
توطن ورش الغزل والنسيج ومنتجاتها بالمركز الذي بلغت قيمته ع.0 ، وهو يعني وجود توطن كبير لهذه الورش بالمركز ، في ظل وجود ساقية أبو شعرة التي ينتشر بها عدد كبير

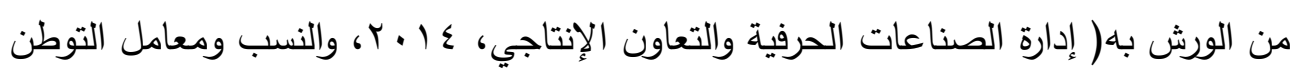
من حساب الباحث).

وتعد صناعة السجاد اليدوي بساقية أبو شعرة نموذجاً للصناعات الحرفية اليدوية

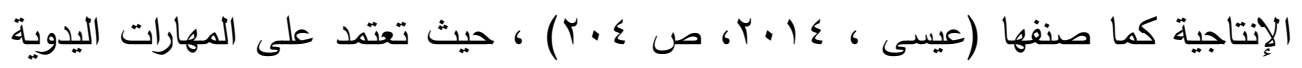
للصانع في عملية الصناعة ، كما تتسم الآلات التي تعتمد عليها الصناعة ببساطتها

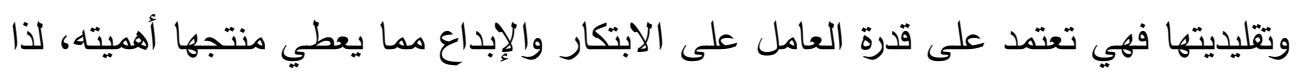
فإن العامل البشري ومهارته تمثل أهمية كبيرة في توطن تلك الصناعة بالقرية .

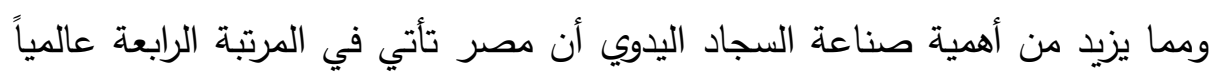

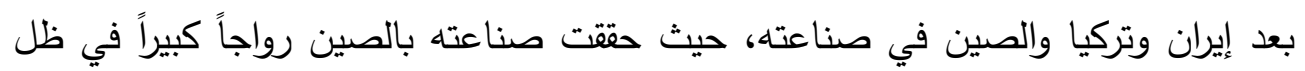

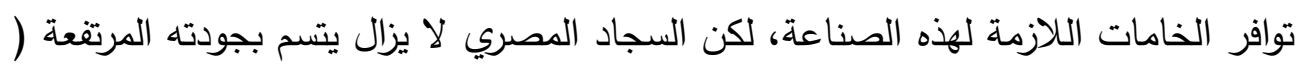

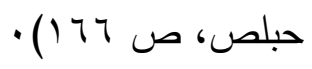
وتتعدد مناطق صناعة السجاد اليدوي في مصر مقل أخميم وأسيوط وفوة وكرداسة والحرانية ونقاده وساقية أبو شعرة ، وتتميز ساقية أبو شعرة بصناعة السجاد اليدوي سواء من ولن ولني الصوف أو الحرير، كما أنها تتتج أدق أنواع السجاد اليدوي، كما ونتيز تتمتع منتجاتها بالجودة

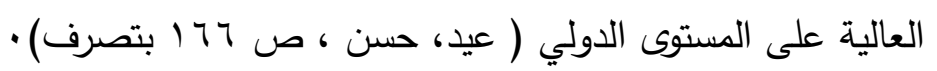


واقع الصناعات الحرفية ومستقبلها بمحافظة المنوفية ـ مصر

وتعد ساقية أبو شعرة إحدى قرى مركز أشمون حيث تقع في شمال شرق المركز، يحدها من الشرق فرع دمياط ، ومن الغرب قريتي سملاي والفرعونية، ومن الشمال كفر الفرعونية ومن الجنوب شنواي، كما أنها إحدى القرى الكبرى بالمركز ، حيث توجد بها وحدة محلية تضم ست نواحِ هي سملاي وشنواي وكفر الحما وكفر الفرعونية والفرعونية بالإضافة إلى القرية الأم، وتوضح الخربطة رقم (1) الموقع الجغرافي لساقية أبو شعرة •

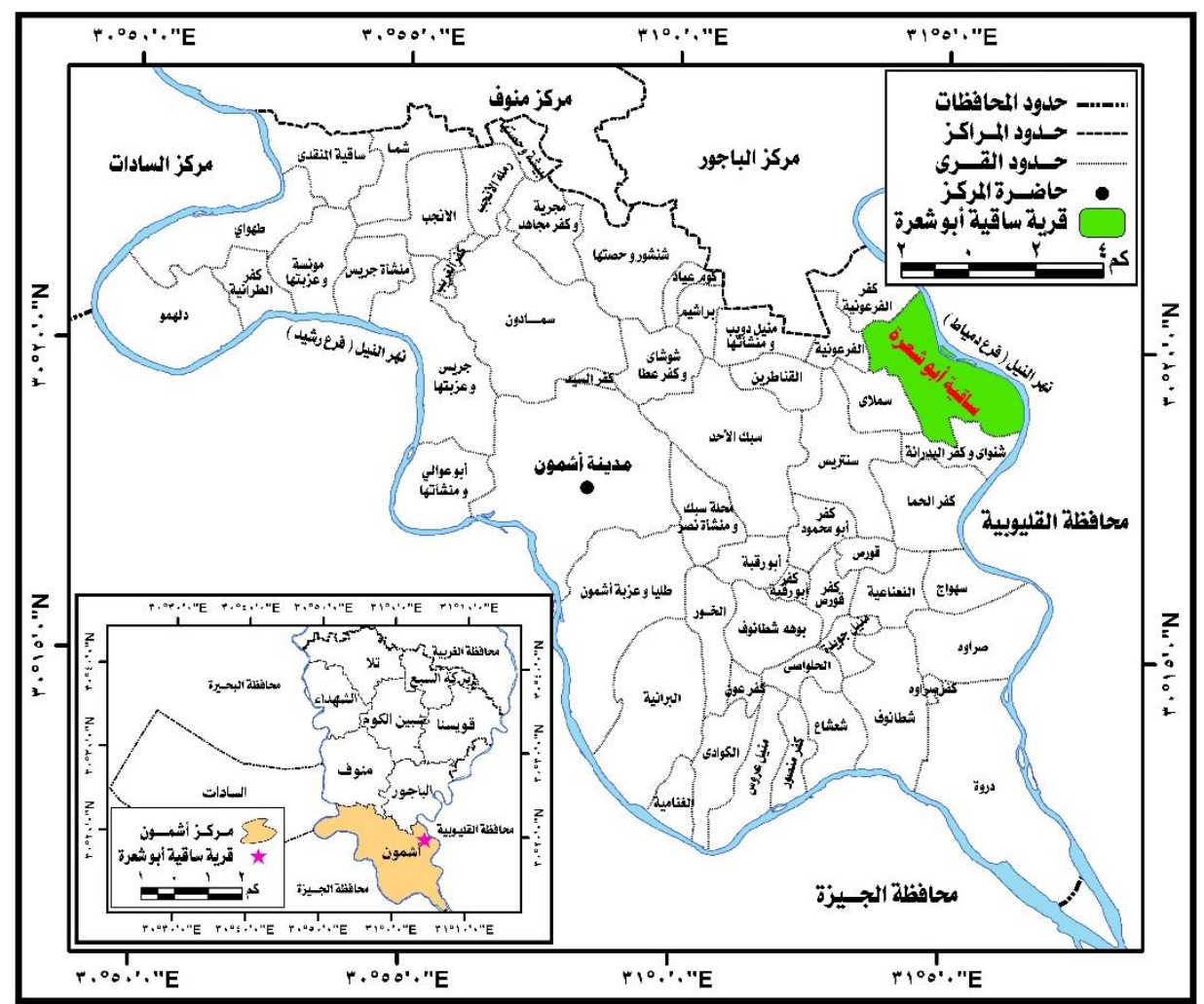

المصدر : الهيئة المصرية العامة للمساحة ، الخرائط الرقمية لمحافظة المنوفية ، مقياس

$$
\text { (1) } 1
$$

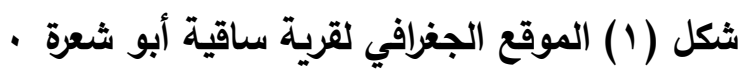

وقد مثلت تلك القرية نوية صناعية أسهمت في انتشار صناعته إلى بعض القرى المجاورة ، ولا تكتسب القرية شهرتها من الكميات المنتجة من السجاد اليدوي فحسب، بل من لـ لـ لئه 
نوعية السجاد المنتج الذي كان له أسواقه العديدة على المستوى الداخلي والخارجي قبل فترة التدهور التي تمر بها الصناعة . • (Y) تطور صناعة السجاد بمنطقة الدراسة

شهدت صناعة السجاد بالقرية تطوراً كمياً وكيفياً ارتبط بالكثير من المتغيرات

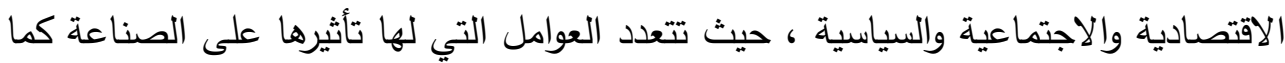
سيتضح ، وأمكن تمييز المراحل التالية لتطور الصناعة بالقرية:

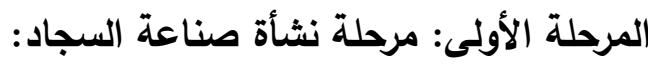

تعد صناعة السجاد صناعة وافدة على القرية ، حيث دخلت إلى القرية عام 1901 على يد بعض سكان القرية الذين تعلموا هذه الصناعة بمنطقة الدراسة بالقاهرة ونقلوها للقرية، وقد كان التركيز في بداية تلك الصناعة الذي استمر حتى عام 19 19 على صناعة السجاد المصنوع من الصوف العادي، أو الصوف والقطن بعدد عقد بسيط، حتى يتمكن الصناع من تنفيذها خصوصاً في مرحلة تعليم الصناعة للسكان، حيث تؤكد الدراسة الميدانية أن المراحل الأولية لتعليم الصناعة يكون التركيز فيها على عمل عقد أقل في السنتيمتر ، فكلما زاد عدد العقد في السنتيمتر كلما أعطى ذلك مؤشراً على جودة الصناعة الصاء ومهارة الصانع، وتتم عملية الصناعة في مصانع ( ورش) من خلال عدد من الأنوال المخصصة لإنتاج السجاد ، وتؤكد نتائج الاستبيان أن بr\% من الوش ته تم إنشاؤها قبل عام

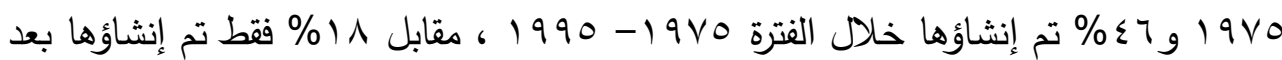
عام 1990 ، حيث تعرضت الصناعة في الفترة الأخيرة للكثير من المشكلات . وتتسم أدوات ومعدات إنتاج السجاد في القرية بطابعها اليدوي الذي يعتمد على المجهود العضلي، حيث يتسم هذا النوع ببساطة تركيبه وسهولة إعداده من الموارد المحلية، كما يتسم بأن كمية الإنتاج التي تعطيها وحدة العمل في فترة زمنية معينة منخفضة للغاية، إذا قورنت بكمية الإنتاج التي تعطيها وحدة العمل عند استخدام المعدات الميكانيكية( صالح،

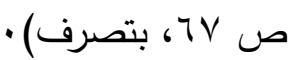


واقع الصناعات الحرفية ومستقبلها بمحافظة المنوفية ـ مصر

ويعد النول الوحدة الأساسية لصناعة السجاد وهو عبارة عن آلة بسيطة مصنوعة من الخشب أو الحديد، لكن الأنوال الخشبية هي الغالبة، يتم تثبيتها بجوار أحد حائط الحجرة حيث تتسع الحجرة إلى نولين، كما يتم وضع منضدة بجواره ليجلس عليها العمال الذين يقومون بعملية صناعة السجاد، وتتسم الأنوال ببساطتها وطول عمرها الافتراضي وسهولة صيانتها ، وفي الغالب لا يمتلك الصانع هذا النول بل يمتلكه أحد أصحاب المصانع ويقوم بإعطائه لبعض العاملين وإمدادهم بالمادة الخام ليحصل منهم على الإنتاج في النهاية ، كما

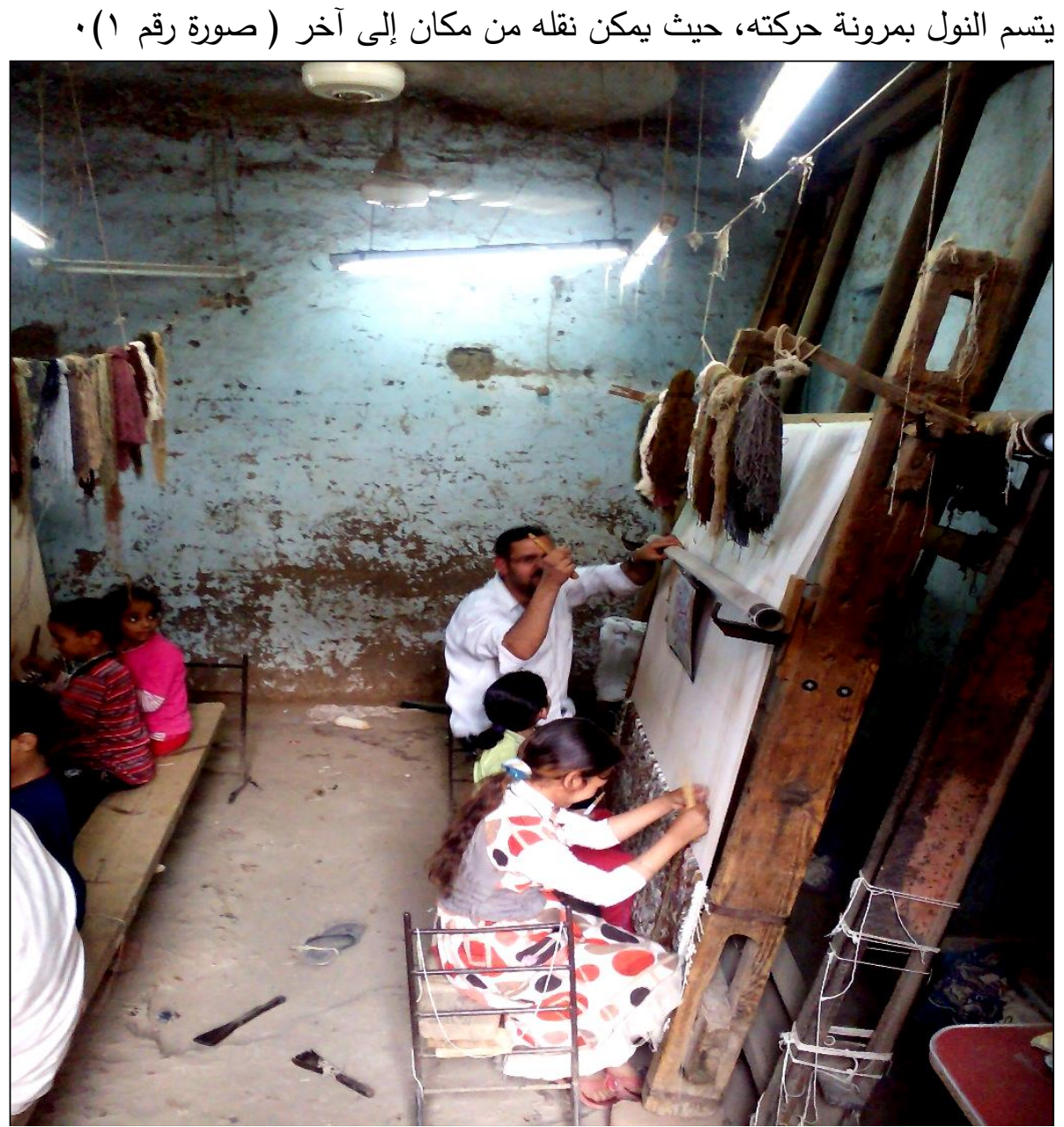

صورة رقم (1) توضح منظور جانبي لنول صناعة السجاد بساقية أبو شعرة . 
وقد بلغ عدد مصانع السجاد في القرية أربعة مصانع وعدد الأنوال ـ بولاً بمتوسط

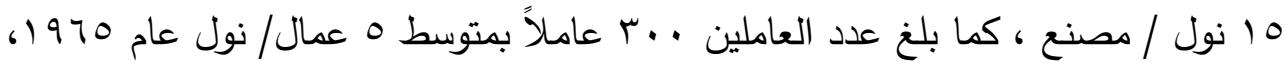
لكن سرعان ما شهدت الصناعة تطوراً ملحوظاً، حيث انتقلت من طور البداية إلى تحقيق بعض الانتشار، ويوضح الجدول التالي رقم(1) تطور أعداد المصانع وأنوال السجاد بساقية

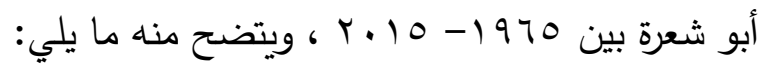

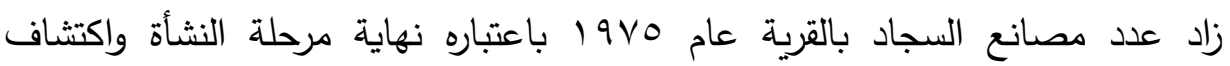
الصناعة بين سكان القرية إلى ستة مصانع مقابل أربعة مصانع عام 1970 ، ، بمدل نمو قدره •0\% ومعدل نمو سنوي قدره • (\%)، وهذا يؤكد على التطور الذي شهده

$$
\text { عدد المصانع }
$$

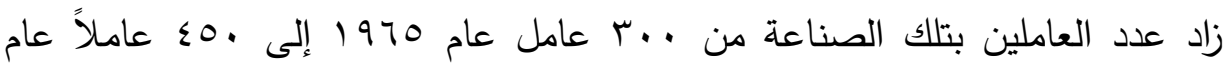
I9Vo بمعدل Vo عامل / مصنع ، أي أن الصناعة حققت انتشاراً بين سكان القرية خصوصاً إذ كان عدد سكان القرية وقتذالك محدود ·

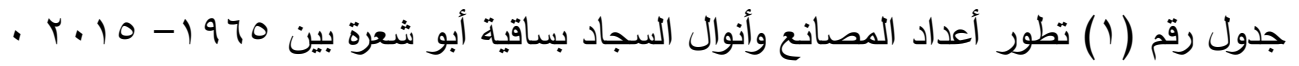

\begin{tabular}{|c|c|c|c|c|c|}
\hline \multicolumn{2}{|c|}{ الإنتاج بالمتر } & \multirow{2}{*}{ عدد الأنوال } & \multirow{2}{*}{ عدد العمال } & \multirow{2}{*}{ عدد المصانع } & \multirow{2}{*}{ البيان } \\
\hline صوف & حرير & & & & \\
\hline r.. & . & 7. & r. . & $\varepsilon$ & 1970 \\
\hline$\varepsilon \ldots$ & $\leqslant 7$. & 10. & $\leq 0$. & 7 & $19 \times 0$ \\
\hline$\vee \ldots$ & r... & $\varepsilon \ldots$ & rq.. & 1. & 1910 \\
\hline . & ro.. & ro.. & $0 .$. & $r$. & 1990 \\
\hline . & ro... & 10. & $1 \% \ldots$ & r & $r \ldots$ \\
\hline - & r... & $07 \varepsilon$ & 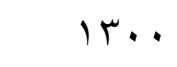 & 11 & $r .1$. \\
\hline - & $10 \ldots$ & $7 .$. & $7 .$. & IV & $r .10$ \\
\hline
\end{tabular}


واقع الصناعات الحرفية ومستقبلها بمحافظة المنوفية ـ مصر

\begin{tabular}{|c|c|c|c|c|c|}
\hline$r \ldots$ & $r \mid r v$ & VTr & 170. & 17.9 & المتوسط \\
\hline \multicolumn{6}{|c|}{ 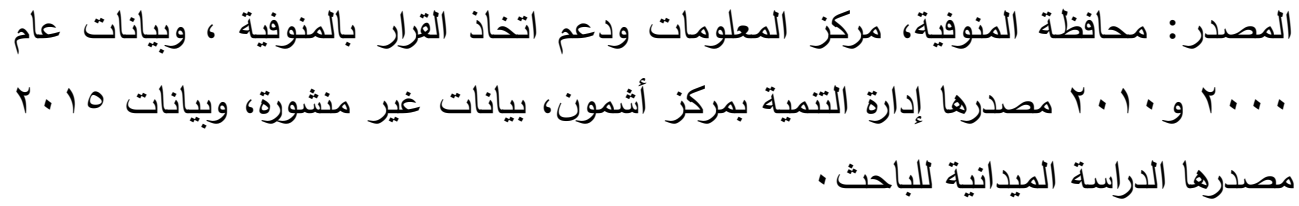 } \\
\hline
\end{tabular}

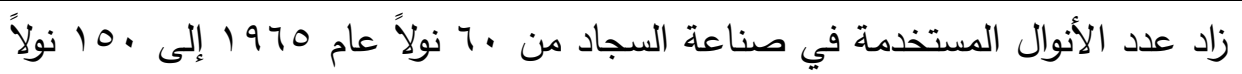

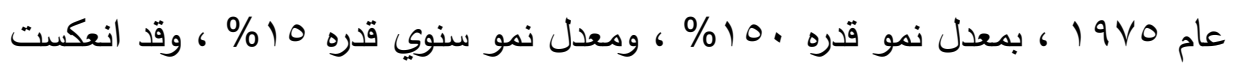

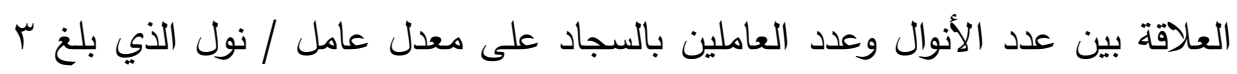

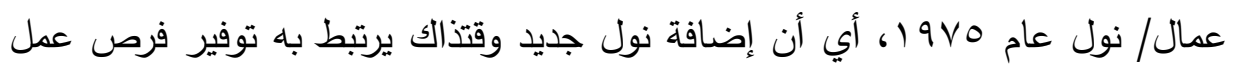
لنحو ثلاثة من العمال، بالإضافة إلى الأطفال الذين يمارسون الحرفة .

مثلت تلك الفترة بداية الصناعة وانتشارها بالقرية وهذا يعد متغيراً كمياً ، كما شهدت

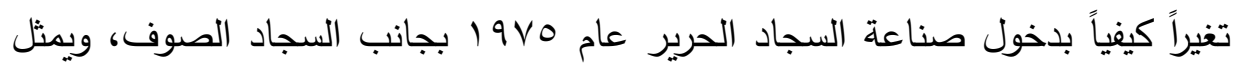

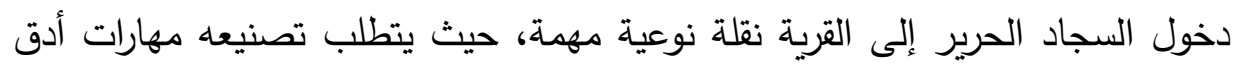
من السجاد الصوف، كما تتطلب مدخلاته تكلفة أعلى، لكن عوائده كانت مرتفعة جداً وقتذاك، الأمر الذي أسهم في تحقيق الصناعة للمزيد من الانتشار كما سيظهر في المرحلة التالية(مقابلة مع أحد أصحاب مصانع السجاد بالقرية) •

شهدت إنتاجية المصانع تطوراً ملحوظاً من ه متراً عام 1970 إلى ب.ب؟ ا متراً عام

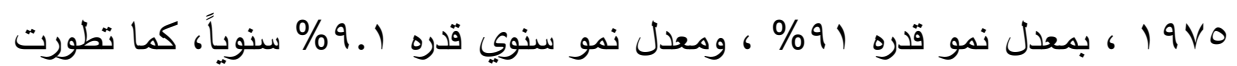
إنتاجية العامل من متر واحد عام 1970 إلى الضعف عام 19У0 في ظل اكتسابه العديد من المهارات، وهذا انعكس على إنتاجية النول التي زادت من خمسة أمتار عام

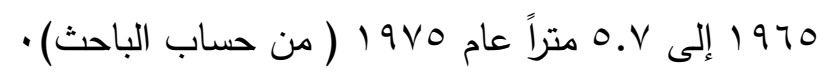

وتحقق في هذه المرحلة للصناعة انتشارها، وأسهم في هذا الانتشار حداثة هذه الصناعة ورغبة السكان في تعلمها والعوائد التي كان يحققها العاملون بالصناعة بالمقارنة

IrN

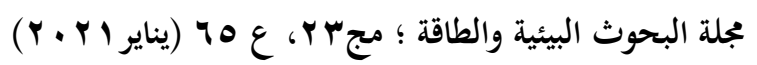


بالزراعة، حيث تتسم القرية بتقزم الحيازة الزراعية وضآلة نصيب الفرد من الأراضي الزراعية بها، الأمر الذي انعكس على زيادة أعداد الدصانع والأنوال والعاملين والإنتاج.

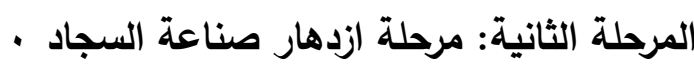

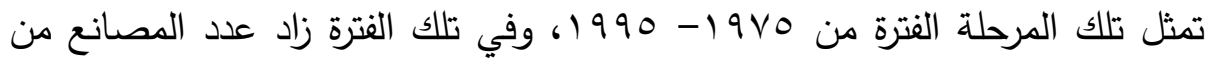

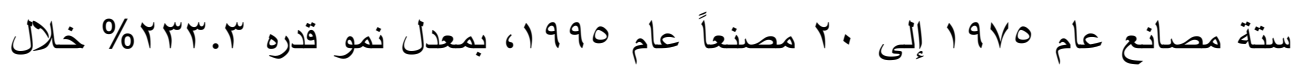

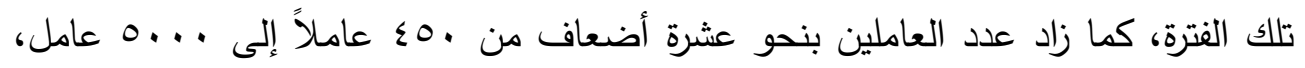

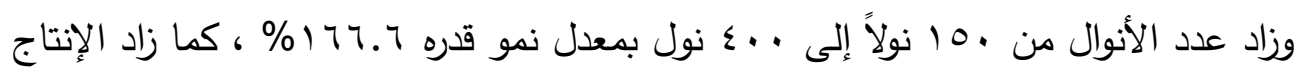

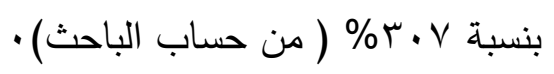

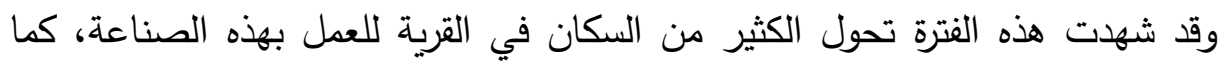

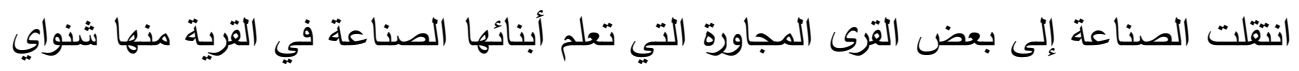

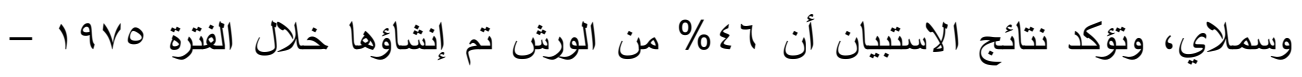

وتذهب بعض الدراسات أن ساقية أبو شعرة تعد أكبر مركز لإنتاج السجاد الحرير في

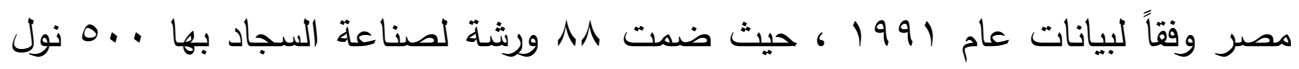

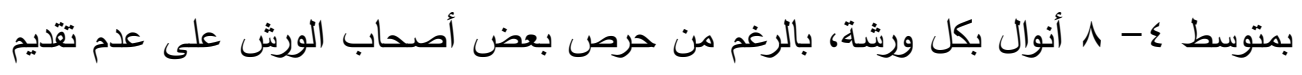

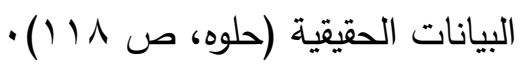

وأسهم في نمو هذه الصناعة وازدهارها بتلك الفترة العديد من العوامل منها:

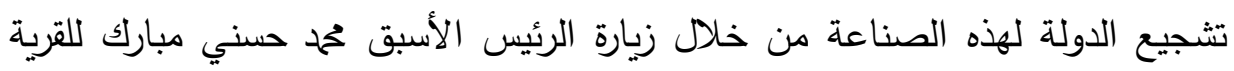
بعدما رأى إنتاجها من السجاد في أحد المعارض في العاصمة الفرنسية .

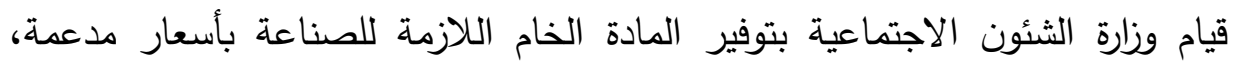
الأمر الذي انعكس على زيادة صافي العائد من الصناعة . 
واقع الصناعات الحرفية ومستقبلها بمحافظة المنوفية ـ مصر

الارتباطات الخارجية للعديد من كبار مصنعي السجاد بالقرية مع بعض جهات التسويق

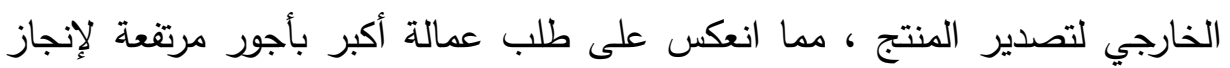
المزيد من الكميات - ات

التحول إلى إنتاج السجاد الحرير الذي يعد أبرز معالم تلك المرحلة، الذي حقق عوائد كبيرة أسهمت في ازدهار الصناعة وانتشارها ( مقابلة مع صاحب مصنع سجاد بالقرية) • اشتراك القرية في العديد من المعارض التي وفرتها الدولة عن طريق وزارة الشئون الاجتماعية لتسويق منتجها من السجاد، مما انعكس على تزايد حجم الطلب على المنتج من سجاد القرية .

المرحلة الثالثة: مرحلة تدهور صناعة السجاد .

تمثل تلك المرحلة الفترة من 1990 حتى الآن ، حيث انخفض عدد المصانع بعد

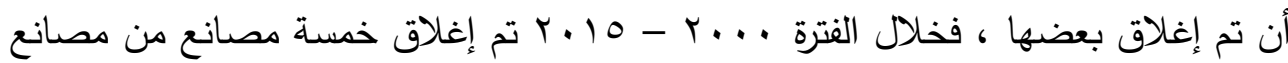
السجاد بالقرية كانت توفر مئات فرص العمل للسكان ، كما تم التحول من الثكل الرسمي للصناعة الذي يتم في مصانع مرخصة يمكن متابعتها إلى سيادة الورش والمصانع غير المرخصة ، حيث تم إحصاء تسعة مصانع مرخصة وثمانية مصانع غير مرخصة عام

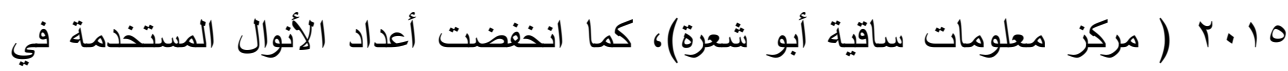
الصناعة بصورة واضحة، مما جعل الكثير من العاملين بالصناعة يتركوها ليعملوا بالقاهرة

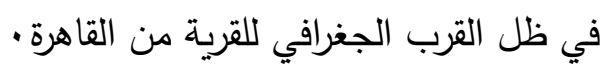

وقد أسهمت العديد من العوامل في التدهور الذي شهدته صناعة السجاد بالقرية خلال

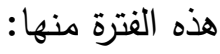
تدني دور الحكومة في دعم صناعة السجاد وغيرها من الصناعات الحرفية . المنافسة التي يجدها السجاد اليدوي المصري من السجاد الإيراني والتركي في الأسواق

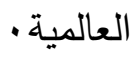


تدهور السياحة الصصرية في ظل تدهور الحالة الأمنية، الأمر الذي انعكس على الحركة السياحية التي كانت أحد أهم مصادر تسويق السجاد .

• المغالاة في الضرائب المطلوبة من ورش ومصانع السجاد ، مما انعكس على العائد

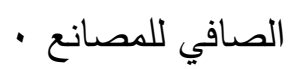

• تحكم الصين في أسعار المواد الخام اللازمة للصناعة، حيث تعد الصين مصدرها الأساسي كما تبين من الدراسة الميدانية .

انخفاض أجور العاملين وقلة الطلب على العمالة في ظل ركود تسويق المنتج مما

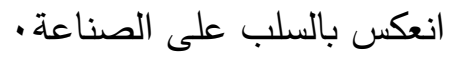

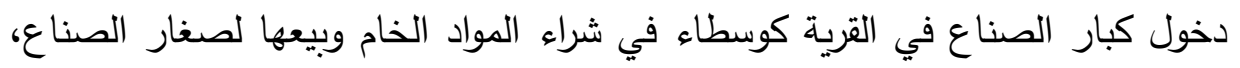

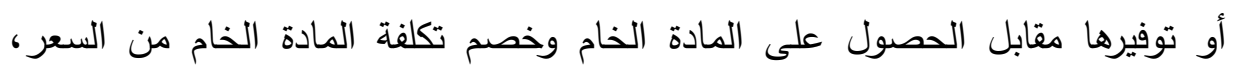
وكذلك دخولهم كوسطاء في تسويق المنتج من خلال المعارض التي تتاح لهم ولا تتاح

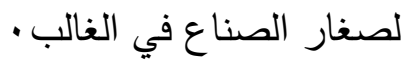

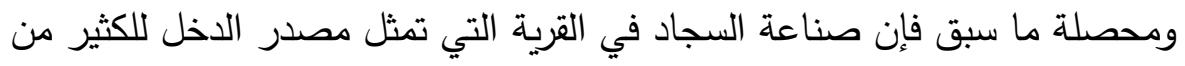

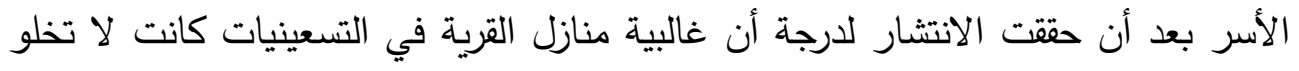
من نول لتصنيع السجاد بها، تعرضت للتدهور لعوامل عديدة، مما يجعل من إعادة تتميتها

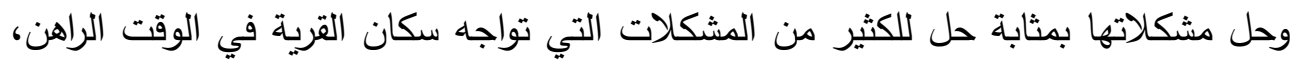
فلهذه الصناعة العديد من الأدوار الاجتماعية والاقتصادية . 
(r) العوامل المؤثرة في صناعة السجاد بمنطقة الدراسة .

تشغل العوامل المؤثرة في الصناعة ركناً مهاً في دراستها ، فهي تجيب على تساؤل مهم لماذا توطنت الصناعة في هذا المكان ولم تتوطن في غيره ، وتتعدد العوامل التي تئثر في إنتاج السجاد وتسويقه وتوطنه بالقرية ، ومن ثم فإن الوقوف على أبرز هذه العوامل له أهميته في التحليل الجغرافي لهذه الصناعة ومن هذه العوامل:

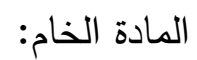

تمثل المادة الخام أحد المكونات الأساسية لصناعة السجاد، حيث تتعدد مظاهر أهميتها بين المكونات الأخرى، فجودتها لها تأثير على جودة المنتج وقدرته على المنافسة لاسيما أنها صناعة تصديرية في الغالب، وأسعارها لها دورها في تحديد هامش الربح، حيث تهودين

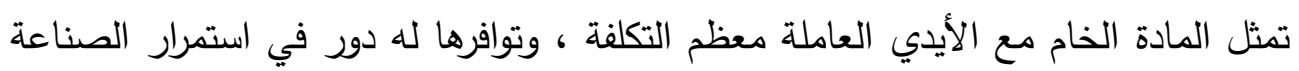

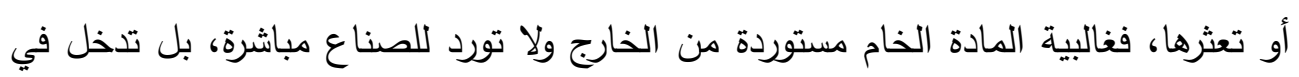
حلقة من الوسطاء الذين يتتاقلوها بينهم إلى أن تصل للمنتج بأسعار مرتفعة .

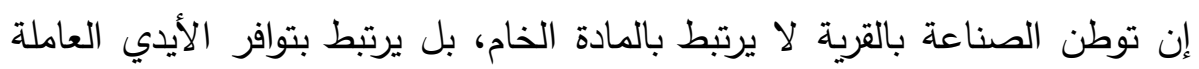

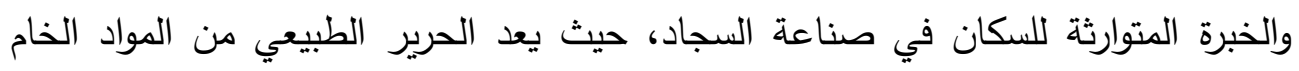
ذات القيمة العالية التي تتحمل تكاليف النقل، لذا أصبح من السهل نقل الحرير الطبيعي إلى لى

$$
\text { حيث يصنع }
$$

وتعتمد صناعة السجاد بالقرية في الوقت الراهن على الحرير الطبيعي المستورد في الغالب كمادة خام ، حيث يميل نسبة كبيرة من الصناع إلى تفضيل الحرير المستورد على بلى المحلي بنسبة § ٪\% و 7r \% لكليهما على التوالي لعدة أسباب منها: • قلة المواد الخام المحلية من الحرير وعدم توافرها بالكميات المطلوبة . • تميز المواد الخام المستوردة بنقائها بالمقارنة بالمواد الخام المحلية . • رخص أسعار المواد الخام المستوردة بالمقارنة بالمحلية ( مقابلة مع صاحب مصنع

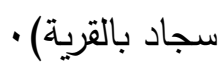


ويختلف الحرير الطبيعي عن الحرير الصناعي في أن الأول تقوم بصناعته وحدات صغيرة مكونة من أسر في مناطق ريفية مزدحمة بالسكان وعمالها على قدر كبير من المهارة

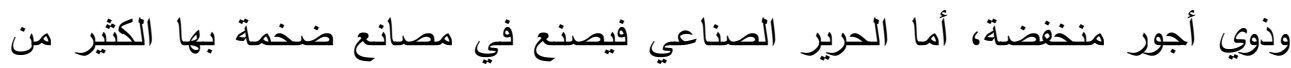
الآلات المعقدة ، كما أن إنتاجية العامل في الحرير الطبيعي ضئيلة للغاية والقيمة المضافة له صغيرة، بعكس إنتاجية العامل في الحرير الصناعي، كما يصل سعر الحرير الطبيعي

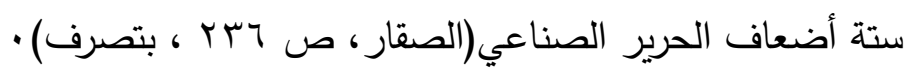

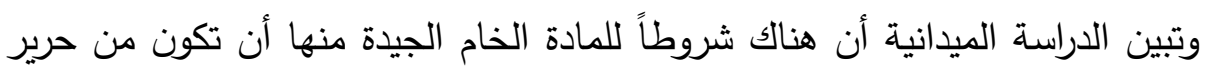
طبيعي خالص، حيث قد تلجأ بعض المناطق أمام ارتفاع أسعار الحرير الطبيعي- حيث يصل متوسط سعر الكيلو جرام إلى .0 جن جنيهاً - إلى خلطه ببعض كميات من الحرير الصناعي لتقليل تكلفة إنتاج المتر، كما يشترط توافرها ومناسبة أسعارها للإنتاج بشكل اقتصادي، وتوضح الصورة رقم(r) شكل المادة الخام في بداية تصنيع السجادة •

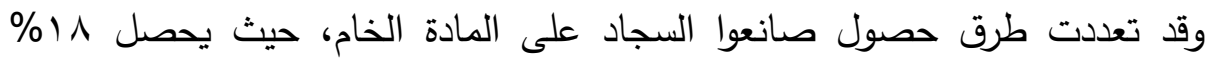
عليها بأنفسهم ، كما يحصل r؟٪ عليها عن طريق الوسطاء ، ويحصل اسب\% عليها عن طريق الاثنين معاً، ويحصل ^^\% عليها بطرق أخرى ، أي أن الوسطاء يمثلون النسبة الأكبر في إمداد مصانع وورش السجاد بالقرية بالمادة الخام ، مما ينعكس على ارتفاع أسعارها ، حيث يرى ب9\% من العاملين بالصناعة وجود مشكلات في الحصول على المادة

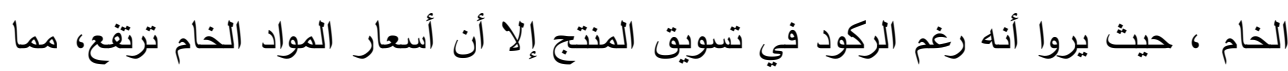
يؤثر على صافي الربح الذي يتجه إلى التناقص أو إلى عدم وجود صافي ربح ، ويوضح الجدول التالي رقم (Y) تكلفة إنتاج متر السجاد الحرير بساقية أبو شعرة عام 10 بـr، ويتضح منه أن تكلفة المادة الخام تمثل أهم مكونات تكلفة إنتاج متر السجاد، حيث تصل نسبتها إلى r.r٪\% من الإجمالي، ويأتي ذلك بسبب:

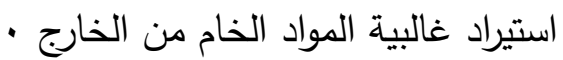
تعدد الحلقات الوسيطة بين الاستيراد ووصول المادة الخام للصناع• 
واقع الصناعات الحرفية ومستقبلها بمحافظة المنوفية ـ مصر

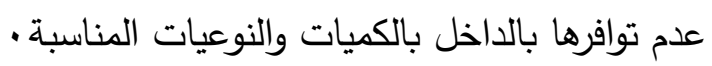

• عدم وجود دعم حكومي للمواد الخام ، كما لا توجد جهة حكومية خاصة باستيراد

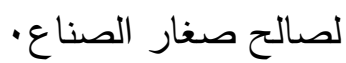

وتمر المادة الخام بعدة مراحل مهمة قبل تصنيعها وهي صباغتها بالألوان المطلوبة، وهذا يتناسب مع تصميم السجادة الذي يراعى فيه الألوان وعدد العقد في السنتيمتر ، حيث يتم رسم تصميم السجادة قبل بداية العمل بها من قبل متخصص بالقرية بناء على طلب صاحب يره الورشة، حيث يطلب منه تصميماً معيناً يتحدد بناء على طلب العميل أو على التصميم المنتشر في السوق، ويقوم ؟9\% من الورش بإنتاج التصميم في القرية حتى لا يضطروا إلى التعامل مع المصممين بالقاهرة الذين يطلبون مبالغ كبيرة •

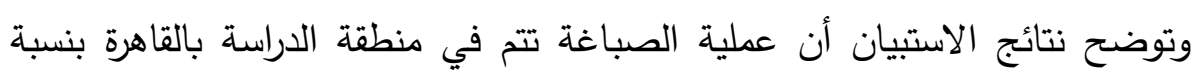
\% Fr

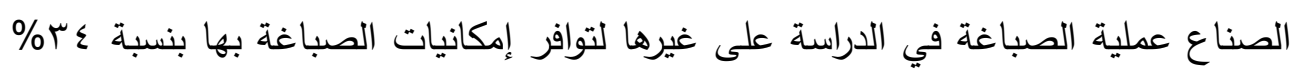

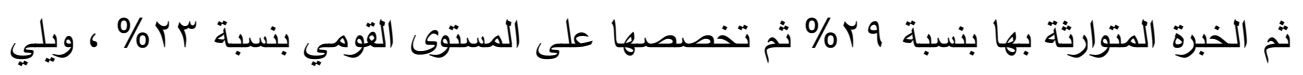
ذلك ارتباط المصانع والورش بالقرية بأصحاب هذه المصابغ بنسبة ؛ (\% ، ويلي عملية الصباغة تجميع كل لون ووضعه في شكل حزم فوق النول لكي يتم الاستعانة به عند الصناعة بما يناسب التصميم حتى يتم الانتهاء من السجادة . 


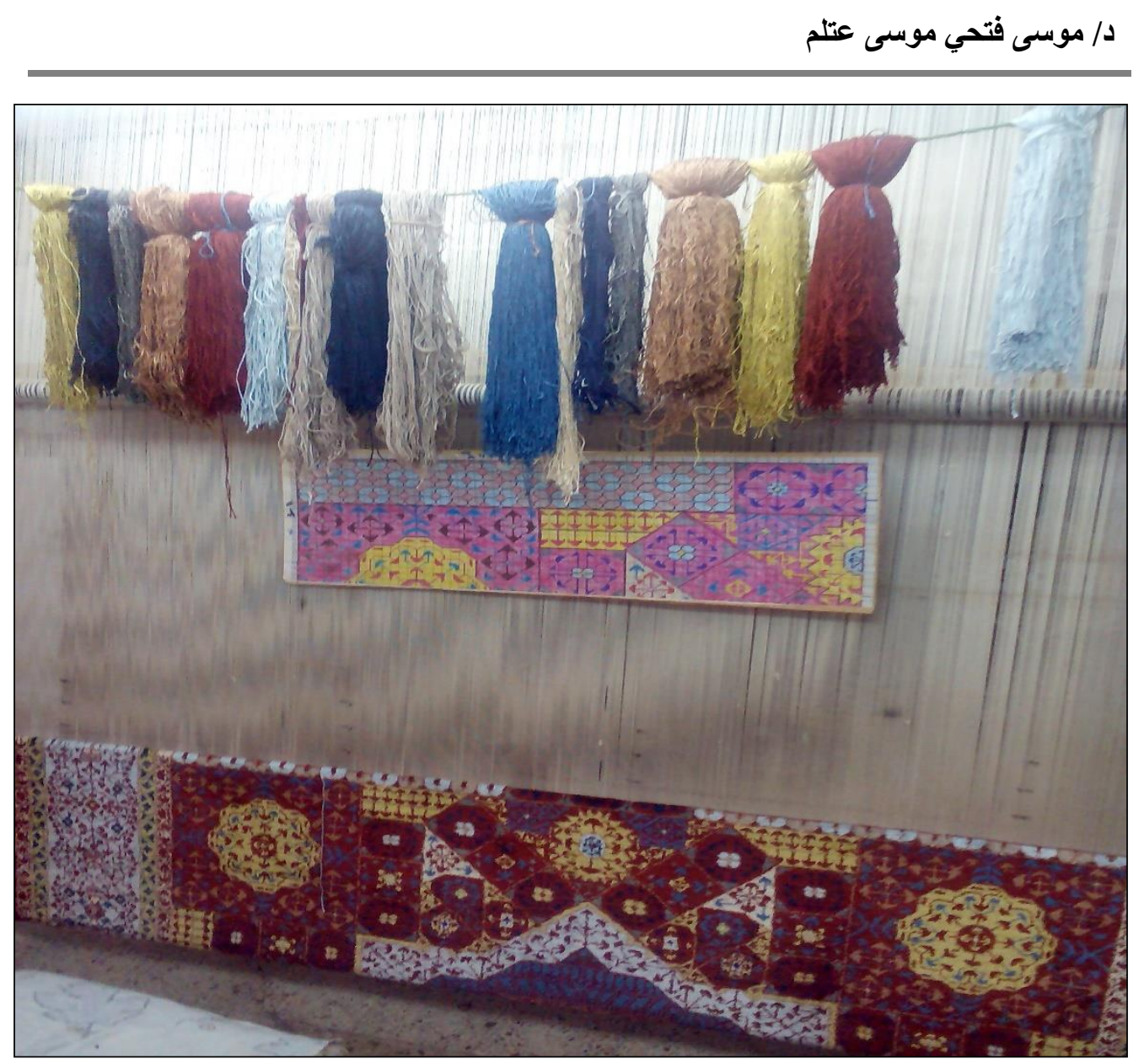

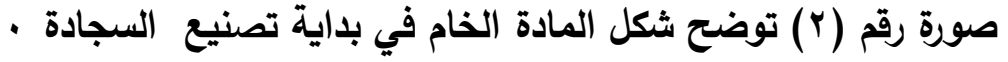

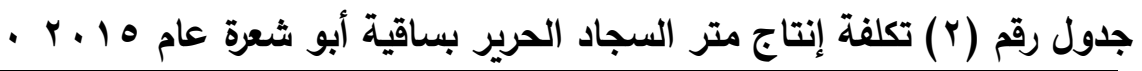

\begin{tabular}{|c|c|c|}
\hline النسبة من إجمالي التكلفة & متوسط التكلفة بالجنيه & 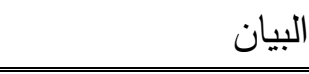 \\
\hline$\varepsilon r . r$ & 110. & المادة الخام \\
\hline$\varepsilon 1.9$ & $11 \%$. & الأيدي العاملة \\
\hline 0.7 & 10. & القص والكي والغسيل \\
\hline 1.9 & 0. & الصباغة \\
\hline 1.9 & 0 . & تركيب برواز للسجادة \\
\hline
\end{tabular}


واقع الصناعات الحرفية ومستقبلها بمحافظة المنوفية ـ مصر

\begin{tabular}{|c|c|c|}
\hline 1.9 & 0. & تصميم الرسم \\
\hline r.v & $1 \ldots$ & تكاليف أخرى \\
\hline $1 \ldots$ & rTVo & الجملة \\
\hline
\end{tabular}

ويصل متوسط كمية المادة الخام التي تحتاجها المصانع والوش في الشهر إلى

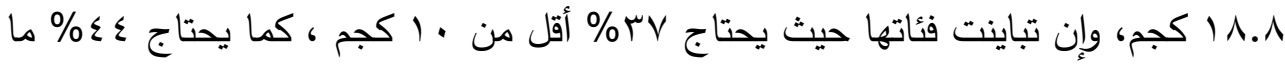
بين • (- •ـ كجم ، ويحتاج 9 (\% منها •ـ كجم فأكثر، ويتناسب الكميات التي تحتاجها المصانع والورش مع عدد الأنوال وعدد العاملين وحجم الطلب على المنتج الذي ينعكس

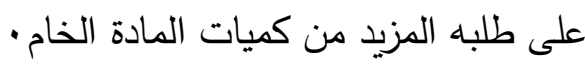
ومحصلة ما سبق أن الحصول على المادة الخام يعد من أهم مراحل صناعة السجاد

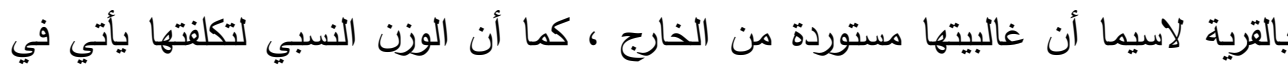
المرتبة الأولى بين عناصر التكلفة (r.r\&\%) ، مما يجعل توفير المادة الخام اللازمة لهذه

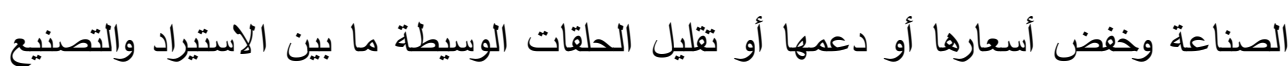
بمثابة خطوات على طريق تتمية صناعة السجاد بالقرية .

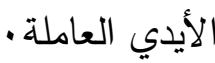

تمثل الأيدي العاملة العمود الفقري في صناعة السجاد بالقرية، حيث تعتمد عملية الصناعة على مهارات العاملين بالصناعة وقدراتهم الإبداعية في الوصول بالمنتج إلى الثكل المطلوب ، وتبلغ نسبة العاملين بصناعة السجاد ؟. ؟Y\% من جملة السكان، حيث تم تعلم الحرفة عن طريق الوراثة ، فغالبية منازل القرية بها نول مما يسهل من عملية تعليم الصناعة

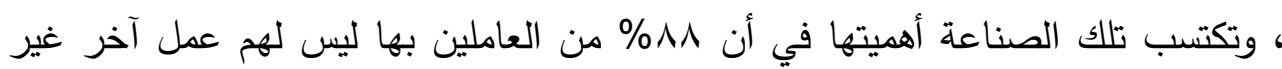
صناعة السجاد مقابل r ا ( \% لهم وظائف أخرى يشتغلون بها ، ويقومون بعملية الصناعة في أوقات الفراغ أو أيام العطلات .

ويعد العمل أكثر عناصر الإنتاج تكلفة خصوصاً في بعض الصناعات التي تتطلب تخصص ومهارات فنية، كما لا تعد تكلفة العمل بمفردها العامل الوحيد في التوطن 
الصناعي، بل إن إتاحة العمل يعد عاملاً مهماً خصوصاً العمل الذي يتطلب مهارات خاصة، كما تمثل إنتاجية العامل محدداً من محددات اختيار مواقع الصناعة، وترتبط إنتاجية العامل بالكمية والكفاءة في وقت زمني معين ( Wheeler,J,p.202) .

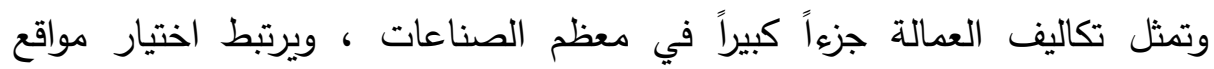
الصناعات كثيفة العمالة بتوافر أعداد كافية من العمال بأجور منخفضة، كما يرتبط توطن

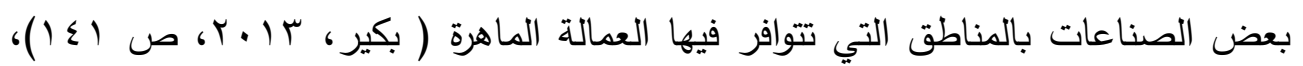

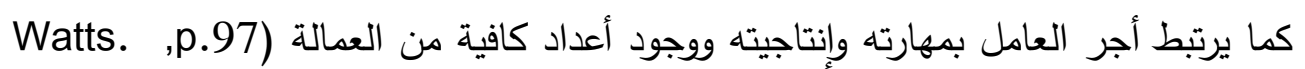

ويبلغ متوسط عدد العاملين بالورش والمصانع بالقرية ؟.9 عامل / ورشة، وتتباين

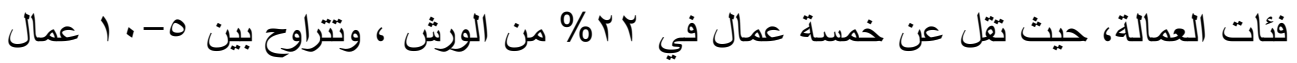

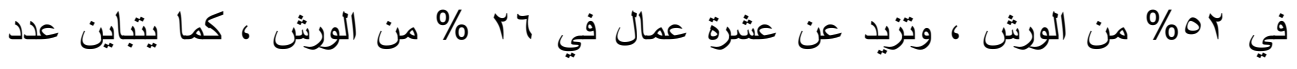
العاملين في فترة الدراسة عن العطلات، حيث تزيد في العطلات خصوصاً بعد انتهاء العام

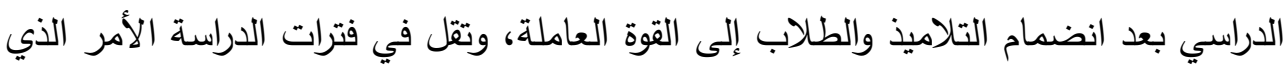

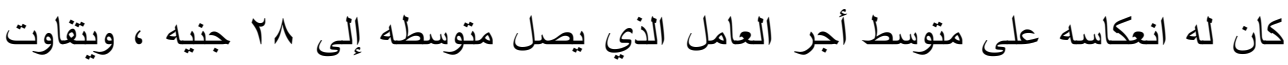
حسب السن والمهارة والإنتاج واستمرارية العامل .

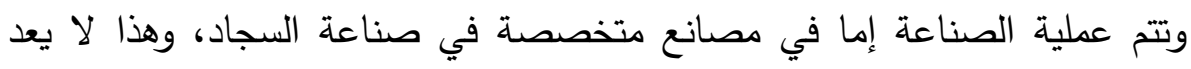

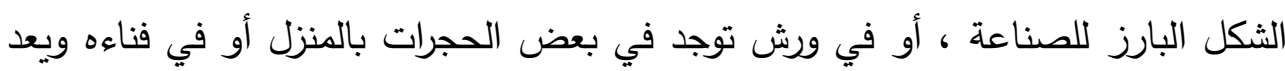

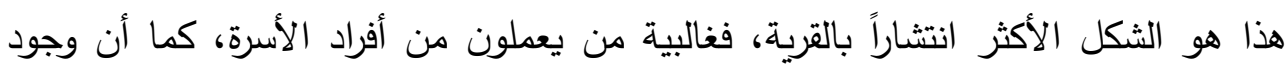

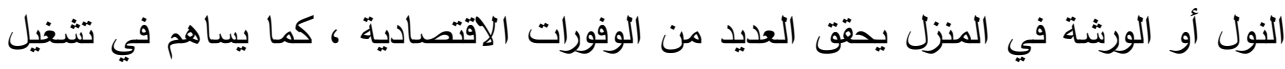

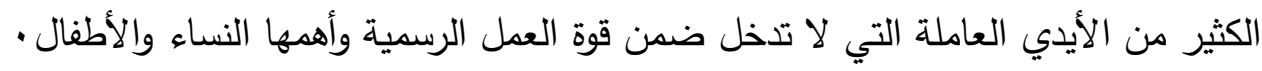

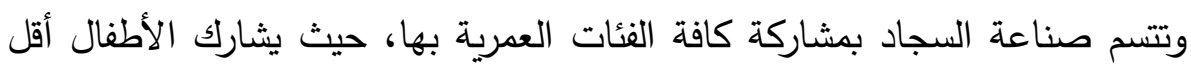

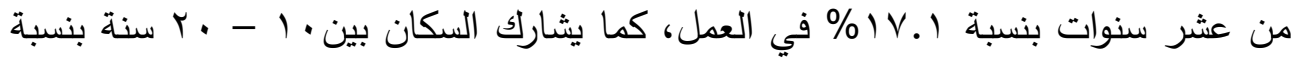

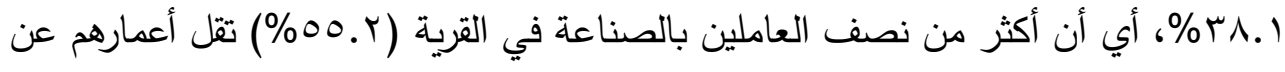
. 


\section{واقع الصناعات الحرفية ومستقبلها بمحافظة المنوفية ـ مصر}

وتكتسب الصناعات الصغيرة أهميتها في توفير فرص عمل بتكلفة بسيطة، كما تسهم في تدعيم دور المرأة الريفية في النشاط الاقتصادي وزيادة فرص العمل وتحسين دخول الأسر، وما لذلك من انعكاس على ارتفاع مستوى المعيشة ، بالإضافة إلى دورها في دعم

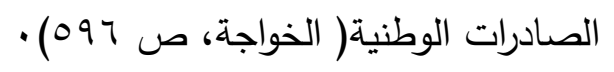

ويشارك الذكور والإناث في صناعة السجاد على حد سواء ، حيث بلغت نسب

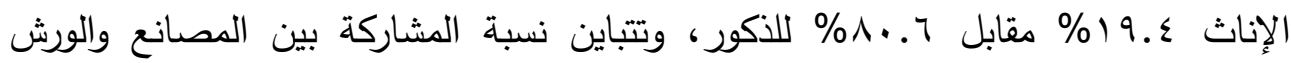
الصغيرة، حيث تتخفض نسبة الإناث في المصانع مقابل ارتقاعها في الورش المنزلية في إطار المحافظة على العادات والتقاليد ، ومن ثم فإن المتفرغات للمنزل في بيانات التعداد يقمن بالمشاركة في صناعة السجاد، كما يشارك نسبة كبيرة من الأطفال •

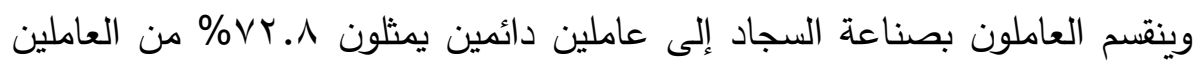
وعاملين مؤقتين يمثلون r. r r منهم ، وفي ظل عدم وجود تأمين اجتماعي على الكثير من العاملين بشكل يجعلهم ثابتون في مكان واحد أو مصنع واحد لصناعة السجاد، فإنهم

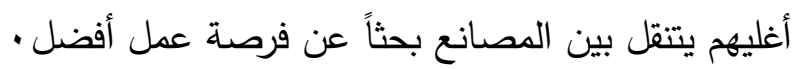
كما انعكس التذهور الذي شهدته الصناعة على السكان داخل قوة العمل في القرية،

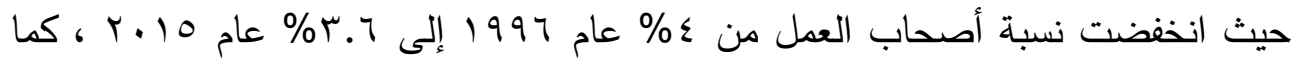

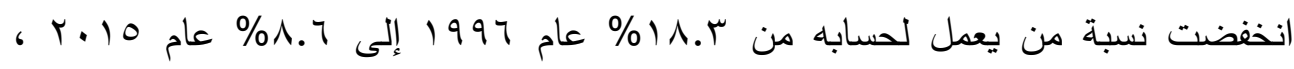

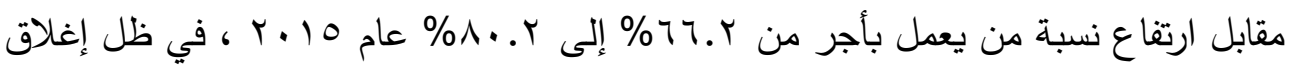
بعض مصانع السجاد بالقرية وانتقال بعض العاملين بها إلى مهن ووظائف أخرى ، ديث هيث انتقل نسبة كبيرة من الثباب للعمل بالقاهرة في ظل القرب الجغرافي للقرية منها ، وتدني أجر العاملين بالسجاد بالمقارنة بفترات الازدهار في الصناعة التي كانت أجور العاملين مرتفعة( من حساب الباحث اعتماداً على بيانات تعداد عام 999 ألوبيانات مركز المعلومات

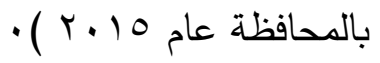
ومحصلة ما سبق أن الصناعة أعطت للسكان بمثل ما أعطى سكان القرية لها، فقد مثلت فرصة لتشغيل نسبة كبيرة من سكان القرية، وتتميز الصناعة بأنها كثيفة العمالة، 
ويؤدي تشغيل النول الواحد إلى توفير فرص عمل لثلاثة أشخاص، كما تتسم بمرونتها من حيث احتياجاتها من العمالة، وتثارك الفئات العمرية المختلفة في الصناعة، وقد كان لمهارة الأيدي العاملة بهذه الصناعة انعكاسها على الشهرة العالمية التي اكتسبها إنتاج السجاد من - القرية • التسويق

يعد السوق من أهم العوامل التي أسهمت في اختيار موقع العديد من الصناعات ، فقرب الصناعة من السوق يقلل تكلفة النقل للمنتج ، ويتحكم في موقع الصناعة النسبة بين وزن المواد الخام والمنتج ( Wheeler,J,p.200)، وقد تأثرت الصناعة بالأيدي العاملة التي جذبتها لتتوطن بتلك القرية ، كما تأثرت بالشهرة التي اكتسبتها الصناعة بالقرية التي كان لها دورها في تسويق منتجاتها . ورغم أن السجاد يعد منتجاً غير قابل للتلف، وهذا يعطي فرصة فئه أكبر لتسويقه، فإن التكلفة الكبيرة في مراحل تصنيعه تجعل غالبية المنتجين يفضلون الإسراع في تسويقه حتى

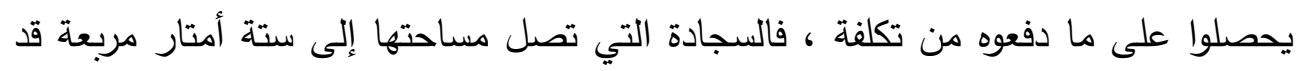
تزبد تكلفتها عن 17 ألف جنيه مصري، مثل مجهود الصانع وأسرته نحو نصف هذا المبلغ

وفي الوقت الذي كان للدولة دور كبير في عملية تسويق السجاد من خلال وزارة الشئون الاجتماعية ووزارة الصناعة وغيرها من الوزارات والهيئات كما اتضح؛ نجد أن دور الدولة تضاءل بشكل ملحوظ، ويوضح الثكل التالي رقم (Y) كيفية تسويق السجاد بساقية أبو شعرة ، ويتضح منه أن التسويق المباشر الذي يتم بين البائع والمشتري لا تتجاوز نسبته الخُمس،

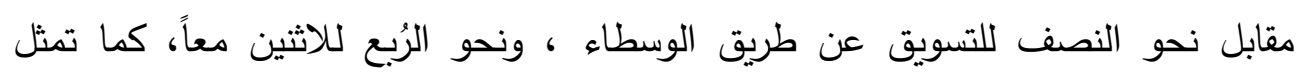

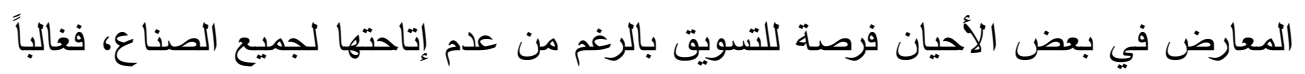
ما يكون لكبار الصناع الفرصة في الاشتراك في هذه المعارض بدرجة أكبر من صغارهم . 
واقع الصناعات الحرفية ومستقبلها بمحافظة المنوفية ـ مصر

\section{شكل رقم (2) كيفية تسويق السجاد بمنطقة الدر اسة}

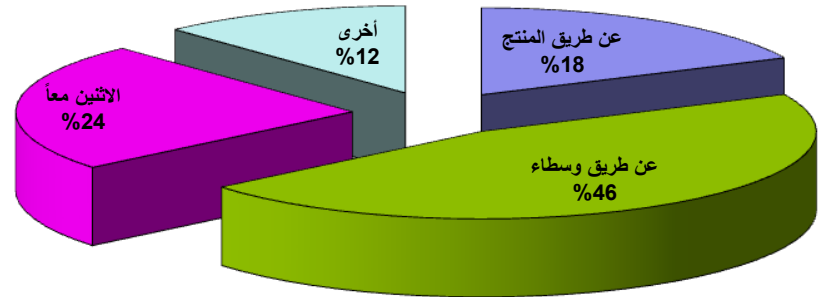

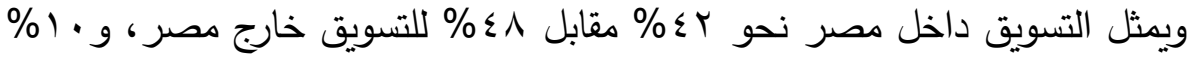
للاثنين معاً، ويتفق كلا النمطين من التسويق بأن معظمه يتم عن طريق الوسطاء والتجار الذين يأخذون الإنتاج من الصناع ويقومون بتسويقه بطريقتهم الخاصة ، وهذا يمثل أحد مشكلات تسويق السجاد ، لأن نسبة كبيرة من العائد تذهب لهؤلاء الوسطاء في ظل غياب لإن لهاب دور الدولة ومؤسساتها في التسويق، وهذا يتفق مع بعض الدراسات التي أكدت أن التسويق

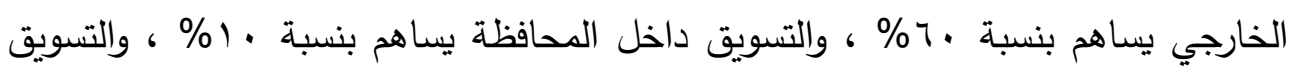

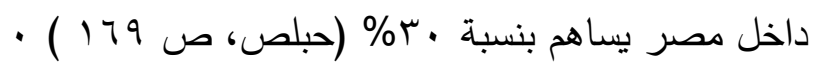
ويتسم تسويق السجاد بموسميته، حيث يرى ب^^\% من الصناع وجود موسمية في التسويق ويرى § إ عدم ارتباط التسويق بموسم معين ، ويتسم التسويق بتركزه في فصل الصيف ، ويرتبط التسويق الداخلي والخارجي بجودة المنتج من السجاد، حيث اتضح من 
الدراسة الميدانية أن مواصفات المنتج الجيد من السجاد تأتي على رأسها مهارة الصانع

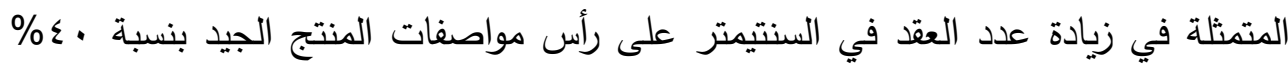
تليها جودة التشطيب النهائي للسجادة بنسبة .ب٪\% ، ويضاف إلى إلى ذلك جودة التصميم

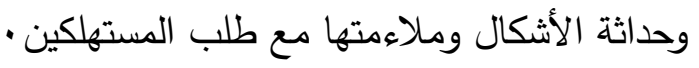
وفي الوقت الذي يتسم فيه السجاد اليدوي الدصري ببعض السمات التي التي جعلته قادراً

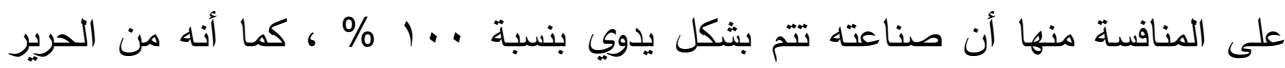

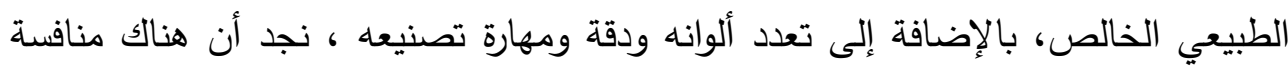

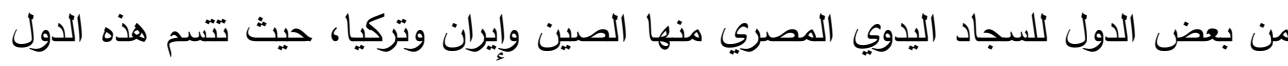

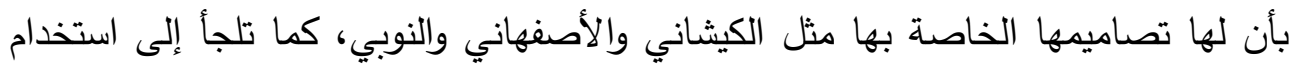

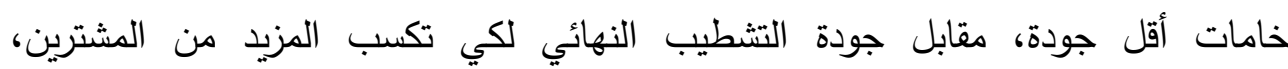
فالمستهلك يهتم بالسعر أكثر من اهتمامه بالجودة في الكثير من الأحيان • ومحصلة ما سبق أن صناعة السجاد تنتقد إلى الدور الحكومي في تسويق المنتج

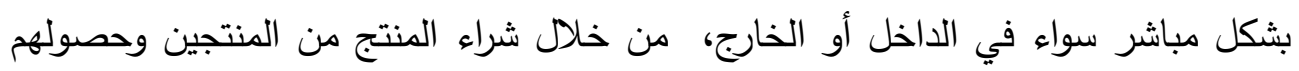
على العائد المناسب، أو بشكل غير مباشر من خلال توفير المعارض وأماكن الترويج للمنتج في المناطق السياحية والمناطق المهمة التي تتناسب قدرتها الشرائية مع شراء السجاد الداد

$$
\begin{aligned}
& \text { اليدوي الذي يتسم بارتفاع أسعاره - }
\end{aligned}
$$

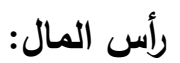

يعد رأس المال من أهم العناصر المؤثرة في توطن صناعة السجاد، وينقسم إلى رأس

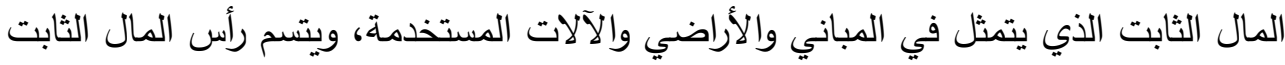
بمحدوديته، حيث تعتدد الصناعة على النول الذي تصل تكلفة تصنيعه إلى . . با جنيهاً،

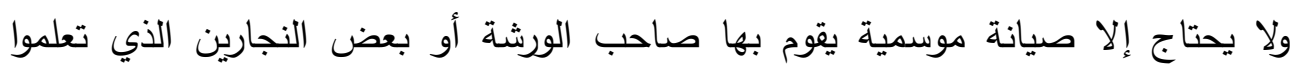

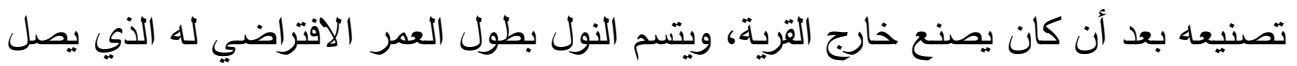

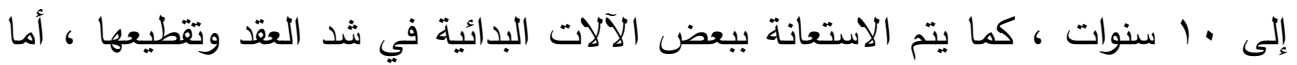




\section{واقع الصناعات الحرفية ومستقبلها بمحافظة المنوفية ـ مصر}

رأس المال المتغير الذي يتمثل في تكاليف المواد الخام وصباغتها وأجور الأيدي العاملة فيتسم بارتفاعه ، حيث تصل تكلفة إنتاج المتر المربع من السجاد إلى ه ب ج جنيهاً .

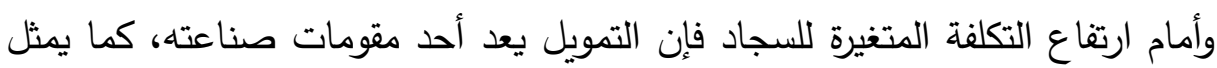

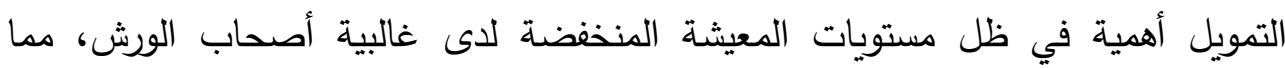
يجعلهم يعتمدون على الوسطاء في إمدادهم برأس المال اللازم لعملية الصناعة . وكان من المفترض أن يكون للحكومة دورها في توفير رأس المال اللازم لتتمية الصناعة التي توفر فرص عمل لمئات الأسر ، لكن الصندوق الاجتماعي للتتمية الذي يعد

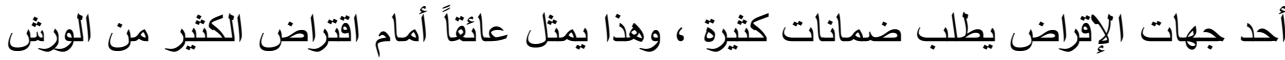
خصوصاً أن نسبة كبيرة منها غير مرخص ، كما أن إدارة الصناعات الحرفية بالمحافظة دورها في دعم الصناعة محدود للغاية باستثناء بعض البرامج التدربية التي تتفذها للارتقاء بمستوى الأيدي العاملة ، كما يقوم مركز تحديث الصناعة ببعض الأنشطة في القرية إلا أن بأن

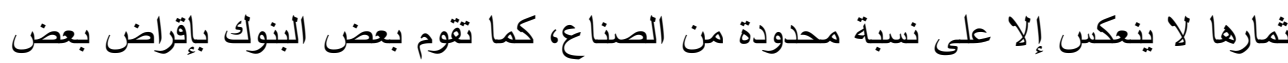
المصانع المرخصة بالقرية وتتباين مصادر تمويل صناعة السجاد بالقرية حيث أتى التمويل عن طريق الوسطاء في الصدارة بنسبة ؛ه\% يليه التمويل الذاتي بنسبة . ب\% ثم التمويل من جهات أخرى بنسبة 7 1\% ، أي أن التمويل عن طريق الوسطاء له الغلبة بين مصادر تمويل صناعة السجاد ويعود ذلك إلى: عدم قدرة غالبية الورش على توفير رأس المال اللازم لعملية التصنيع التي تحتاج

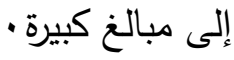

$$
\text { وجود العديد من التعقيدات الروتينية من قبل جهات التمويل الحكومي . }
$$

يتسم التمويل من قبل الوسطاء بإعطاء التمويل للصناع مقابل الحصول على

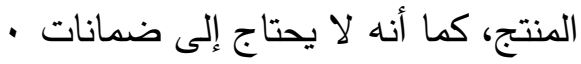

ومحصلة ما سبق أنه بالرغم من تعدد الجهات المسئولة عن تقديم الدعم المادي وغير المادي للصناعات الحرفية فإن ؟V\% من عينة الدراسة يروا وجود مشكلات تتعلق

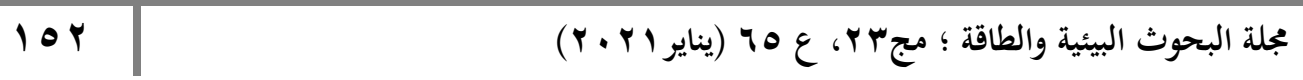


بحصولهم على القروض اللازمة لمشاريعهم يأتي على رأسها ارتفاع سعر الفائدة بنسبة

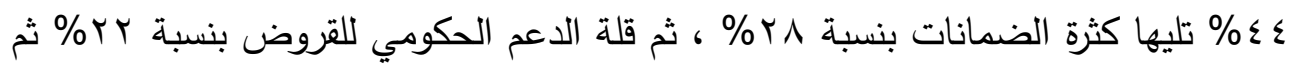
الأسباب الأخرى بنسبة ؟\%، وهذا يتطلب التوسع في سياسة إقراض المشاريع الصناعية

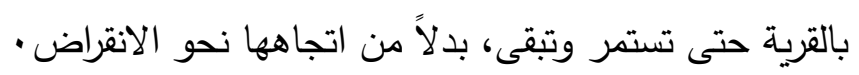
النقل وإمكانية الوصول إلى القربية:

لعبت إمكانية الوصول إلى منطقة الدراسة دورها في التأثير على الصناعة، فالطريق ليس مجرد ظاهرة خطية فقط، بل إن الطريق يعد ناقل الحركة والنشاط ، فالطريق يساهم في نقل المواد الخام اللازمة من مصادرها بالقاهرة ، كما يساهم في نقل السجاد لتشطيبه في منطقة الدراسة بالقاهرة وغيرها من المناطق، كما أسهم الطريق في دعم عملية الوصول إلى بلى

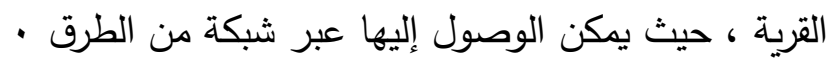
وتبعد قرية ساقية أبو شعرة عن مدينة أشمون عاصمة المركز بحوالي V كم ، كما تبعد عن مدينة شبين الكوم عاصمة المحافظة بحوالي وب كم، وتعد هذه المسافات المحدودة

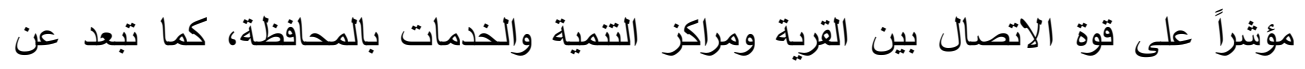

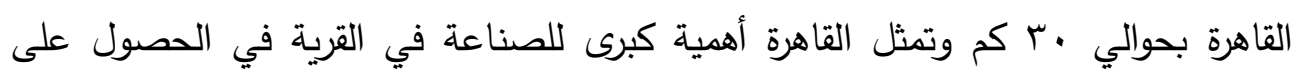
المادة الخام وفي تسويق المنتج وصباغة الحرير وتشطيب السجاد بعد تصنيعه، ويوضح الشكل رقم (r) الموقع والعلاقات المكانية لساقية أبو شعرة في الوجه البحري • 
واقع الصناعات الحرفية ومستقبلها بمحافظة المنوفية ـ مصر

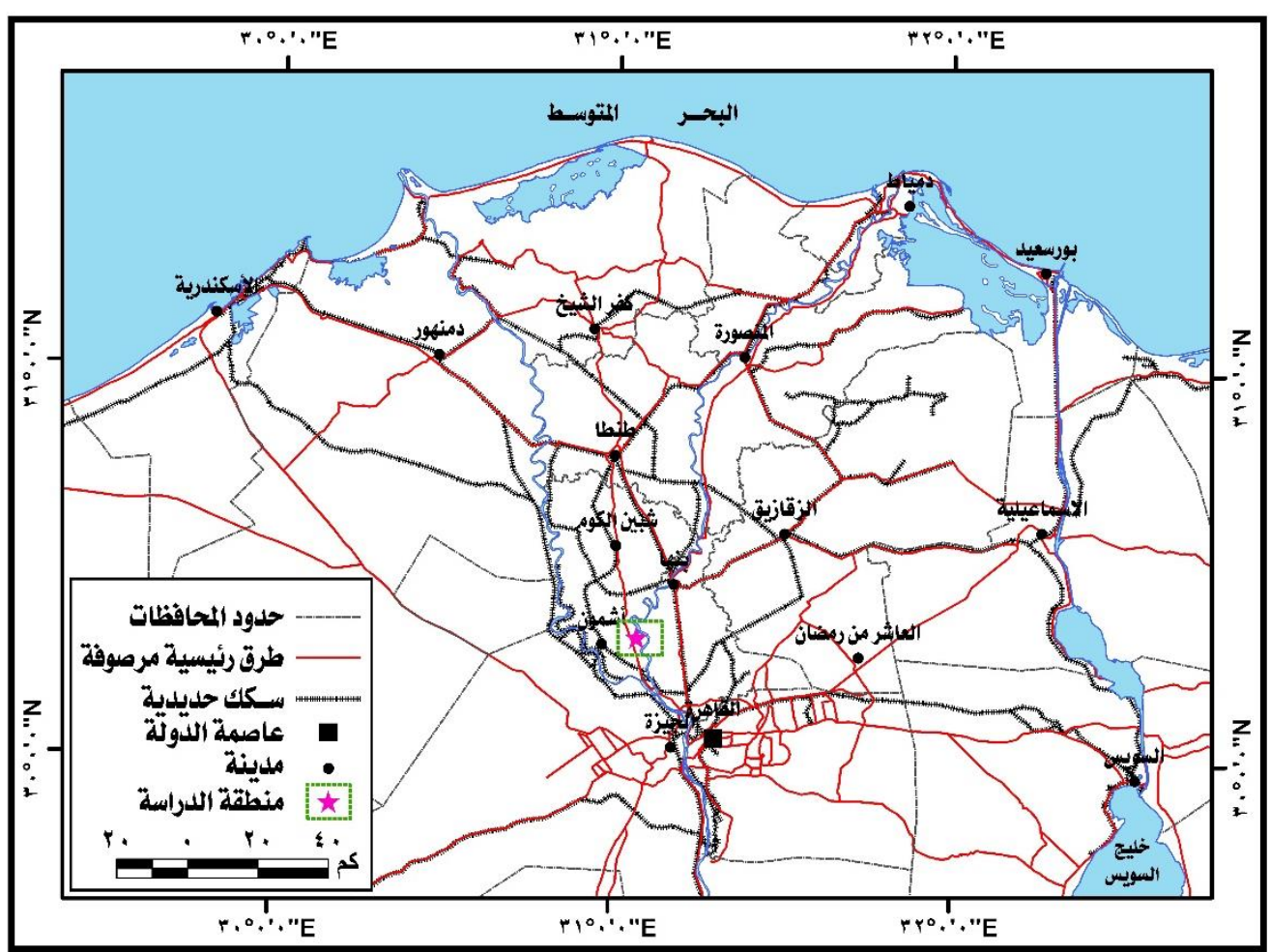

المصدر : الهيئة المصرية العامة للمساحة، الخرائط الرقمية لمحافظات الجمهورية،

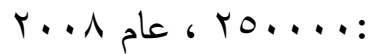

شكل (r) الموقع والعلاقات المكانية لقربية ساقية أبو شعرة فى الوجه البحرى كما أن هناك تأثيراً متبادلاً بين الموقع الجغرافي للقرية وطرق النقل المختلفة بها (عبده، ص 11 1 ) ، فمن الممكن استغلال الموقع الجغرافي للقرية على فرع دمياط وقربها من القناطر الخيرية إحدى الوجهات السياحية في تسويق السجاد، فيمكن أن تكون ساقية أبو شعرة مقصداً سياحياً داخلياً وخارجياً، حيث يمكن أن تكون القرية جزء من برنامج للسياحة النيلية يبدأ من القناطر الخيرية ويستمر إليها مع ضرورة إنشاء مرسى للسفن واللنشات

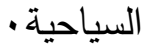

$10 \leq$

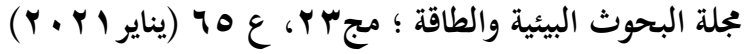


ومحصلة ما سبق أنه على الرغم من تعدد طرق النقل التي تربط ساقية أبو شعرة بيعض القرى المجاورة وتربط بينها وبين القاهرة ، فإن غالبية هذه الطرق تتسم برداءة حالتها وتحولها إلى برك في فصل الشتاء عندما تسقط الأمطار ، كما أن شبكة الشوارع الداخلية للقرية تتسم بضيقها الواضح وتردي حالتها، الأمر الذي يجعل من قرار تحسين حالة شبكة

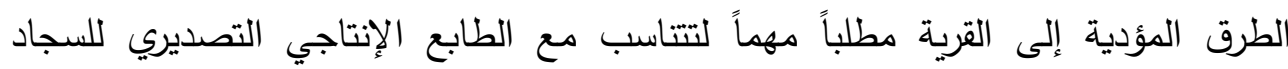
بالقرية -

\section{السياسة الحكومية:}

يمكن للسياسة الحكومية أن يكون لها دورها الإيجابي في دعم صناعة السجاد من خلال العديد من الإجراءات منها تخفيض الضرائب عليها وتقليل التعقيدات الإدارية في عملية الترخيص والحصول على القروض ومن خلال توفير المادة الخام ودعمها كما حدث في بعض السنوات في التسعينيات، أو من خلال دعم وتقديم القروض الميسرة بفوائد بسيطة، أو من خلال تقديم فرصة للمصانع للإعلان عن منتجها في بعض المعارض المهمة بأسعار

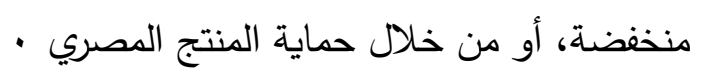
لكن الدور الحكومي في صناعة السجاد ليس إيجابياً على طول الخط، بل إن هناك العديد من أشكال التدخل السلبي لها تأثيرها على الصناعة مثل عدم دعم مستلزمات الإنتاج، الأمر الذي انعكس على ارتفاع أسعارها ، وعدم فرض رسوم إغراق على بعض الواردات من السجاد اليدوي الذي يباع في السوق المصري بأسعار زهيدة، وعدم توفير جهات مسئولة عن النه تسويق المنتج الذي يتسم بارتفاع التكاليف المتغيرة له، وعدم وجود الدعم المادي وغير المادي للصانع من خلال التأمين الصحي ، أو من خلال تحديث التصميمات التي تقوم

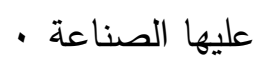

وتزداد أهمية الدور الحكومي في الوقت الحالي في إحياء هذه الصناعة التي استطاعت أن تنتقل إلى بعض القرى المجاورة لتكون بمثابة نوية صناعية ، لكن تدني الدور الحكومي أو غيابه انعكس على انخفاض عدد المصانع وعدد الأنوال وعدد العاملين وبالتالي الإنتاج ، لذا يرى ؟7\% من الصناع عدم وجود دور للحكومة في دعم الصناعة مقابل 
واقع الصناعات الحرفية ومستقبلها بمحافظة المنوفية ـ مصر

דب\% يرون للحكومة دور من خلال مركز تحديث الصناعة وصندوق دعم الصناعات - الصغيرة كما أن دور جمعية منتجي السجاد بالقرية محدود ، حيث يرى ل7\% من الصناع عدم وجود دور لها في الفترة الحالية بالمقارنة بدورها الذي كانت تقوم به في السابق ، الأمر الذي يعني ضرورة تكثيف الدور الحكومي والشعبي من أجل تتمية هذه الصناعة . ( ( ) اقتصاديات صناعة السجاد اليدوي بمنطقة الدراسة . تعكس اقتصاديات صناعة السجاد العلاقة بين التكلفات والعوائد، ففي التسعينيات كانت تكلفة المنتج محدودة وكان العائد كبيراً ، مما كان لله انعكاسه على تحقيق بعض لهض

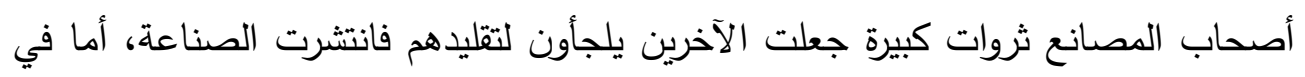
الفترة الحالية فإن ارتفاع التكلفات انعكس على وجود هامش ربح محدود للغاية، فانكمت الصناعة بشكل ملحوظ لاسيما بعد حالة عدم الاستقرار التي يعيشها الاقتصاد المصري في الوقت الحالي التي كان لها انعكاسها على الصناعة التي تعاني من عدم وجود دعم حكومي وعدم وجود منافذ تسويقية داخلية أو خارجية للمنتج · لون وتوضح نتائج الدراسة الميدانية أن متوسط تكلفة المتر المربع من السجاد بالقرية بلغت

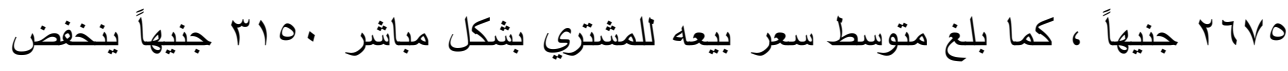

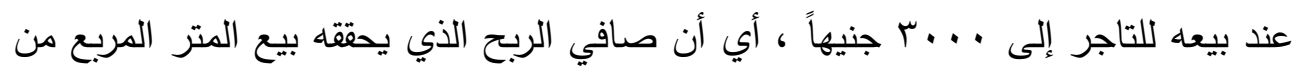

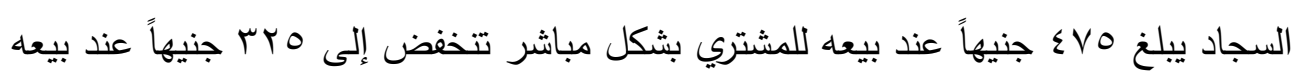
للتاجر، ويبلغ المتوسط · .ـ جنيهاً كصافي عائد لمتر السجاد، كما يوضح ذلك الشكل التالي رقم (ع) الذي يوضح متوسط صافي عائد المتر من السجاد بمنطقة الدراسة عام 1 . r ، ويتضح مما سبق أن صافي عائد الجنيه المستثر في صناعة السجاد يبلغ 10 . . جنيهاً فقط ، وهو رقم ضعيف يعكس ما تعانيه الصناعة من مشكلات كان لها انعكاسها على انكماش الاستثمار فيها ، وليس أدل على ذلك من إغلاق بعض المصانع أبوابها وترك مه لهن بعض الحرفيين هذه المهنة ليعملوا بالقاهرة أو غيرها . 


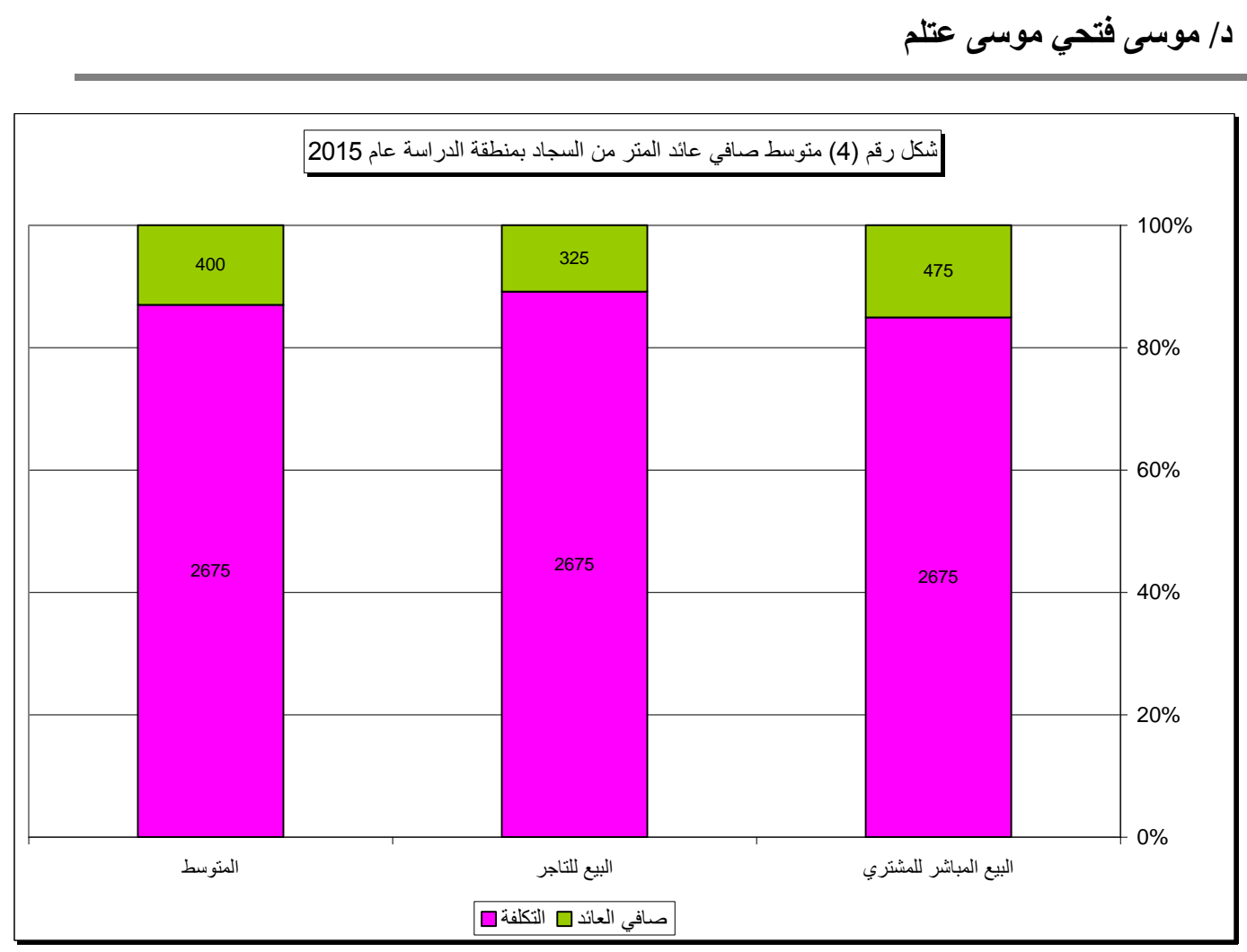

ويرتبط باقتصاديات الإنتاج كمية الإنتاج وسعره وتكلفته ، حيث تبين من بيانات

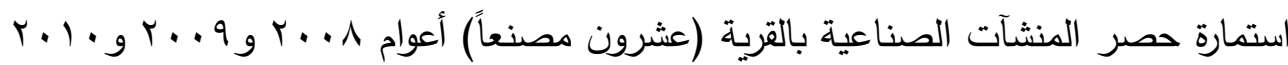
ما يلي:

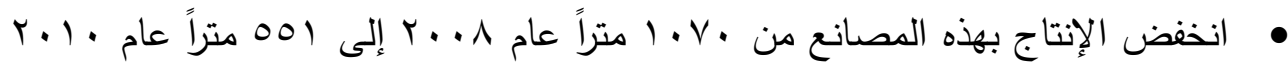

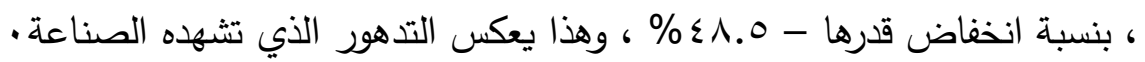

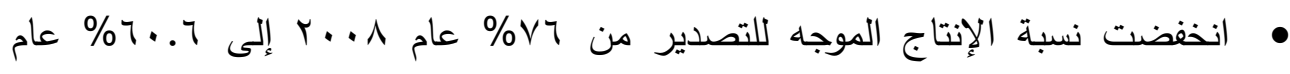

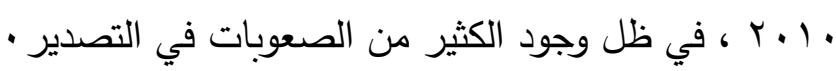

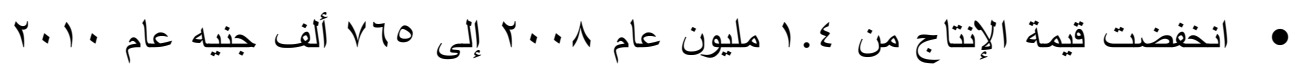
بنسبة انخفاض بلغت - 99 \% ، وهذا بلا شك كان له انعكاسه على صافي العائد • المحقق

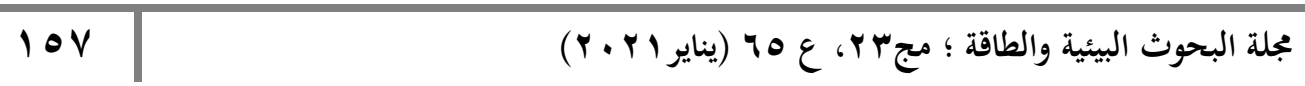


وأمام انخفاض العائد في الصناعة انخفض متوسط إنتاج المصنع من به متراً عام

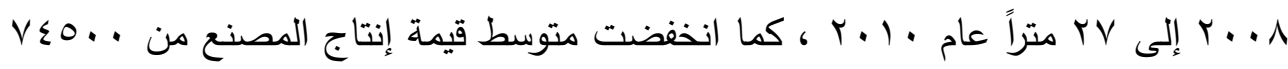

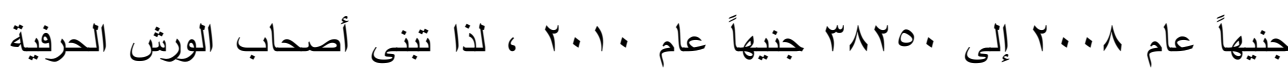
بالقرية بعض الاستراتيجيات من أجل خفض التكلفة والحفاظ على هامش الربح منها: • استخدام عدد عقد أقل في صناعة السجادة ، حتى يتم تقليل المواد الخام المستخدمة وتقليل عدد أيام العمل التي يحتاجها السجادة، ومن ثم التوفير في عنصري المادة الخام

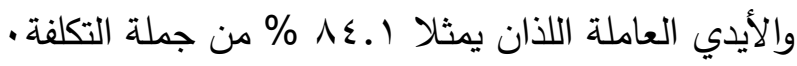

الاعتماد على العمالة الأسرية بنسبة كبيرة لتحقيق بعض الوفورات الاقتصادية • • استخدام مواد خام أقل جودة في بعض الأحيان للحفاظ على هامش الربح. • تلجأ بعض المصانع خارج القرية إلى خلط حرير صناعي بكميات محدودة من أجل تخفيض التكلفة .

• ثضيل نسبة كبيرة من الوش صناعة السجاد الصغير ، حتى لا ترتفع التكلفة وحتى لا

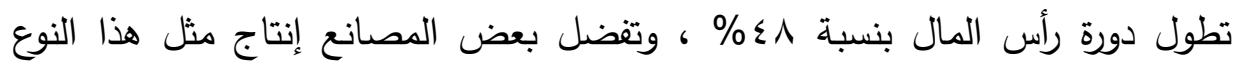
لمرونة بيعه وخفض تكاليف الإنتاج وصعوبة تسويق السجاد الكبير ، كما يفضل بr\% من المصانع إنتاج السجاد الكبير لوجود طلب عليه من بعض الجهات، كما يلجأ 7 (1 \% من المصانع بإنتاج الاثنين ، وبصورة عامة يقف الطلب على المنتج ووجود تعاقد عليه

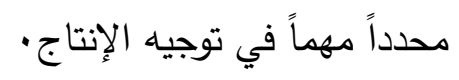

ومحصلة ما سبق أن صافي العائد من صناعة السجاد انخفض بشكل ملحوظ في ظل ارتفاع تكلفة الإنتاج وانخفاض أسعار بيع المنتج ، الأمر الذي يعني ضرورة التتخل

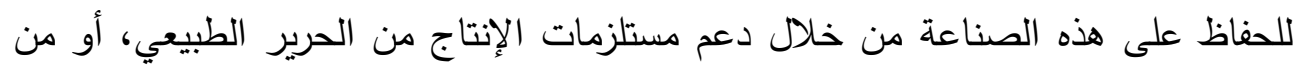

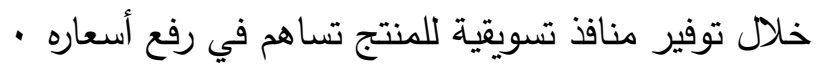


(0) الآثار التنموية لصناعة السجاد على منطقة الاراسةة . تقوم الصناعات الريفية بدور اقتصادي واجتماعي مهم في إنعاش القرية، هذا بالإضافة إلى ما تحققه من تشغيل الأطفال والنساء في أوقات فراغهر ، كما أن بعض منتجاتها من السجاد والأكلمة تصدر للخارج( صادق، ص VTV T بتصرف) ، وقد كان لاخول صناعة السجاد إلى القرية وانتشارها بها آثاره التتموية العديدة ، سواء من حيث توفير فرص صرص عمل للسكان وتحسين مستوى المعيشة، أو من خلال استخدام عائد الصناعة في التوسع في الورش القائمة أو إنشاء مشاريع تتموية جديدة ، حيث تكتسب هذه الصناعة أهميتها في ظل مل مل مجموعة من السمات التي تتسم بها القرية منها:

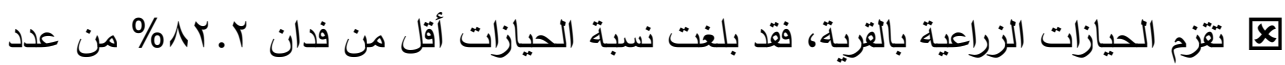

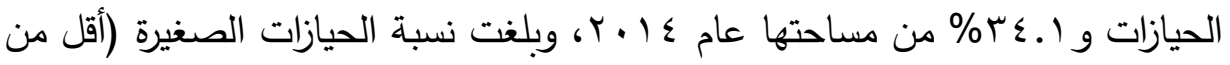

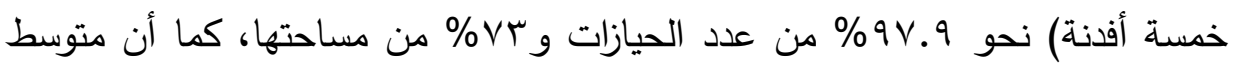
مساحة الحيازة بها بلغ ه ه. . فداناً مقابل 91 . . فداناً لمتوسط المركز • 区 تعد الأراضي الزراعية أهم مقومات التتمية في الريف، فإلى جانب تفتتها وتقزمها الذي اتضح فإن نحو 0 1. 7 منها جاء ضمن أراضي الدرجة الثالثة والرابعة (وزارة الإسكان، والنسبة من حساب الباحث)، مما يؤكد وجود مشكلات في قدرة هذه الأراضي على الإنتاج وتحقيق عوائد معقولة ، مما جعل النشاط الزراعي في القرية لا يحظى بأولوية ضمن الأنشطة الاقتصادية كسائر القرى المجاورة • 囚 عمل نسبة كبيرة من السكان الذين يصنفون أنهم خارج قوة العمل في هذه الصناعة مثل نمان الأطفال والنساء المتفرغات للمنزل ، وانعكاس ذلك على زيادة نسبة قوة العمل بالقرية . 囚 تتمية القدرات الذاتية للحرفيين، ورفع نسبة مشاركة الإناث في النشاط الاقتصادي

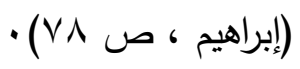


واقع الصناعات الحرفية ومستقبلها بمحافظة المنوفية ـ مصر

وتتعدد تأثيرات الصناعة على القرية في العديد من الجوانب منها:

التأثير على توزيع قوة العمل:

بلغت نسبة قوة العمل 9.9٪\% من جملة السكان(10 سنة فأكثر) بالقرية مقابل

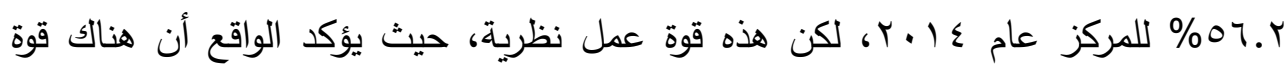
عمل فعلية يشارك فيها صغار السن والنساء المتفرغات للمنزل، الأمر الذي يعكس دور الصناعة في وصول القرية إلى نسبة كبيرة من التشغيل لنسبة كبيرة من سكانها .

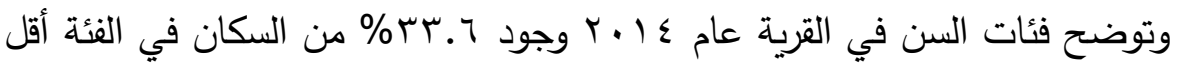

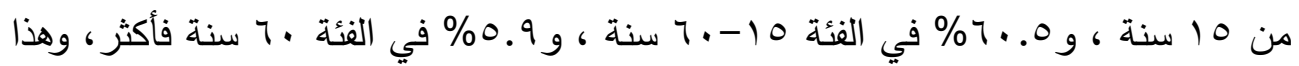
له انعكاسه على نسبة الإعالة في القرية .

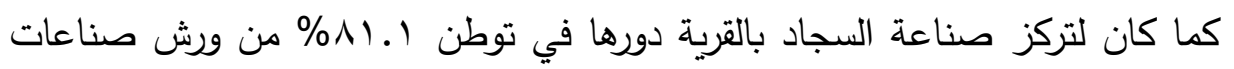

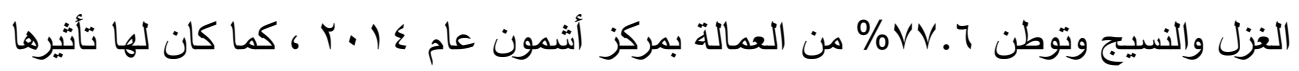

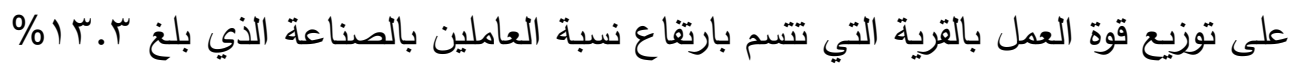
مقابل ؟.9\% للمركز و^.^\% للمحافظة ، كما انخفضت نسبة العاملين بالزراعة بالقرية

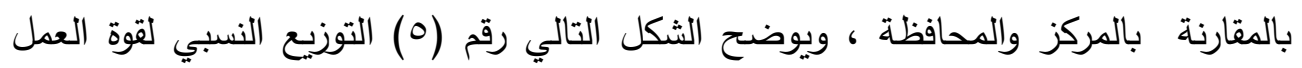

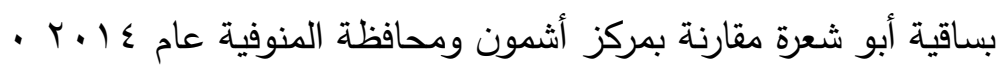

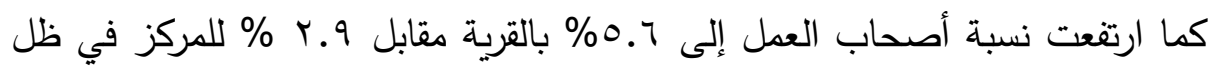
حيازة بعض السكان ورش لصناعة السجاد، كما انعكس توافر بعض فرص العمل بالقرية على انخفاض نسبة العاملين بالحكومة والقطاع العام إلى 1.7.7 (1\% من جملة العاملين

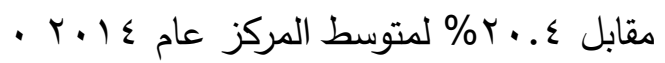

17.

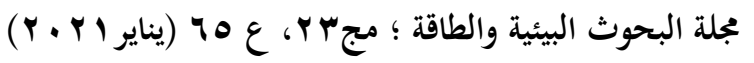




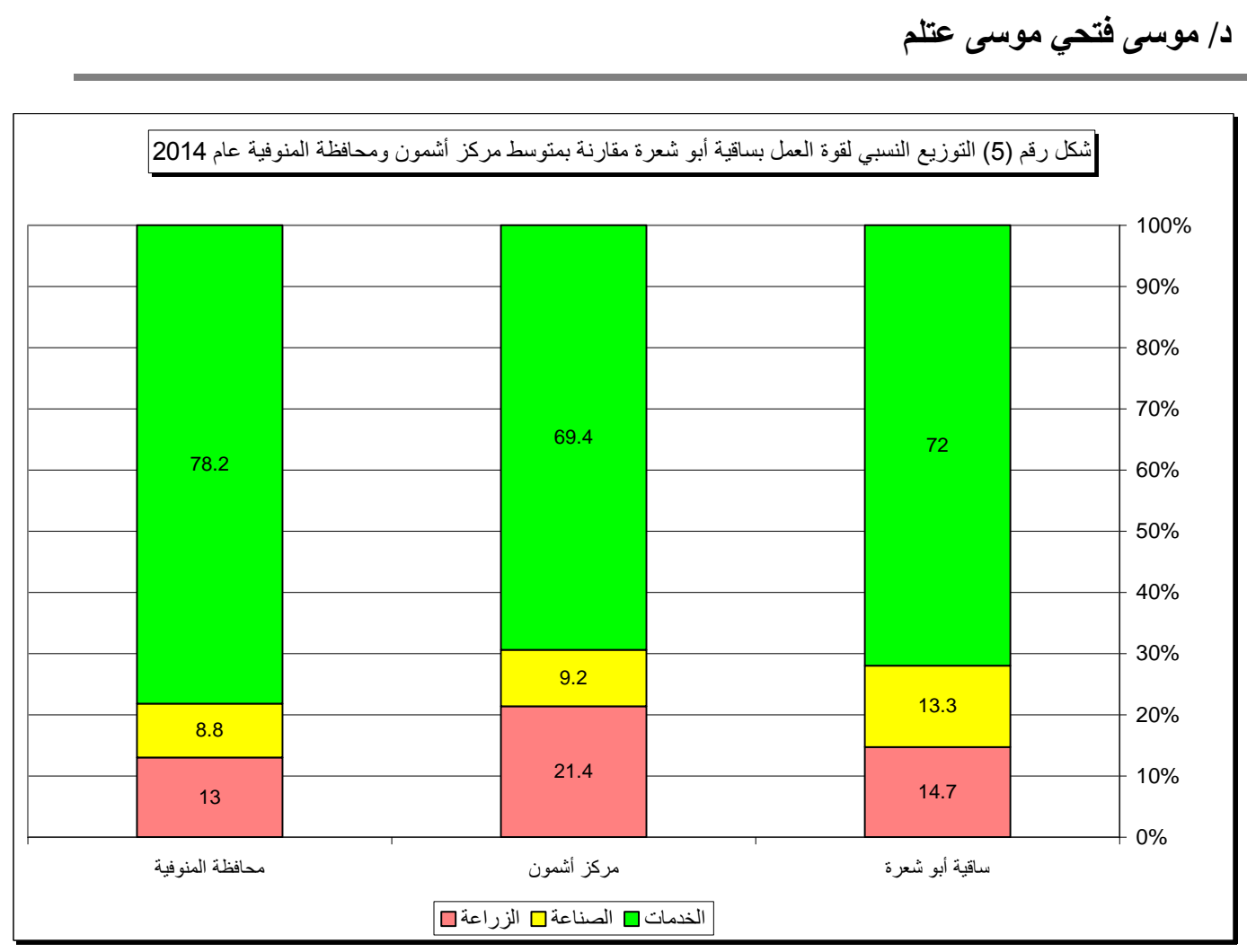

كما كان لصناعة السجاد دورها في زيادة نسبة العاملين بالمهن الحرفية بالقرية إلى

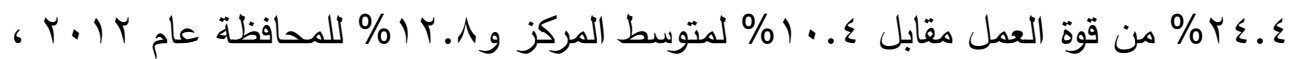

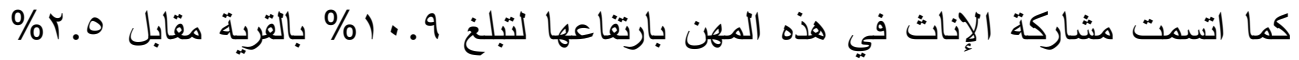
للمركز و r.ء \% للمحافظة .

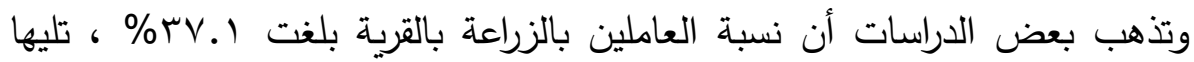

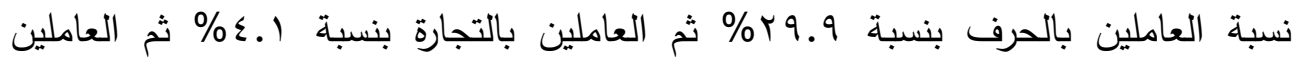

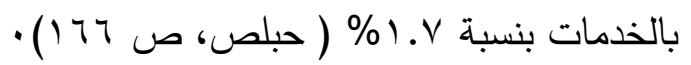
ومحصلة ما سبق أن صناعة السجاد كان لها انعكاسها على زيادة الوزن النسبي للحرفيين بين أنشطة القرية ، وهذا بلا شك يغير من طبيعة تركيب الأنشطة الاقتصادية للقرية وما لذلك من انعكاسات تتموية . 
واقع الصناعات الحرفية ومستقبلها بمحافظة المنوفية ـ مصر

التأثير على الخدمات والمرافق بالقرية:

ينشر بالقرية العديد من الخدمات يأتي على رأسها الخدمات التعليمية، حيث يوجد الخدات بالقرية مدرستان ابتدائيتان ومدرستان إعداديتان ومدرسة ثانوية عام واحدة ، و و فصول لرياض الأطفال ملحقة بالدرسة الابتدائية ، وتتسم كثافة الفصول بالقرية بارتفاعها بالمقارنة

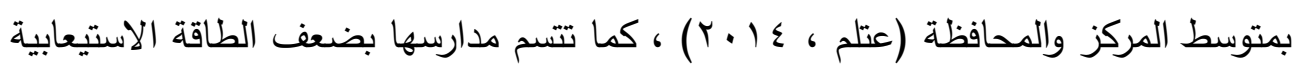

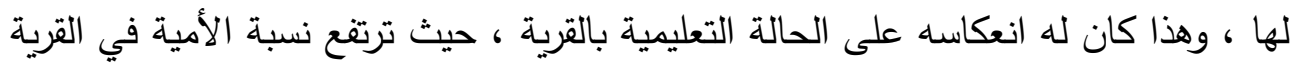

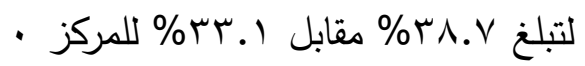

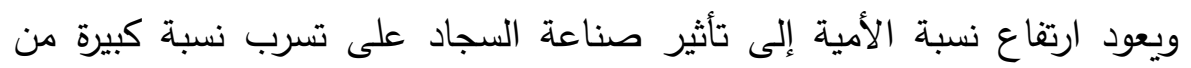
التلاميذ من الددارس في فترة ازدهار الصناعة في التسعينيات من أجل العمل بالصناعة في التاعيز

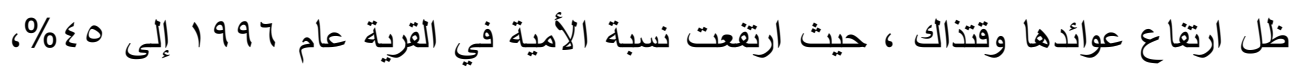

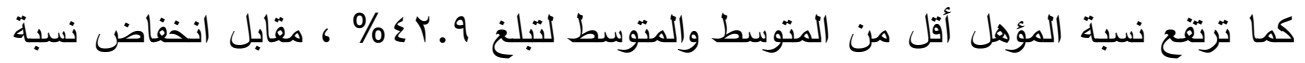

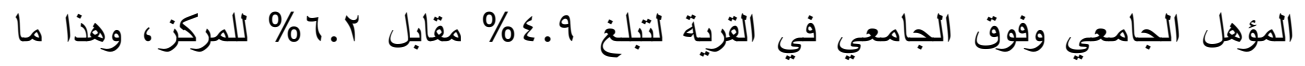
أكتته بعض الدراسات أن ارتباط السكان بصناعة السجاد بالقرية انعكس على ارتفاع نسبة لعابة

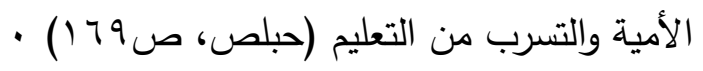

لذا فإن التوجه نحو خفض معدلات الأمية في القرية يجب أن يحظى بأولوية في الوقت

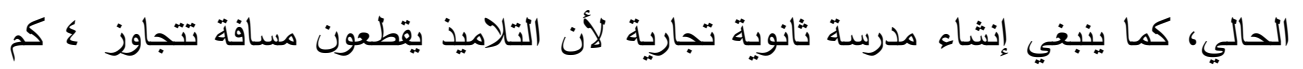

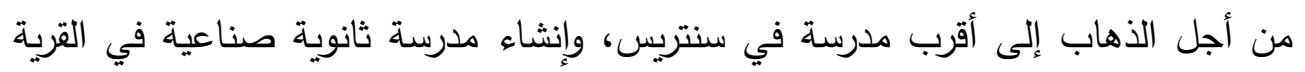
تتضمن بعض الأقسام بها التي تخدم الصناعة والصناعات اليدوية الأخرى الموجودة بالمركز مثل صناعة الفخار وصناعة التطعيم بالصدف. ويوجد بالقرية وحدة صحية تنتقد للكثير من المقومات حتى تقوم بدورها على الوجه الأكمل كما تتنشر بها بعض العيادات الخاصة، بالإضافة لبعض العيادات الملحقة

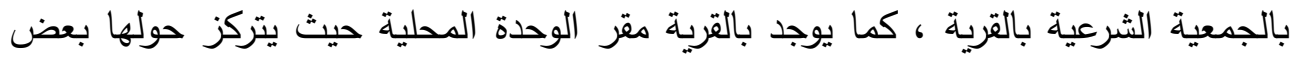

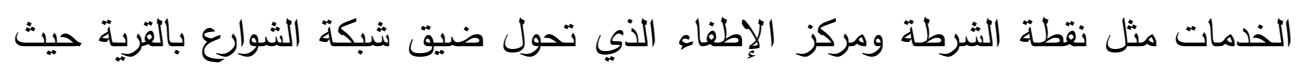

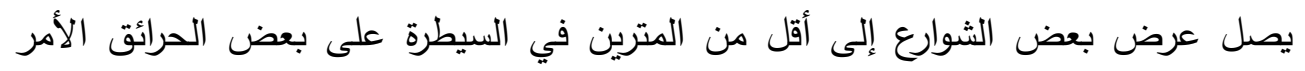


الذي يتطلب ضرورة قيام إدارة التنظيم بالقرية بدورها خصوصاً في ظل وجود نسبة كبيرة من - المباني بالطوب اللبن كما يوجد بالقرية سنترالاً ومكتباً للبريد وه مخابز ومركزاً للشباب وبعض جمعيات خدمة

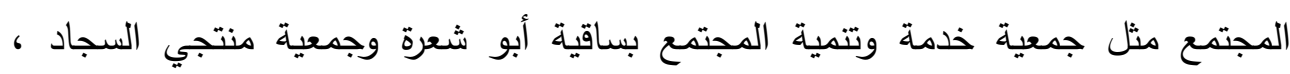
وبعض الخدمات الأخرى مثل محلات تجارة التجزئة والصيدليات والمكتبات . وتعاني القرية من تدني حالة شبكة الشوارع بها، فحالتها سيئة وتزداد سوءاً في فصل الثتاء مع سقوط الأمطار، الأمر الذي يتطلب تمهيد شبكة الثوارع لتحسين حالتها، مما يتطلب التدخل لتحسين شبكة الشوارع بالقرية .

وتوجد بالقرية محطة مياه للشرب حيث تصل نسبة الأسر التي تحصل على مياه مأمونة 9. \% \%، كما تقتقد القرية إلى شبكة صرف صحي بالرغم من أهميتها ، لذا فإن نظام الصرف يعتمد على الترنشات في ظل عدم وجود شبكة صرف صحي، وهذا كان له

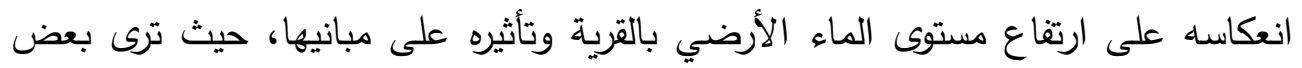

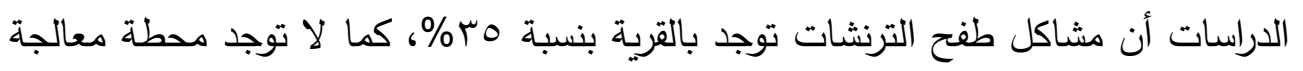

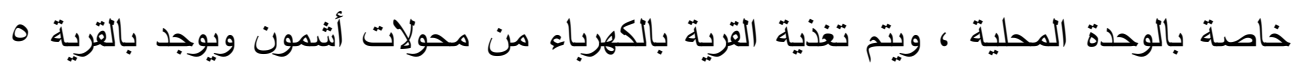
محولات ، لكن القرية تعاني ضعف قدرات محولات التوزيع بحيث لا تتناسب مع مساحة واستهلاك القرية ( حبلص، ص صل 10 1) .

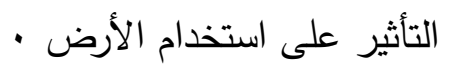
تتعدد استخدمات الأرض في القرية ، كما يوضح ذلك الثكل رقم (؟) الذي يتبين منه أن الاستعمال السكني هو الاستعمال الغالب خصوصاً في منطقة القلب القديم للقرية، كما تتركز الاستعمالات السكنية التجارية والتجارية والسكنية الحرفية داخل وحول مجمع الاسل الخدمات الرئيسي للقرية وحول طريق داير الناحية ، ويميل الاستخدام التجاري إلى التركز

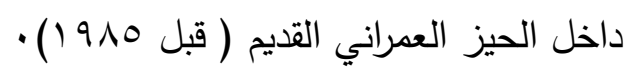

كما تتنشر أغلب مناطق الخدمات خارج حدود حيز 1910 ، حيث تنتشر الخدمات التعليمية والصحية والإدارية في القرية في نطاق يقع جنوب القرية ، كما توجد بعض 
واقع الصناعات الحرفية ومستقبلها بمحافظة المنوفية ـ مصر

المساحات الفضاء والفراغات البينية لكنها تتسم بمحدويتها، كما تتسم القرية بشبكة شوارع ضيقة للغاية، ويختلط الاستخدام الحرفي للأرض في صناعة السجاد مع الاستخدام السكني ، فنادراً ما نجده مستقلاً، في ظل التزاوج بين كلا الاستخدامين وبين الوظيفة الاجتماعية والاقتصادية للمسكن مما يحقق وفورات كبيرة •

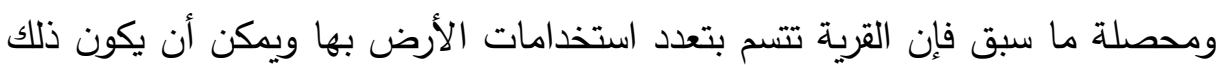

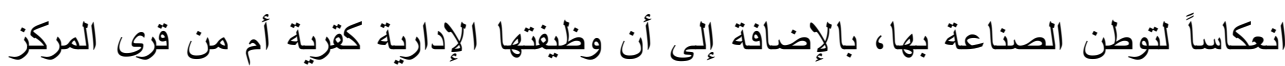
تقم خدماتها للقرى المجاورة انعكس على توطن بعض الخدمات بها. - التأثير على العمران شهدت القرية نمواً عمرانياً واضحاً تعكسه الخريطة رقم (V) التي توضح مراحل النمو

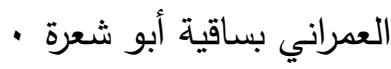




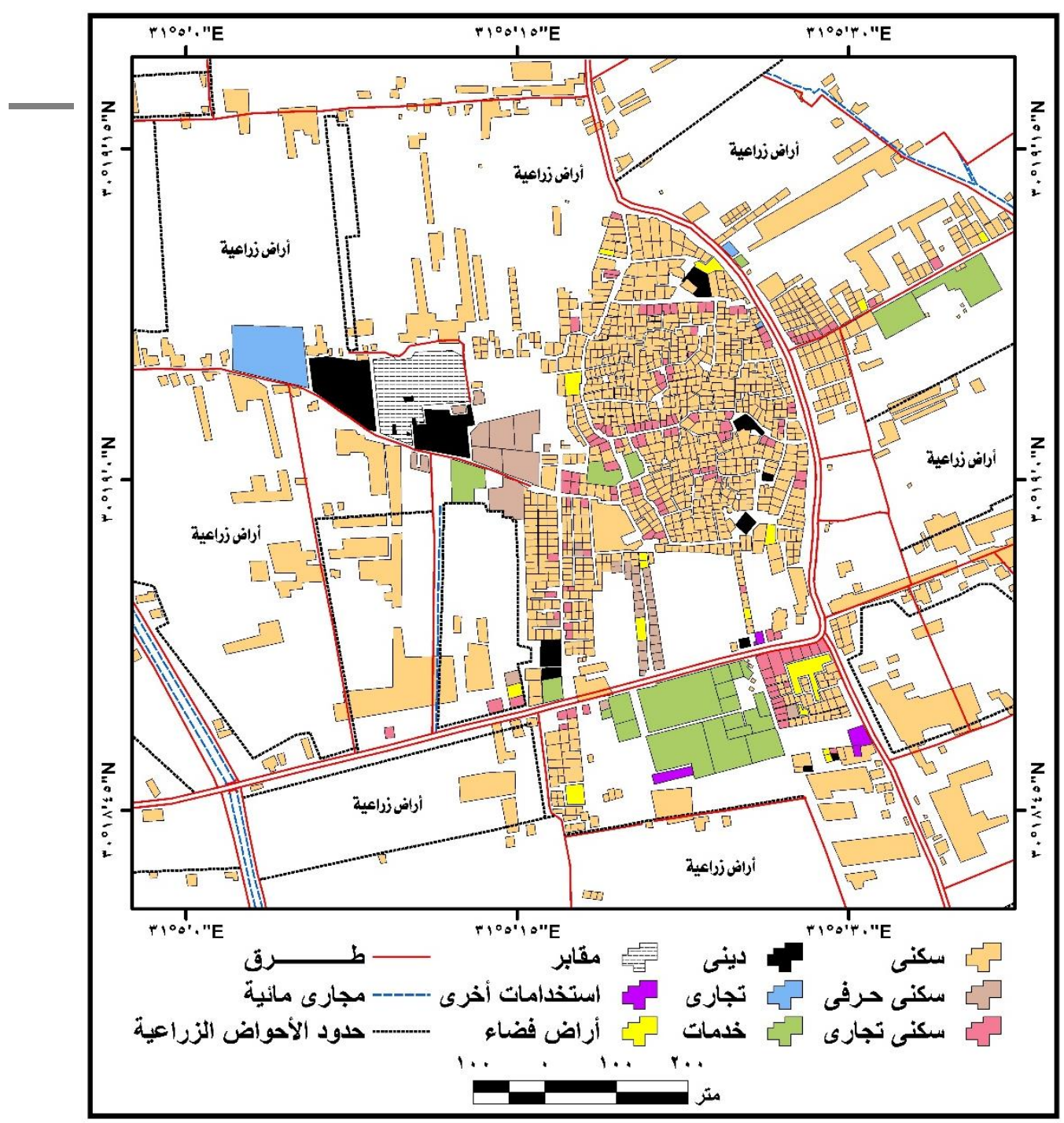

المصدر : 1- وزارة الاسكان والمرافق والمجتمعات الجديدة ، الهيئة العامـة للتخطيط العمراني ،

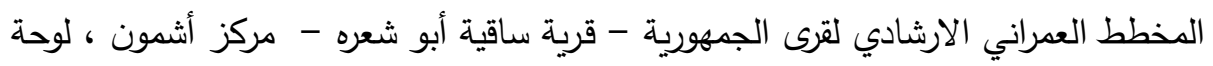

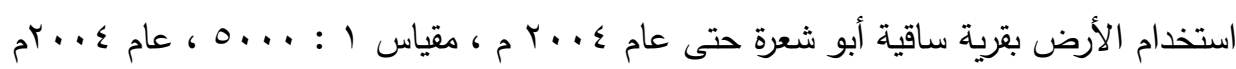

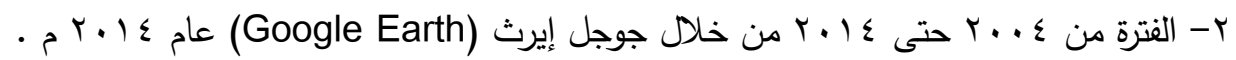

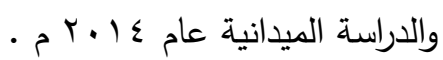

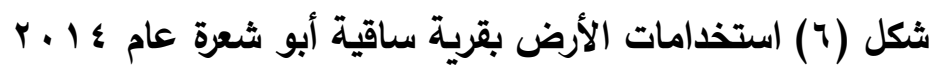


واقع الصناعات الحرفية ومستقبلها بمحافظة المنوفية ـ مصر

ويتضح من البيانات أن مساحة الكتلة العمرانية قبل عام هبه ا كانت محدودة ، لكنها

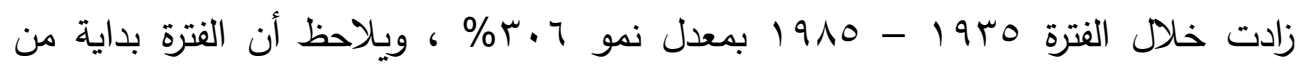
1910 ههدت نمواً عمرانياً كبيراً واضحاً للقرية يمكن ربطه بعوائد صناعة السجاد، كما

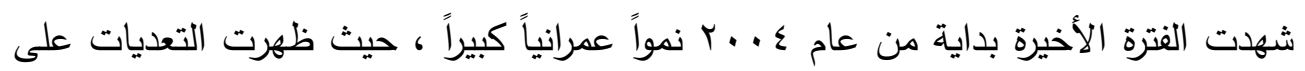

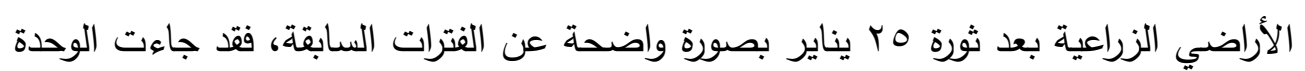
المحلية بساقية أبو شعرة على رأس الوحدات في المركز في حالات التعديات ومساحتها وفقاً

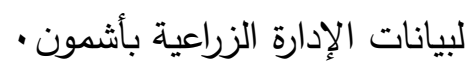
وتؤكد العلاقة بين النمو السكاني للقرية ونمو أعداد المباني تفوق الثانية على الأولى لإنى

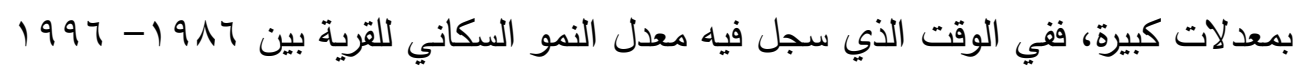

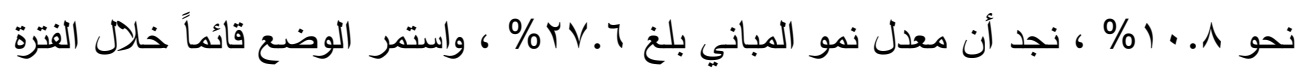

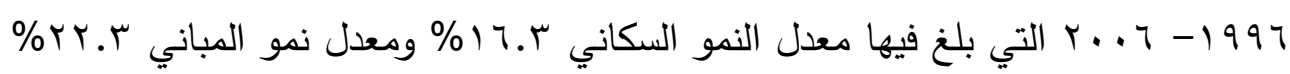
، وهذا يؤكد ما تشهده القرية من نمو سكاني ونمو عمراني انعكس على تتاقص المساحة المزروعة بها من ناحية ، وارتباط ذلك بالأوضاع الاقتصادية للقرية من ناحية أخرى . 


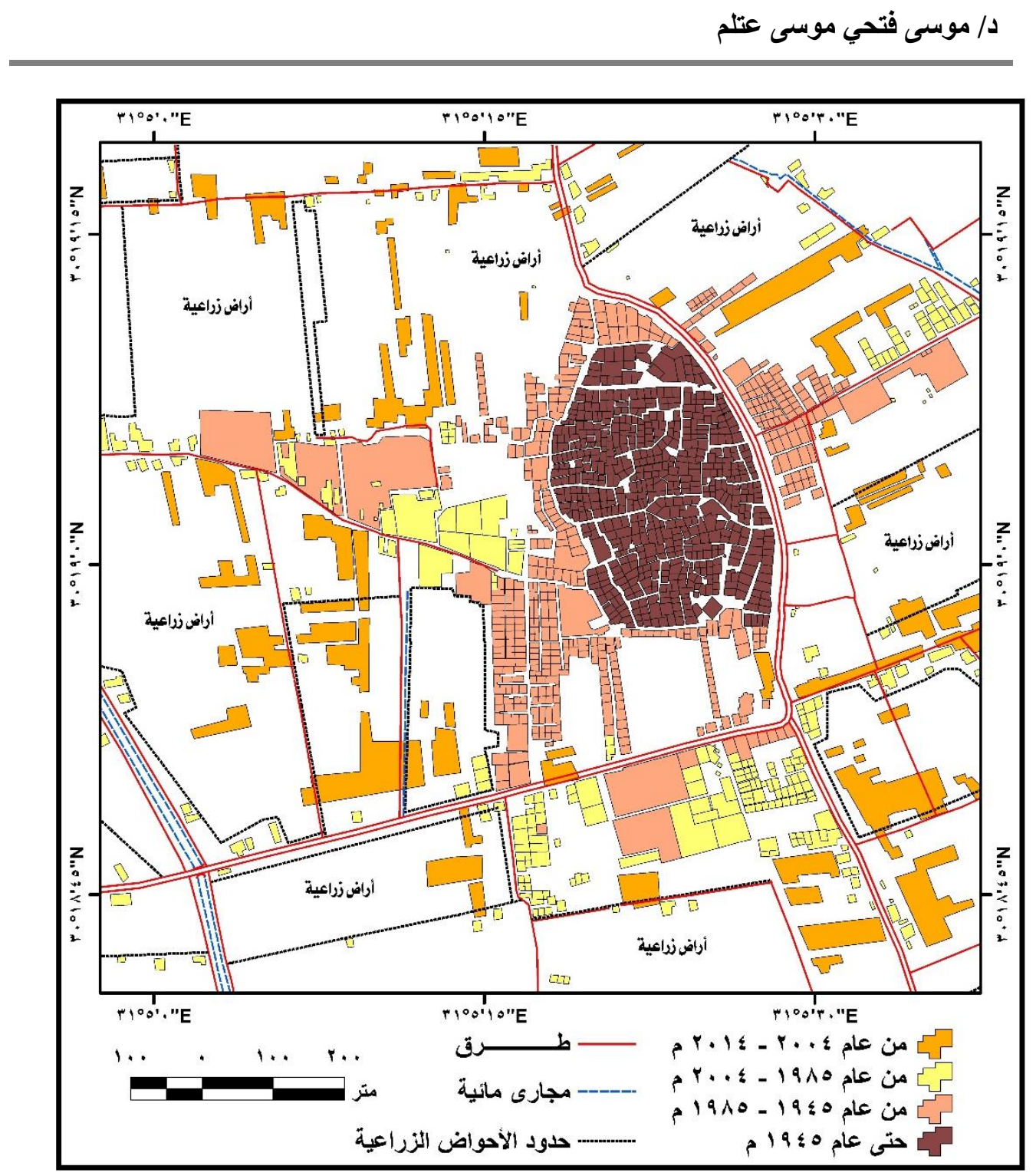

المصدر : 1- وزارة الاسكان والمرافق والمجتمعات الجديدة ، الهيئة العامـة للتخطيط

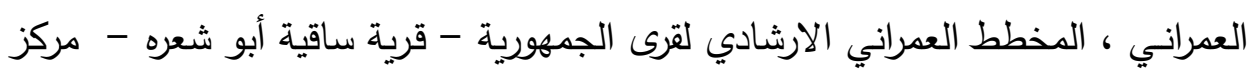

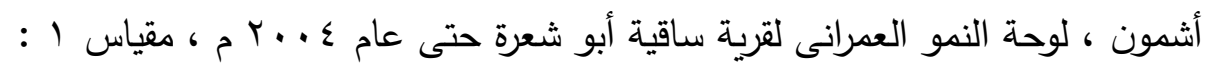

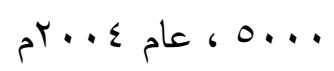

\begin{tabular}{|c|c|}
\hline 178 & 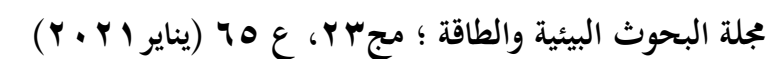 \\
\hline
\end{tabular}


واقع الصناعات الحرفية ومستقبلها بمحافظة المنوفية ـ مصر

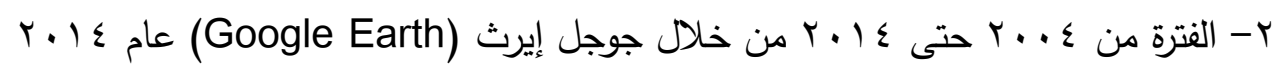

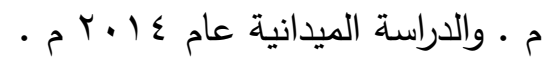

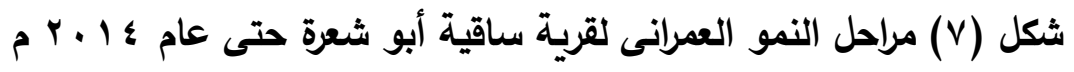

وبالرغم من تزايد أعداد المباني فإن حالة المباني في الكتلة العمرانية القديمة (قبل ه1911) تشهد تردياً ، فبعض مبانيها لا تزال بالطوب اللبن هذا فضلانًا عن قلة نموها الرأسي

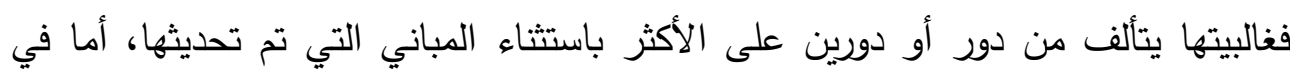
المناطق الجديدة حول شارع داير الناحية بالقرية، فإن مبانيها حالتها جيدة وتتسم بارتفاعها

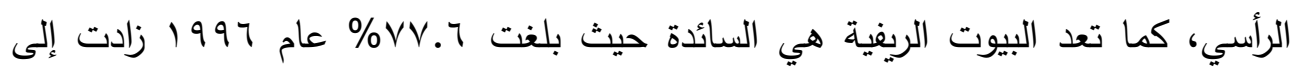

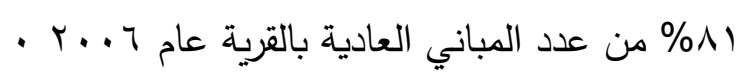

كما يلاحظ تعدد استخدام المباني بالقرية ، حيث استخدمت بعض المباني في السكن والعمل معاً كما هو الحال في ورش صناعة السجاد، وهذا يقلل من تكلفة البحث عن مكان لإنشاء ورشة كما أنه يحقق العديد من الوفورات، لكن لله بعض السلبيات مثل سوء التهوية

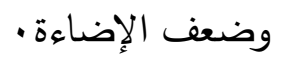

التأثير على بعض الحرف المساندة للصناعة .

تشهد صناعة السجاد ما يمكن تسميته بالارتباط الصناعي الرأسي، حيث تنقل المادة الخام من مرحلة إلى أخرى، بحيث تمثل كل مرحلة صناعة مستقلة قائمة بذاتها، فمن لن

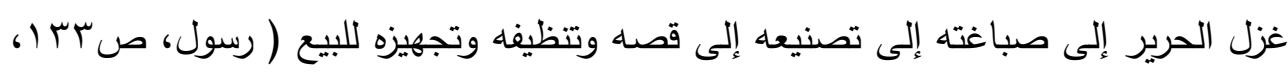
•بتصرف)

وترتبط بصناعة السجاد بعض الحرف والأنشطة المكملة، منها تصميم السجادة حيث أوضح § 9\% من الورش أن التصميم يتم داخل القرية، ويتم حساب تكلفته على أساس حجم التصميم وحداثته وعدد مربعاته، ومن شروط التصميم الجيد الدقة والتتوع والتحديث ووضوح • الألوان ومناسبته لاحتياجات الأسواق وعرد

171

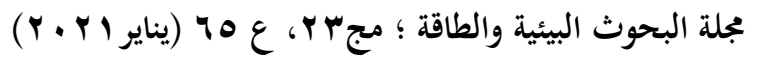


ويرتبط بصناعة السجاد إنتاج الحرير الطبيعي حيث يمكن لبعض المزارعين القيام بتربية دودة القز لقدرتها على إنتاج الحرير، حيث أكد البعض أن بعض القرى المجاورة

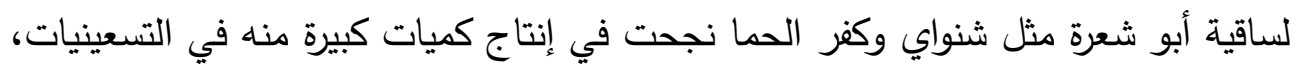
لكن مع استيراد الحرير الصيني الذي اتسم بانخفاض أسعاره وقتذاك عن الحرير المحلي بدأ إنتاج الحرير في التتاقص والتلاشي •

كما يرتبط بالصناعة غزل الحرير الذي يتم الحصول عليه كمادة خام لكن هذا لا يتم في القرية إلا على مستويات محدودة، حيث يتم الحصول عليه بعد عملية الغزل والصباغة في منطقة الدراسة والسادس من أكتوبر وبعض المناطق الأخرى •

وترتبط بصناعة السجاد صباغة الحرير ليكون صالحاً للاستخدام وفق ما تحتاجه السجادة من ألوان، وتتم عملية الصباغة في القرية بكميات محدودة، حيث يتم صباغة معظم الحرير خارج القرية ، مما يفقد القرية فرصة لتشغيل عدد كبير من السكان، وقد تبين من الدراسة الميدانية أن عدم وجود منشآت صناعية لصباغة السجاد بالقرية يعود إلى: عدم وجود صرف صحي بالقرية لكي يقوم بصرف مخلفات صباغة السجاد التي يتم استخدام بعض المركبات الكيميائية فيها -

قلة خبرة العاملين بالقرية في أعمال الصباغة، بالرغم من نجاح بعض المشاريع التي تم

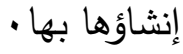
عدم تبني الدولة إنشاء مصانع أو مصابغ لصباغة الحرير بحيث تقلل من تكلفة الانتقال

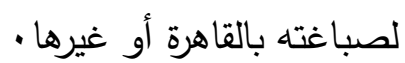
ويرتبط بصناعة السجاد صناعة الأنوال وصيانتها، حيث كانت تتم خارج القرية، لكن

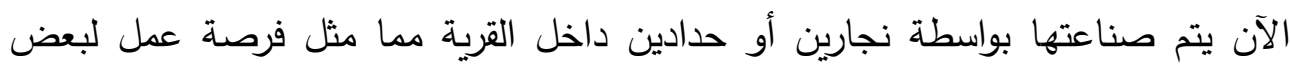
السكان، كما يرتبط بتلك الصناعة التجهيز النهائي للسجادة من غسيل وعمل إطار لها لها لهانه وقص وكي لكن لا توجد منشآت متخصصة في القرية بهذه العملية، الأمر الذي يعني ضرورة وجود منشأة متخصصة في تجهيز السجاد قبل عملية التسويق داخل القرية، لأنها 


\section{واقع الصناعات الحرفية ومستقبلها بمحافظة المنوفية ـ مصر}

ستوفر فرص عمل لبعض السكان من ناحية، وتوفر في تكلفة نقل السجاد إلى أماكن تجهيزه

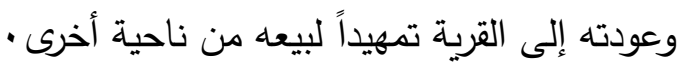

ومحصلة ما سبق فإن دخول الصناعة للقرية كان لها تأثيره الإيجابي على بعض مظاهر الحياة بها مثل وجود الكثير من الخدمات وبعض مظاهر البنية الأساسية وفرص العمل وزيادة الوزن النسبي للعاملين بالصناعة وأصحاب المهن الحرفية بها ، كما كان لها تأثيره السلبي من حيث زيادة معدلات الأمية في ظل عدم حرص بعض الأسر على تعليم أبنائها وتسربهم من التعليم للالتحاق بهذه الصناعة التي كانت تمثل لهم فرصة لتحسين الاخل والارتقاء بمستوى المعيشة دون تكبد مشقة السفر للخارج أو الانتقال للعمل بالقاهرة .

تعاني صناعة السجاد في مصر العديد من المشاكل منها ما يتعلق بالمادة الخام، ومنها ما يرتبط بالإنتاج، ومنها ما يتعلق بالتمويل، بالإضافة إلى المشاكل المتعلقة بالعمالة

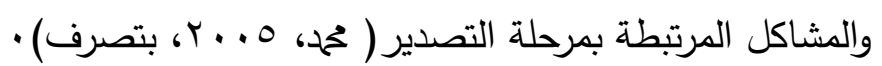
كما قام مجلس الوزراء بإعداد دراسة عن مشكلات الصناعات الصغيرة في محافظات مصر ، واتضح منها أن محافظة المنوفية تعاني عدم وجود السيولة الكاملة ووجود منتجات كثيرة مستوردة بالأسواق تضارع المنتج المحلي وأرخص منه وتعدد الجهات الإدارية التي يتعامل معها أصحاب المشروعات وكساد بعض المنتجات مثل السجاد والحرير، وتذبذب

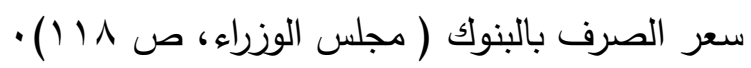
وبالرغم من أهمية صناعة السجاد بالقرية التي أحدثت تتمية في الكثير من المجالات، وتحقيق الصناعة بالقرية شهرة تجاوزت حدود المحافظة وحدود مصر؛ فإنها تواجه العديد من المشكلات، بعضها مشكلات اقتصادية نتيجة ارتفاع تكلفة الحصول على المادة الخام وانخفاض العائد ومشكلات في التسويق، وبعضها مشكلات إدارية نتيجة وجود بعض التعقيدات في إصدار التراخيص ، وبعض المشكلات الأخرى . 
وتتعدد المشكلات التي تواجه صناعة السجاد بالقرية، كما يوضح ذلك الجدول رقم (r) والثكل رقم (^) الذي يوضح درجة انتشار مشكلات صناعة السجاد بساقية أبو شعرة، حيث يمكن تتاول هذه المشكلات بالتفصيل على النحو التالي: جدول رقم (r) يوضح درجة انتشار مشكلات صناعة السجاد بساقية أبو شعرة •

\begin{tabular}{|c|c|}
\hline درجة انتشارها \% & 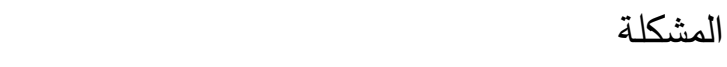 \\
\hline $9 \leq$ & مشكلات الحصول على المادة الخام وزيادة أسعارها \\
\hline$\wedge 7$ & صوبة التسويق الداخلي والخارجي \\
\hline$\wedge \varepsilon$ & انخفاض الدعم الحكومي المقدم للصناعة \\
\hline$\Lambda$. & تعدد الوسطاء في صناعة السجاد \\
\hline$\vee 7$ & عدم وجود جهات لتقديم التمويل المدعم \\
\hline 7. & وجود بعض الأمراض المرتبطة بالصناعة \\
\hline $0 \wedge$ & تدهور السياحة في مصر \\
\hline 07 & تسرب العمالة وقلة أعداد العاملين المهرة \\
\hline
\end{tabular}




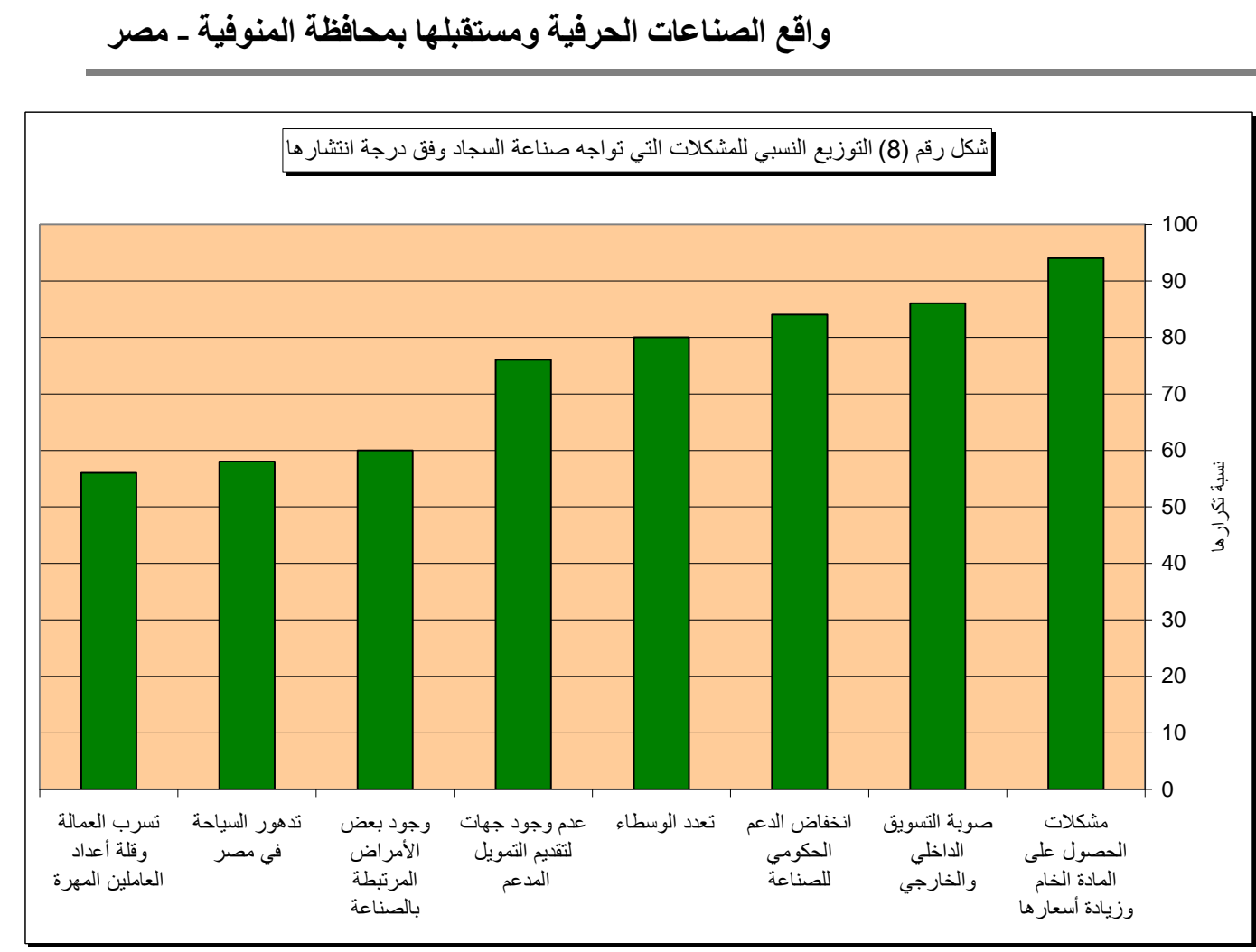

مشكلات الحصول على المادة الخام • مثل

تبين بعض الدراسات حول المشكلات التي تواجه صناعة السجاد في مصر أن

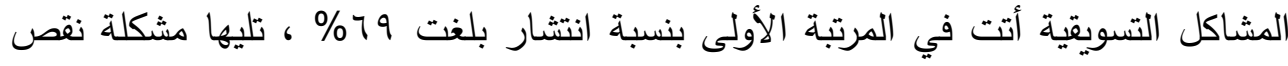

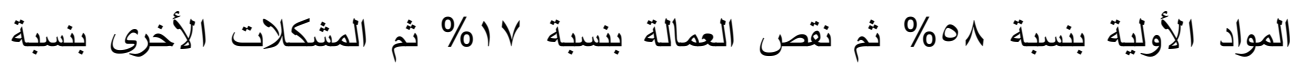
VIV V أي أن نقص المواد الخام يعد أحد مشكلات صناعة السجاد(الجهاز المركزي للتعبئة

- العامة والإحصاء ، 9 . . ب ، بتصرف) ومن مشكلات المواد الخام اللازمة لصناعة السجاد أن معظمها يتم استيراده من الخارج وأن الصين هي المتحكم الرئيسي فيها، كما أن الحرير الذي يتم استيراده لا يتمتع

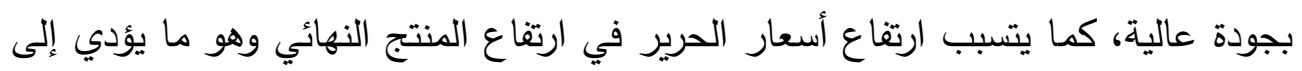

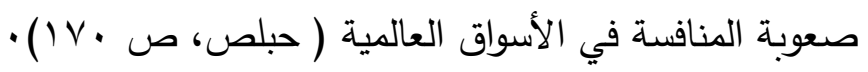


وتعد مشكلة نقص المواد الخام اللازمة لصناعة السجاد وارتفاع أسعارها أكثر

المشكلات انتشاراً بين مشكلات الصناعة في القرية، حيث يرى ب9\% من عينة الدراسة وجود مشكلات تتعلق بالمادة الخام مقابل ^^\% لا يرون وجود مشكلات، لأن المادة الخام تمثل r.r٪\% من إجمالي تكلفة إنتاج السجاد، وتعدد مشكلات الحصول على المادة الخام في منطقة الدراسة ومنها: • عدم وجود مواد خام محلية بكميات كافية تساهم في خفض نسبة الحرير المستورد من ·لخارج

• ارتفاع أسعار المادة الخام بشكل يؤثر على تدني صافي العائد من الصناعة . • • عدم توافر المادة الخام باستمرار، مما يؤثر على استمرارية عملية التصنيع . • تعدد الحلقات الوسيطة التي تمر بها المادة الخام من استيراد عن طريق بعض الشركات الكبرى لتذهب لكبار التجار الذين ينقلونها بدورهم لصغار التجار ثم يقوم هؤلاء ببيعها إلى الصناع ، مما يضاعف من ثمنها بدرجة كبيرة •

• ثتسم المواد الخام في بعض الأحيان بتردي نوعيتها . ومحصلة ما سبق أن مشكلة عدم توافر الحرير الطبيعي في مصر واللجوء إلى الاستيراد من الخارج وما تبعه من ارتقاع أسعار المواد الخام له تأثيره البالغ على الصناعة خصوصاً في ظل خضوع أسعار الحرير للعرض والطلب وعدم وجود تسعيرة لها، وتؤثر مشكلات المادة الخام في ظهور العديد من المشكلات الأخرى التي تواجه صناعة السجاد كما سيتضح. مشكلات صعوبة التسويق الداخلي والخارجي للسجاد . تمدئ تعد مشكلات التسويق إحدى صور غياب الدور الحكومي في دعم الصناعات الحرفية، حيث يتسم السجاد اليدوي في أن إنتاجه لا يوجه للسوق المحلي فحسب، بل إن كميات كبيرة منه توجه للخارج عن طريق التصدير الذي يتم في الغالب عن طريق كبار 
واقع الصناعات الحرفية ومستقبلها بمحافظة المنوفية ـ مصر

التجار والوسطاء الذين يشترون المنتج من الصناع بالقرية بأسعار زهيدة ليقوموا بتسويقه في

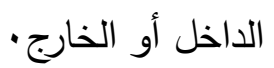

وقد رصدت دراسة(كحم، ه . . †) بعض مشكلات تسويق السجاد في مصر في تركز صادرات السجاد المصري في الأسواق التقليدية(أمريكا الشمالية والدول الأوروبية) وعدم إعطاء العناية الكافية لأسواق الدول الأفريقية ودول أمريكا الجنوبية والدول العربية والآسيوية، ووجود اختلال في توزيع صادرات السجاد على دول العالم مما يتطلب وجود استراتيجية تصديرية جديدة تعمل على زيادة صادرات السجاد إلى دول العالم المختلفة بصورة متوازنة، بالإضافة إلى تركز الطلب المصري على السجاد في الأسواق الآسيوية .

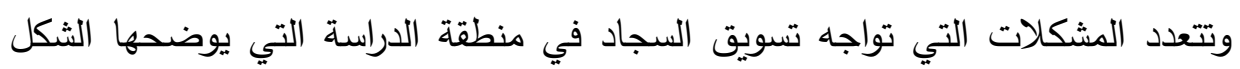
التالي رقم (9) ، حيث يمكن عرضها على النحو التالي: 囚 يعد عدم وجود أسواق داخلية ومعارض على رأس مشكلات تسويق السجاد على عرضى على

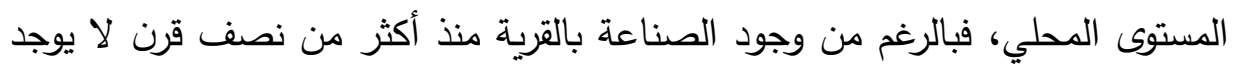
معرض بالقرية لعرض منتجاتها من السجاد، كما لم تقم الجهات الحكومية بدورها في توفير معارض داخلية لعرض السجاد وتسويقه في الأسواق الداخلية .

囚 يتجه أكثر من نصف السجاد بالقربة إلى الأسواق العالمية عن طريق الوسطاء وكبار التجار الذين يقومون بتسويقه في ظل عدم وجود جهة حكومية متخصصة في تسويق المنتج ، ويجد المنتج من السجاد في طريقه للتصدير العديد من العقبات منها تعدد

الإجراءات وتعقدها وطول مدة استخراج موافقات التصدير وغير ذلك من الصعوبات . 囚 يلجأ غالبية الصناع إلى إنتاج السجاد صغير الحجم ، نظراً لارتفاع سعر الوحدة المنتجة والرغبة في تسريع دورة رأس المال • لـاله

囚 يرتبط تسويق السجاد ببعض المناطق السياحية ، ومن ثم فإن رواج السياحة ينعكس بالإيجاب على تسويق السجاد، لكن السياحة المصرية في الفترة الأخيرة تشهد انخفاضاً

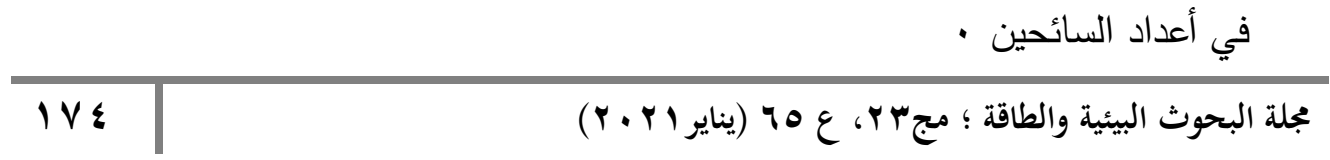


囚 أن عدم وضع محافظة المنوفية على خريطة السياحة في مصر يمثل إثكالية واضحة ، فالمحافظة تحتوي على العديد من مقومات السياحة الريفية ، حيث يمكن أن تكون ساقية أبو شعرة مقصداً سياحياً داخلياً وخارجياً بالتنسيق بين المحافظة وهيئة تنشيط السياحة لاسيما في ظل موقع القرية على فرع دمياط وقربها من القناطر الخيرية، حيث يمكن أن تكون القرية جزء من برنامج للسياحة النيلية يبدأ من القناطر الخيرية ويستمر إليها مع دع ضرورة إنشاء مرسى للسفن واللنشات السياحية .

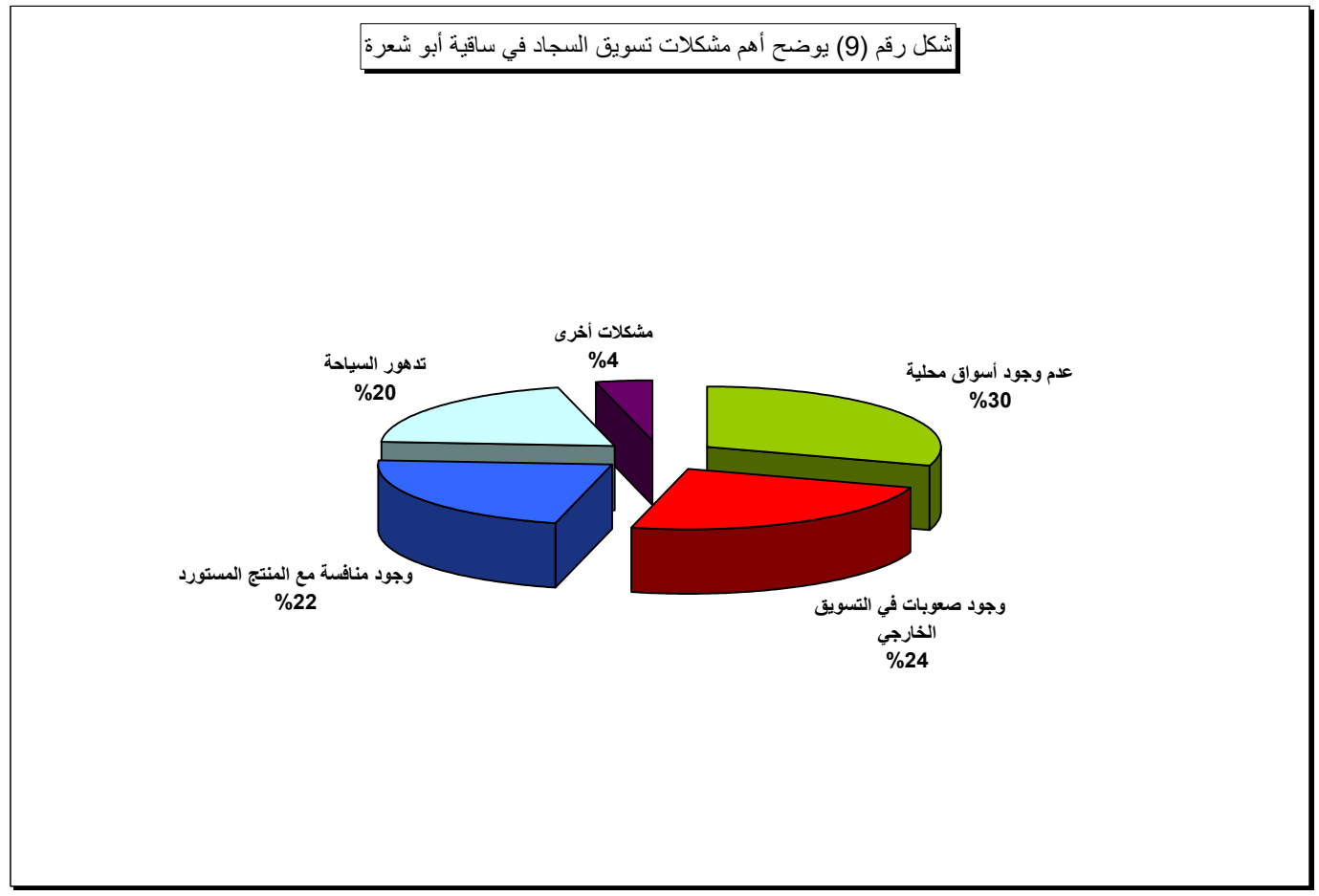

区 يجد السجاد المصري منافسة كبيرة من السجاد الإيراني والصيني والتركي والهندي،

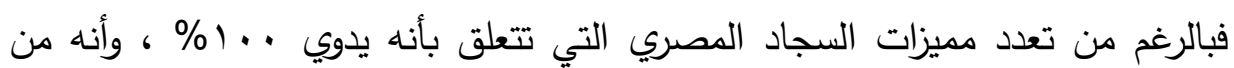
الحرير الطبيعي الخالص كما يتسم بدقة تصميمه ومهارة صناعه وتعدد ألوانه، فإن أسعاره تكون مرتفعة والتشطيب النهائي له لا يكون بنفس جودة تشطيب السجاد لبعض لها

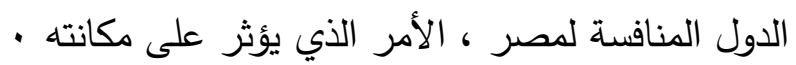


واقع الصناعات الحرفية ومستقبلها بمحافظة المنوفية ـ مصر

凤 هناك بعض المشكلات الأخرى التي تواجه تسويق السجاد منها عدم وجود متخصصين في التسويق لدراسة احتياجات السوق العالمي من أنواع السجاد وتصميماته ، وعدم وجود تود حماية من وزارة الصناعة للمنتج المصري عن طريق فرض رسوم إغراق أو إصدار قوانين كما تفعل بعض الدول الأخرى •

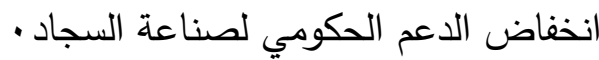
من المفترض أن تتعدد أشكال الدعم الحكومي من أجل تشجيع انتشار الصناعة وتحقيقها عوائد كبيرة تتعكس على سكان القرية والقرى المجاورة ، حيث تشرف على الصناعة العديد من الجهات منها الصندوق الاجتماعي للتتمية ومركز تحديث الصناعة وإدارة الصناعات الحرفية والتعاون الإنتاجي وديوان المحافظة، فإن الواقع يؤكد انخفاض الداعم الحكومي أو تلاشيه وأبرز ملامح انخفاض الدعم: • يرى §؟\% من صانعي السجاد عدم وجود دور للحكومة في دعم صناعة السجاد، كما يرى بr\% وجود دور للحكومة من خلال مركز تحديث الصناعة وصندوق دعم الصناعات الصغيرة والصندوق الاجتماعي للتنمية .

• قامت الحكومة في التسعينيات بتوفير المواد الخام بأسعار زهيدة ومد الورش بقروض بفوائد ميسرة وتسلمت المنتج من السجاد لتقوم بتسويقه، فحققت الصناعة رواجاً اقتصادياً بفضل وزارة الشئون الاجتماعية وقتذاك، لكن الآن لا توجد هذه المظاهر • يواجه بعض أصحاب المصانع تعقيدات روتينية بنسبة \%Vr في سبيل حصولهم على قروض لثراء الخامات وتشغيل المصانع، الأمر الذي جعل بعض المصانع تغلق أبوابها

$$
\text { وما سببه ذلك من بحث عمالها عن فرص عمل · }
$$

* كانت للحكومة دور في توفير معارض لتسويق المنتج من السجاد لكن هذا الدور صار محدوداً للغاية . 
• توجد بالمحافظة إدارة للصناعات الحرفية لا يوجد بها قاعدة بيانات عن حجم هذه الصناعات وطاقتها الإنتاجية ومشكلاتها، فكيف تمد يد العون لهم.

• كان للحكومة دور في إدخال تصميمات جديدة لصناعة السجاد تتناسب مع حاجة الأسواق العالمية في التسعينيات، ويحاول مركز تحديث الصناعة القيام بهذا الدور على دهى استحياء، لكن دوره كان محل استياء من الكثير من الصناع إذ يرون فيه جهة تتحاز

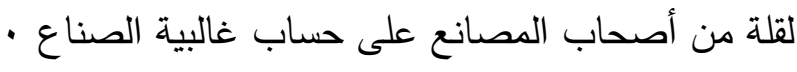
تعدد الوسطاء في صناعة السجاد • تصداء تعد مشكلة تعدد الوسطاء من المشكلات التي تتفاقم في ظل تدني الدور الحكومي في الإشراف والمتابعة والدعم لصناعة السجاد، الأمر الذي جعل فئة التجار والوسطاء يتدخلون في هذه الصناعة في ظل تعدد أدوارهم ما بين إمداد صغار الصناع بالمواد الخام

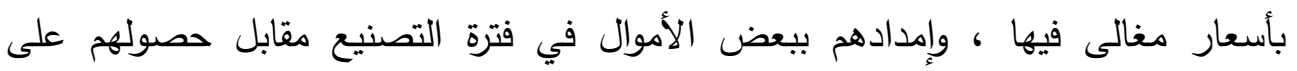
السجادة المنتجة ، ثم شراء المنتج بسعر منخفض دون أن يضعوا في الاعتبار قيمة التكلفة الحقيقية للسجادة، كما يقومون بشراء منتجات صغار الصناع ليعرضوها في معارض توفرها لهح بعض الجهات ليحصلوا على عوائد كبيرة - لمكات وكان من المفترض أن تقوم الجمعية التعاونية الإنتاجية للخدمات الاجتماعية لمنتجي

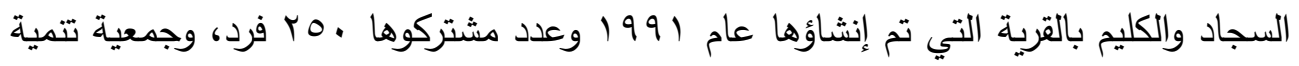

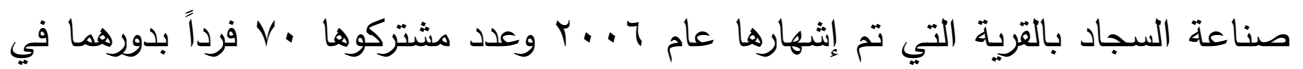
تتمية الصناعة والتغلب على مشكلاتها لكن دورهما محدود للغاية، حيث يرى ل7\% من الصناع أن دورهما غير موجود في دعم الصناع وتتمية الصناعة .

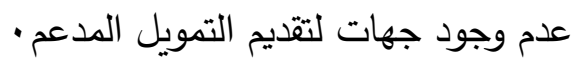
تأتي المشكلة المالية على رأس المشاكل التي تواجه صناعة السجاد ، حيث يرى 9 \% من أصحاب المصانع وجود مشكلات مالية ، ويضاف إليها المشاكل الإدارية المتعددة التي تواجه هذه الصناعة وعدم وفرة الأيدي العاملة، كما ترتبط عملية تتويع المنتج 
واقع الصناعات الحرفية ومستقبلها بمحافظة المنوفية ـ مصر

بمدى توافر الأموال اللازمة لزيادة حجم الإنتاج الذي يتطلبه هذا التتويع، حيث يؤدي عدم وجود تتويع في المنتج إلى ضياع فرص تسويقية عديدة أمام المنتج في الداخل والخارج

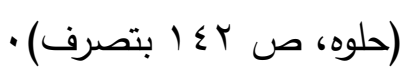

ويعد التمويل العمود الفقري للصناعة ، خصوصاً إذا كانت الصناعة من الصناعات التي تحتاج إلى رأس مال متغير بنسبة كبيرة ، فرأس المال الثابت لمصانع السجاد بالقرية

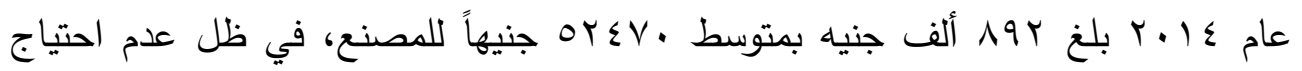

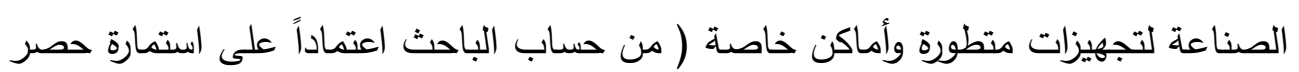
· المنشآت الصناعية ، غير منشورة) وجود بعض الأمراض المرتبطة بالصناعة .

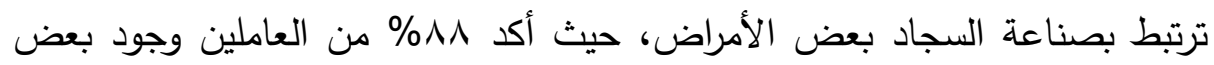
الأمراض التي ترتبط بتلك الصناعة مقابل r Y \% لا يرون وجود أمراض ترتبط بها، وتزداد

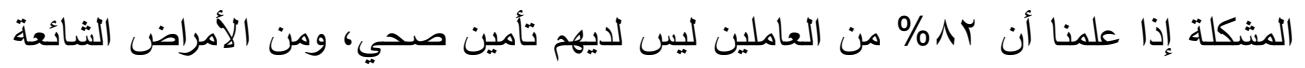
بين العاملين آلام الظهر والعمود الفقري والبواسير التي تتشأ نتيجة جلوس العمال فترات طويلة أمام النول، حيث تصل ساعات العمل إلى V ساعات في الكثير من الورش لا يقطعها سوى وقت محدود لتناول الغداء، كما تتطلب هذه الحرفة الدقة في تتفيذ التصميم الذي تم رسمه على السجادة ، مما يتطلب تركيز العين لفترات طويلة دون إراحتها، الأمر الذي جعل أمراض ضعف النظر شائعة الانتشار بين العاملين بهذه الصناعة .

كما تؤثر بيئة العمل في صناعة السجاد على صحة العاملين بها، حيث تصل

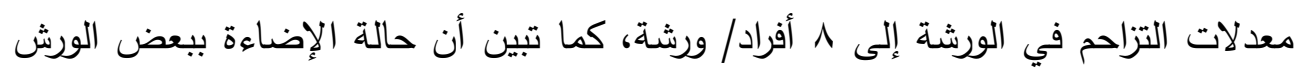

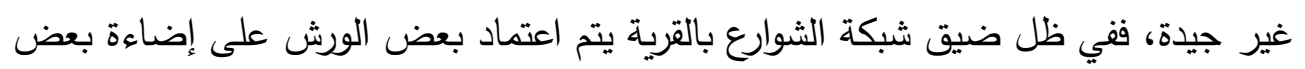

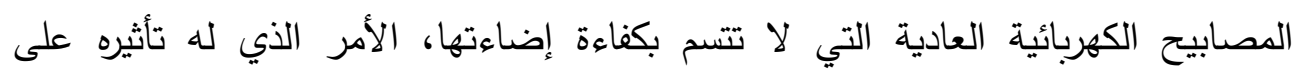
العاملين، كما أن وجود بعض الورش المبنية بالطوب اللبن بالقرية وتردي حالتها الإنشائية

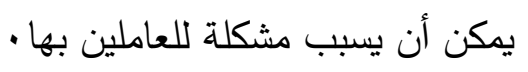

IVA

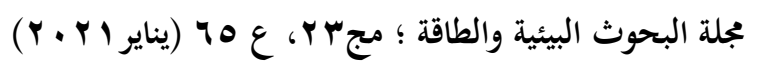


تسرب العمالة وقلة أعداد العاملين المهرة •

إذا كان اختيار ساقية أبو شعرة لتوطن صناعة السجاد بها يعود إلى الخبرة المتوارثة والأيدي العاملة الماهرة بها ، فإن اختيار موقع صناعي معين متغير، فقد يحدث اختيار

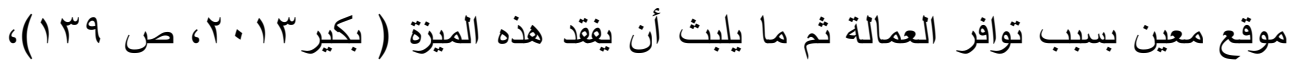

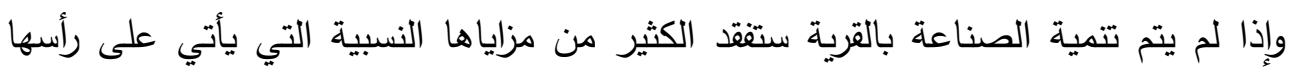
الخبرة ومهارة العاملين التي تراكمت عبر أكثر من نصف قرن • وقد انعكس تذبذب الأجور وركود تسويق المنتج ووجود بعض فرص العمل خارج القرية والكثير من المتغيرات الأخرى على ترك الكثير من العاملين للصناعة التي توارثوها عبر سنوات عديدة والعمل بأنشطة أخرى ، وطالما أن القرية لا يتوافر بها فرص عمل فرل في مشروعات أخرى، فإن غالبيتهم اتجهوا إلى القاهرة في ظل القرب الجغرافي بينها وبين القرية، حيث يرى §9\% من أصحاب الورش بالقرية أن أعداد العاملين بالصناعة تتناقص ، في ظل

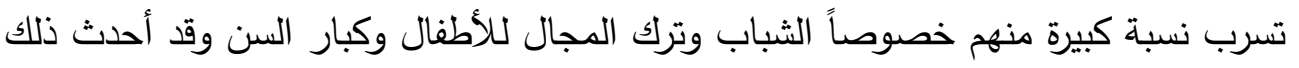

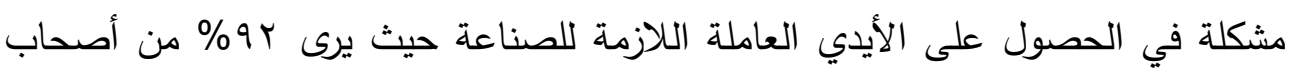
الورش وجود مشكلة في الحصول على الأيدي العاملة، ويرتبط بمشكلات الأيدي العاملة عدم توافرها وقلة خبرة بعض العاملين ومطالبة بعض العاملين بأجور أكبر ،

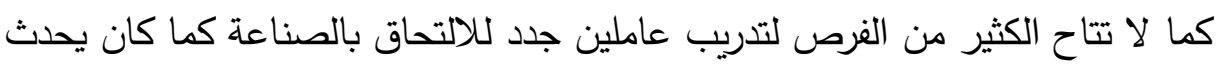
في فترة ازدهار الصناعة، وهذا يتطلب ضرورة اتخاذ التدابير الكفيلة بتنمية هذه الصناعة

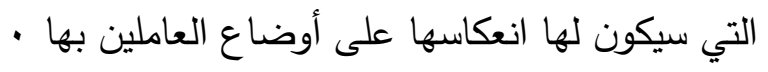

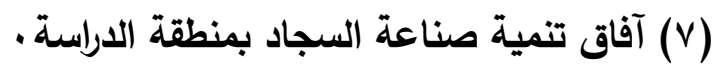

يقوم التخطيط والتنمية على إدراك الواقع بما فيه من محفزات ومعوقات، ومن خلال دراسة واقع الصناعة ومراحلها ومشكلاتها يمكن صياغة العديد من الرؤى التتموية التي كان لنتاج الاستبيان دور كبير فيها، ومن الآفاق التتموية لتتمية صناعة السجاد: 
واقع الصناعات الحرفية ومستقبلها بمحافظة المنوفية ـ مصر

أولاً: توفير المادة الخام اللازمة لصناعة السجاد .

يعد توفير المادة الخام اللازمة لصناعة السجاد من الأمور المههة خصوصاً في ظل استيراد غالبيتها من الخارج، ويمثل الحصول على المادة الخام وتوافرها في الوقت المناسب بالأسعار المناسبة وبالكميات المناسبة وبالنوعيات المناسبة متطلبات تتموية رئيسية لهذه الصناعة التي تعتمد على المواد الخام المستوردة ، ويمكن أن يتم ذلك عن طريق: - 1

تمثل محافظة المنوفية بيئة خصبة للعديد من المشروعات القائمة على الأنشطة الزراعية، ويأتي مشروع تربية دودة القز لإنتاج الحرير على رأس هذه المشروعات لوجود

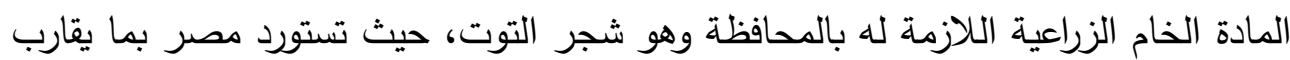
r مليار جنيه حرير وهذه القيمة عالية جداً تؤثر على موازنة الدولة، ومن مميزات المشروع (

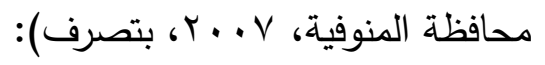
• من ناحية التكلفة نجد أن هذا المشروع لا يتكلف سوى ثمن الحصول على دود القز والمكان الذي تربى فيه، أما بالنسبة للغذاء الذي يتغذى عليه دود القز ، فهو متوافر بكثرة بجميع أنحاء المحافظة .

• من الناحية الإنتاجية والزمنية تستغرق دورة إنتاج الحرير فترة زمنية قصيرة، لذلك فهو - يغطي تكاليفه على المدى القريب الرن

من الناحية العمالية يناسب مشروع تربية دود القز الفئات العمرية المختلفة سواء الأطفال أو الثباب أو ربات المنازل , حيث لا يحتاج إلى جهد متواصل فلا يستلزم التفرغ الكامل له ، بل يمكن ممارسة هذا المشروع بجانب العمل الثابت . من مميزات هذا المشروع توفير فرص عمل على مستوى المحافظة تقدر بحوالي هبألف فرصة عمل ، كما يتوقع أن تبلغ قيمة الإنتاج في حالة نجاح المشروع وانتشاره إلى نصف مليار جنيه.

$1 \wedge$.

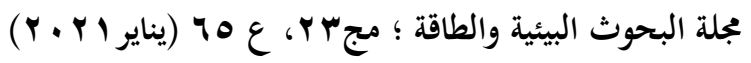


r - إنثاء كيان خاص باستيراد الحرير لصالح الصناعات الحرفية. في ظل تحكم التجار والوسطاء في توفير الحرير المستورد وتحديد أسعاره يعد من الخطوات المهمة تخصيص جهة لتقوم باستيراد الحرير بأسعار تفضيلية، حتى لا ترتفع

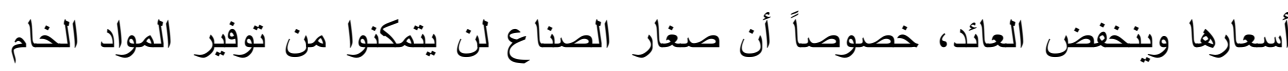
بنفس الأسعار، ويمكن تخصيص حصة من هذه الجهة لكل ورشة تتناسب مع عدد الأنوال وعدد العاملين بها، كما يجب تخفيض الجمارك على مستلزمات الإنتاج المستورد . r- التوسع في إنتاج بعض أصناف السجاد التي تعتاج كميات مادة خام أقل • يتم إنتاج السجاد اليدوي في القرية بمعايير جودة مرتفعة تتمثل في زيادة عدد العقد

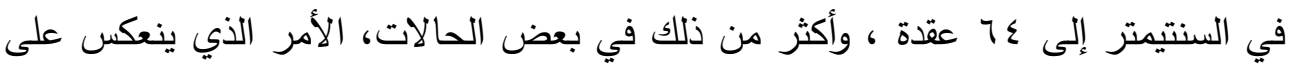
زيادة تكلفة المادة الخام وزيادة التكلفة الإجمالية للسجادة ، الأمر الذي يتطلب إنتاج سجاد بعدد عقد أقل ترشيداً للتكلفة وتشجيعاً للمستهلكين على اقتناء السجاد اليدوي حيث سيكون الإدها سعره أقل - بعدود ثانياً: إنشاء مجمع للصناعات الصرفية بالقرية . تذهب بعض الدراسات إلى ضرورة إنشاء مجمع صناعي كبير يضم كافة العاملين بالصناعة يقوم بإنشائه الصندوق الاجتماعي للتنمية ، وتقوم الجهات التدريبية من الجامعات

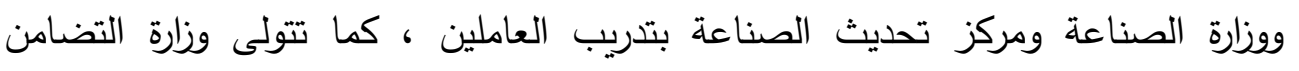
الاجتماعي مسئولية التسويق بعمل معارض ثابتة ومتحركة على المستوى المحلي والدولي

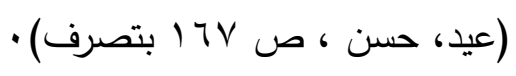

كما اقترحت بعض الدراسات إنثاء وحدات إنتاجية لخدمة هذه الصناعة ، بغية إعداد خاماتها أو ما يتعلق بوسائل إنتاجها، بحيث تكون هذه الوحدات بمثابة مركز تدريب كبيرة

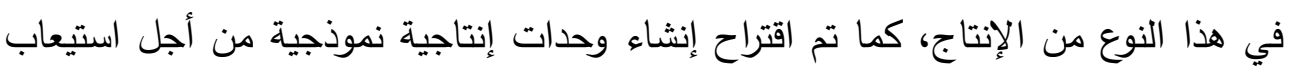
الجهود الفردية المشتتة وتركيز الإنتاج الفني وتوجيه الإنتاج صوب مواصفات محدودة ، حتى يطبع هذا النوع من الإنتاج بطابع الدقة ، فيرتفع مستواه ويسهل تصريفه بالإضافة إلى الإن أن هذه الوحدات ستكون بمثابة مراكز تدريب للصناع الجدد والحاليين، وبهذا تصبح هذه الهن 
واقع الصناعات الحرفية ومستقبلها بمحافظة المنوفية ـ مصر

المراكز مصدر إشعاع يأخذ بيد الصناعات الريفية نحو الازدهار ( صادق ، ص اسج •بتصرف)

ومن المكن أن يتضمن مجمع الصناعات الحرفية بالقرية :

• محدة خاصة بإنتاج الحرير من دود القز من المحافظة

• وحدة خاصة بصباغة الحرير، لما لها من أهمية في صناعة السجاد بدلاً من الذهاب إلى القاهرة وغيرها من المناطق •

ثم وحدة خاصة بتصميم السجاد وتجهيزها بأحدث الأجهزة، لعمل تصميمات حديثة تتناسب

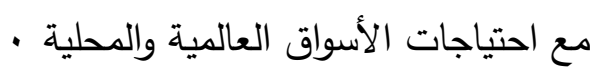

• محدة خاصة بالتسويق تقوم بدورها في تفعيل عملية التسويق والترويج له على المستوى

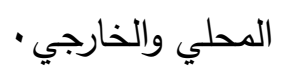

• وحدة خاصة بالدعم المالي للصناع يكون دورها دراسة حاجة الورش المختلفة للدعم

$$
\text { وتيسير الحصول عليه بقروض ميسرة • }
$$

• محدة خاصة بالتدريب لتدريب العاملين الجدد والقدامى على الارتقاء بجودة المنتج • • محدة خاصة بضبط جودة المنتج ليكون مطابقاً لأعلى المواصفات • • وحدة خاصة بالتشطيب النهائي للمنتج وتجهيزه للتسويق الداخلي أو الخارجي • • وحدة خاصة بالصناعات والحرف المساندة لصناعة السجاد . • وحدة خاصة بالتخطيط والتتمية لصناعة السجاد يكون دورها إعداد دراسات للارتقاء بالصناعة والتغلب على مشكلاتها . 
ويرى البعض وجود بعض الارتباطات الصناعية منها ارتباط المادة الخام عن طريق تدفقها من مرحلة إلى مرحلة أثناء الصناعة حتى تصل إلى المرحلة النهائية، والارتباط الخدمي والمعلوماتي الذي لا يشترط فيه انتقال أو تحرك المادة الخام ، بل من خلال تقديم بعض المعلومات والخدمات التي تئثر على الصناعة ، والارتباط الإداري الذي يتضمن العلاقات الإدارية في الصناعة وما تمثله من أهمية لها (Storper,M,p.23 ) ثالثاً: تفعيل الدور الحكومي في تنمية الصناعة بالقرية . يمكن للحكومة المساهمة في تتمية صناعة السجاد من خلال: تمتلك الصناعات الحرفية طاقات تصديرية كامنة قادرة على تقديم منتجات متميزة ذات فرص تصدير واعدة باعتبارها تحمل الموروث الثقافي والحضاري المصري والإبداع الفني الحرفي الأصيل، وبالتالي لا بد أن يوجه لها المزيد من الحوافز الداعمة حتى تحدث طفرة تصديرية هائلة من خلال دفع منتجاتها إلى أسواق التصدير العالمية (رئاسة

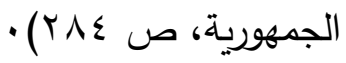

تدريب العمال الجدد على طرق الإنتاج الصحيحة وإعداد ما يلزمها من التصميمات ذات الطابع القومي الأصيل النمابل تسهيل عملية التسويق داخلياً وخارجياً وإمداد الصناعة بالقروض بفوائد بسيطة لتسهيل • عملية التمويل دعم الصناعة عن طريق جهاز تنمية المشروعات الصغيرة الذي تم إنشاؤه بالقرار الجمهوري رقم عبـ لسنة 1999 تحت إدارة الصندوق الاجتماعي للتمية . محاولة تخفيف الشروط الواجب توافرها في المقترضين من قبل الصندوق الاجتماعي للتتمية ، حيث يشترط الأهلية القانونية وحسن السير والسلوك والإلمام بالقراءة والكتابة والتثرغ للمشروع والتواجد بذات المحافظة المقام بها النشاط والانتهاء من الخدمة 
واقع الصناعات الحرفية ومستقبلها بمحافظة المنوفية ـ مصر

العسكرية أو الإعفاء منها، فبعض هذه الشروط تتنافى مع الواقع الذي تعيشه الصناعة مثل اشتراط الإلمام بالقراءة والكتابة أو التثرغ. • تسهيل الحصول على الائتمان وعدم المغالاة في الضمانات • تتسيق جهود الهيئات والجهات التي تتعامل مع المشروعات الصغيرة • تخفيض الضرائب المفروضة على الصناعة والتأمينات الاجتماعية بالقرية، وتيسير حصول الورش على الترخيص •

رابعاً: الاهتمام بتسويق السجاد داخلياً وخارجياً .

يمكن الارتقاء بعملية تسويق السجاد بالقرية عن طريق: م تزويد المنتجين بالمعلومات والبيانات المتعلقة باتجاهات الأسواق الخارجية .

o

م الاهتمام برفع جودة منتجات المشروعات الصغيرة، وإيجاد الحلول الفعالة لمشاكل • التسويق

م الاهتمام برفع مستوى جودة المنتجات الحرفية خصوصاً في مرحلة التشطيب النهائي O قيام مكاتب التمثيل التجاري بالسفارات المصرية بالخارج بدورها في تعريف المستهلكين

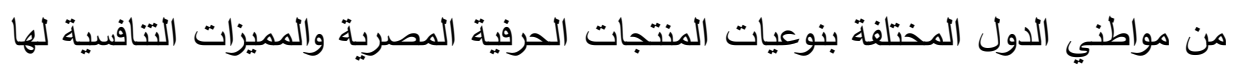

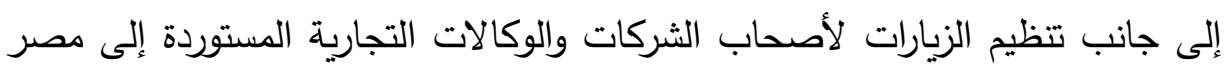
للالتقاء بممثلي المنظمات الحرفية بها، والتعرف على تلك المنتجات على الطبيعة وتحديد احتياجاتهم منها ( رئاسة الجمهورية، ص بر ب بتصرف) • م تشجيع إقامة المعارض الداخلية والخارجية للسجاد لدورها في تتشيط عملية التسويق وما لذلك من انعكاسات تتموية على القرية . 
خامساً: دعم الجهود الأهلية في تنمية السجاد بالقرية .

يوجد بالقرية الجمعية التعاونية الإنتاجية لمنتجي السجاد بساقية أبو شعرة وجمعية تتمية صناعة السجاد ، ويسعى البعض الآن إلى إثهار جمعية ثالثة تحمل اسم تراثنا، لكن هذه الجهود لا تتسم بالتكامل والتعاون فيما بينها ، كما توجد بعض المحاولات التي تقوم بها بعض الجهات بالمحافظة لزياة القرية والتعرف على مشاكلها لكن هذا ينتهي بمجرد انتهاء

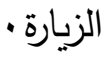

لذا ينبغي دعم هذه الجهود الأهلية حتى تؤتي ثمارها في تتمية الصناعة وحل الكثير

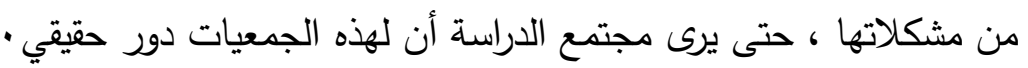

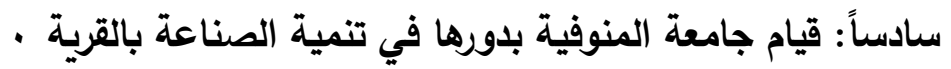
يمكن لجامعة المنوفية من خلال العديد من كلياتها المساهمة في تطوير وتتمية صناعة السجاد، فكلية التربية النوعية التي تقع بمدينة أشمون وتبعد عن القرية بنحو عشرة كيلو مترات عليها دور في تحديث التصميمات وإدخال الحاسب الآلي في إعدادها لأنها تتم بطرق بدائية حتى الآن ، كما يمكن أن تقوم بتطوير طرق النسيج وتدريب العاملين بالقرية

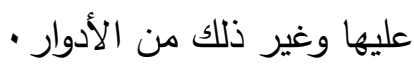
كما يمكن لكلية الهندسة بشبين الكوم أن تقوم بدورها في تتمية هذه الصناعة خصوصاً أن بها مركز لتتمية الريف المصري ، كما أن بعض أقسامها تقوم بدراسات لها ارتباطها

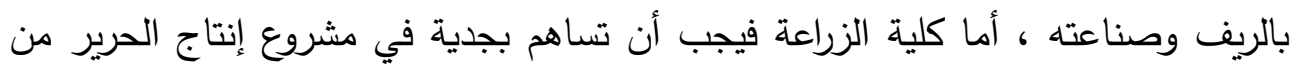
دودة القز حتى نقلل من الاستيراد ، كما يمكن لكلية التجارة أن تقوم بعمل دراسات تتعلق بكيفية تفعيل تسويق المنتج وفع عوائده ، كما يمكن لبعض أقسام كلية الآداب مثل الجغرافيا والاجتماع والإعلام المساهمة في تتمية هذه الصناعة، بالإضافة إلى دور كلية

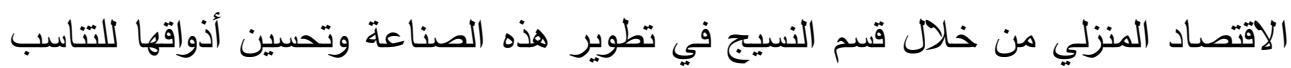

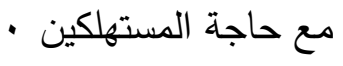
نتائج البحث أسفرت دراسة صناعة السجاد اليدوي عن العديد من النتائج منها: 
واقع الصناعات الحرفية ومستقبلها بمحافظة المنوفية ـ مصر

أسهح عامل الخبرة المتوارثة وتوافر الأيدي العاملة الماهرة في توطنها، الأمر الذي كان له انعكاسه على الكثير من الأوضاع الاجتماعية والاقتصادية بالقرية .

مرت هذه الصناعة بمراحل كل مرحلة لها ما يميزها، حيث بدأت بمرحلة الدخول إلى

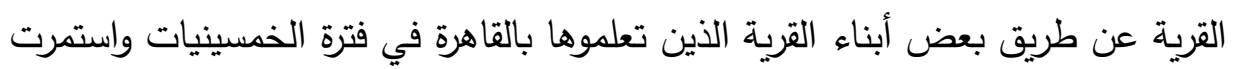

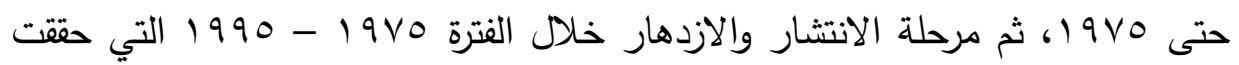
فيها الصناعة نهضتها ، ثم مرحلة التذهور والاتحسار التي عاشتها الفترة بعد 1990

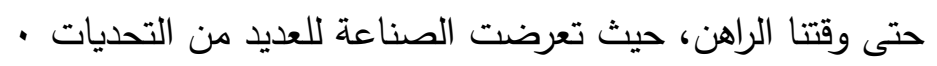

تقف العديد من العوامل وراء توطن صناعة السجاد بالقرية يأتي على رأسها توافر

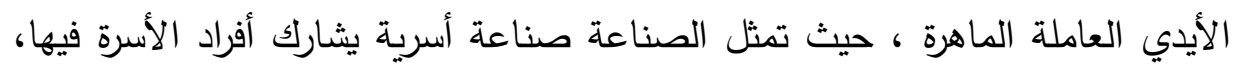
لذا تمثل تكلفة العمل نحو خمسي تكلفة الإنتاج، كما مثل التسويق عاملاً مهماً في هذه

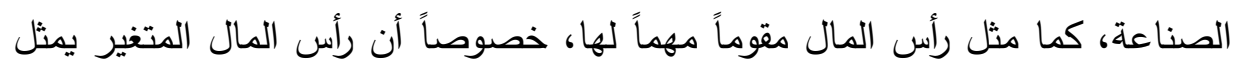

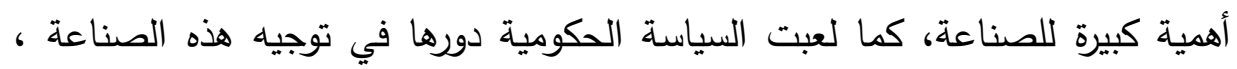
بالإضافة لبعض العوامل الأخرى · لمئل

تعكس اقتصاديات إنتاج السجاد تقلص الفجوة بين التكلفة والعوائد، ففي التسعينيات كانت التكلفة محدودة وكان العائد كبيراً ، مما انعكس على وجود صافي عائد كبير ، أما في الوقت الحالي فقد انخفض هامش الربح.

يتباين الوزن النسبي لعناصر التكلفة من عمل ومواد خام وتسويق بين الصناعات المختلفة، حيث تتزايد تكلفة العمل والمادة الخام بين المكونات المختلفة للتكلفة في صناعة السجاد كنموذج للصناعات اليدوية التي تتطلب مهارات فنية .

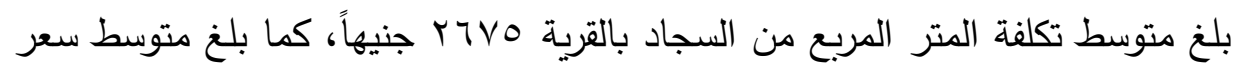

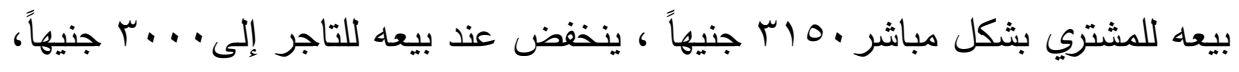


أي أن صافي الربح الذي يحققه بيع المتر المربع من السجاد يبلغ ه \؛ جنيهاً عند بيعه

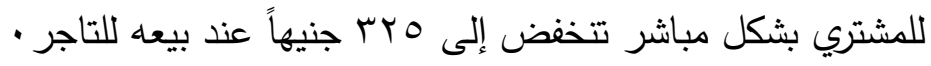

" كان لصناعة السجاد آثارها التنموية على القرية من حيث خلق فرص لعمل لسكانها، والانعكاس على الوزن النسبي للسكان داخل قوة العمل، وعلى الأنشطة الاقتصادية لديهم التي تتفوق فيها الصناعة على متوسط المركز والمحافظة، كما ترتفع نسبة أرباب المهن بالقرية، كما كان لها انعكاسها على الخدمات والمرافق والنمو العدراني بالقرية . تواجه صناعة السجاد باعتبارها صناعة يدوية كثيفة العمل العديد من المشكلات منها نقص التمويل وصعوبة التسويق ومشكلات الحصول على المادة الخام ومشكلات التسويق ومشكلات تسرب العمالة وانخفاض الأيدي العاملة الماهرة ، وتدني الدور

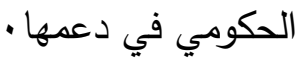

انتهى البحث ببعض المقترحات التنموية للنهوض بالصناعة بالقرية .

$$
\text { توصيات البحث }
$$

انتهى البحث ببعض التوصيات للنهوض بالصناعة وتتميتها منها: • ينبغي توحيد الجهات التي تتعامل مع المشروعات الحرفية والصغيرة في المحافظة

$$
\text { للتيسير على المستثرين - لتهي }
$$

• ينبخي دعم الجهات القائمة على التسويق الداخلي والخارجي للسجاد ، لأن التسويق

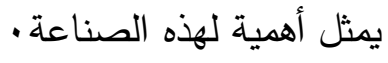

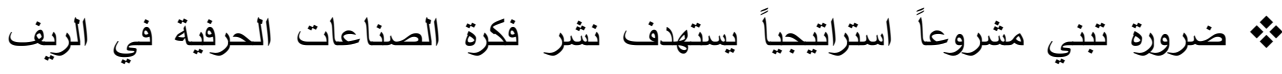
المصري، لما لها من انعكاسات اجتماعية واقتصادية متعددة .

• إنشاء مجمع صناعي متكامل للصناعات الحرفية بالقرية يتضمن كافة الوحدات المطلوبة، من أجل أن تكون القرية نموذجاً للقرى الإنتاجية . 
• • أن تقوم الدولة بتوفير المواد الخام اللازمة للصناعة من مصادرها بأسعار مناسبة ، ولا

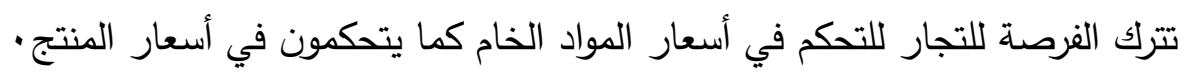
• د دعم صناع السجاد بالقرية سواء ما يتعلق بالدعم المادي أو الدعم الاجتماعي أو الدعم الصحي، في ظل وجود بعض الأمراض التي ترتبط بالصناعة .

• تشجيع إقامة مشروع تربية الحرير بالاعتماد على دودة القز الذي سيكون له دوره في توفير الحرير الطبيعي بالداخل وتقليل الاستيراد من الخارج، بالإضافة إلى دوره في توفير فرص عمل للسكان - توبري

• ضرورة مواكبة التغيرات التي تحدث في أذواق المستهلكين في تصميم السجاد وألوانه وإنتاجه، لضمان استمرارية الطلب على السجاد -

• تشجيع جمعيات المجتمع المدني والجمعيات الحكومية المهتمة بالسجاد بالقرية على القيام بدورها على الوجه الأكمل، لما لذلك من انعكاس على الصناعة .

• ضرورة الارتقاء ببيئة العمل في صناعة السجاد، لما لذلك من انعكاسات صحية على

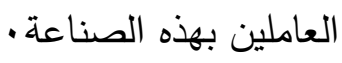

• مضع القرية على خريطة السياحة الداخلية والخارجية، عن طريق الاستفادة من موقعها وتتوع إمكانية الوصول لها، لما لذلك من انعكاس إيجابي على الصناعة . • تشجيع إقامة معارض تسويق السجاد لدورها في تتشيط حركة بيعه سواء كانت معارض

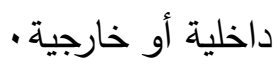

• توفير القروض المطلوبة لتنمية الصناعة بفوائد بسيطة، مع ضرورة تقليل الضمانات المطلوبة للقروض ورفع مبالغ القروض حتى تحقق هدفها .

$1 \wedge \Lambda$

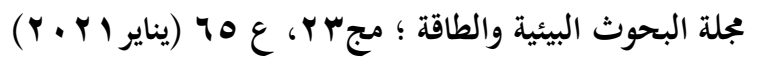


• ضرورة إنشاء مدرسة ثانوية صناعية في القرية تتضمن بعض الأقسام التي تخدم الصناعة والصناعات اليدوية الأخرى الموجودة بالمركز مثل صناعة الفخار وصناعة التطعيم بالصدف .

• ضرورة قيام جامعة المنوفية بدروها في خدمة وتتمية هذه الصناعة من خلال كلياتها المختلفة التي ترتبط بهذه الصناعة مثل كلية الزراعة وكلية التربية النوعية وكلية الاقتصاد المنزلي وكلية الهندسة وكلية التجارة وكلية الآداب • ث م ينبغي قيام محافظة المنوفية بإعداد دليل للصناعات الحرفية في المحافظة ، يتضمن تاريخها وجغرافيتها ومقوماتها ومشكلاتها وكيفية تتميتها خصوصاً أن بعضها مهدد

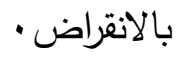


واقع الصناعات الحرفية ومستقبلها بمحافظة المنوفية ـ مصر

\section{مصادر ومراجع البحث}

أولاً: المصادر : n

• الجهاز المركزي للتعبئة العامة والإحصاء، تعداد السكان وتعداد المباني لمحافظة

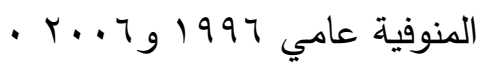

• الجهاز المركزي للتعبئة العامة والإحصاء، صناعة السجاد والموكيت في مصر،

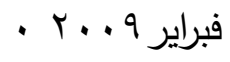

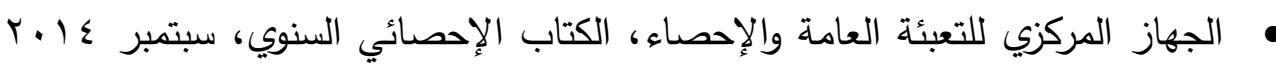

رئاسة الجمهورية، المجالس القومية المتخصصة، الصناعات الحرفية في مصر، تقرير

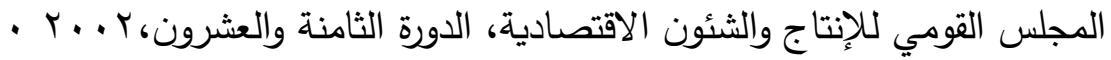

رئاسة مركز ومدينة أثمون، إدارة التتمية، بيانات غير منشورة •

مجلس الثورى، خطة قومية لتتمية الصناعات الصغيرة مع الاستفادة من تجارب الدول

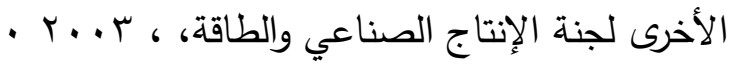

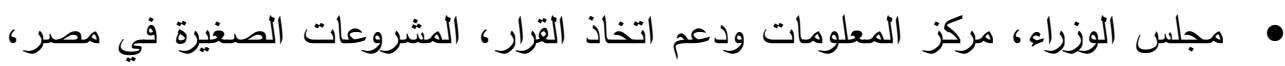

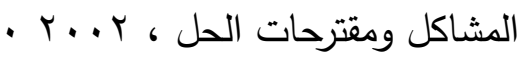

محافظة المنوفية ، إدارة الصناعات الحرفية والتعاون الإنتاجي، بيانات غير منشورة

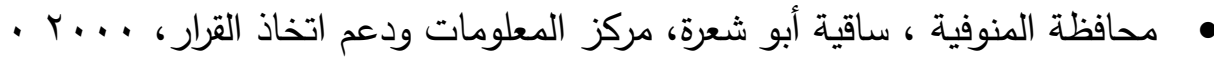

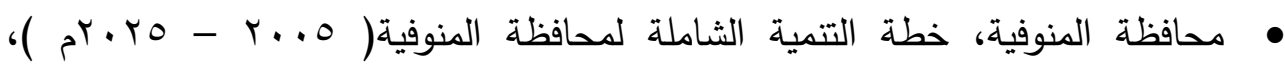

. $r . . V$

• معهد التخطيط القومي، تقرير التمية البشرية لمحافظة المنوفية عام r ب r ، تقرير

• غير منشور

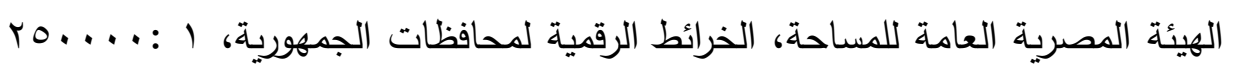

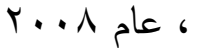

19.

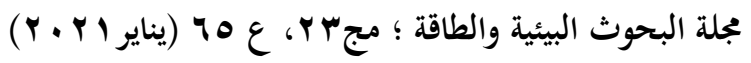


الهيئة المصرية العامة للمساحة، الخرائط الرقمية لمحافظة المنوفية، مقياس | :

$$
\text { r...... }
$$

وزارة الإسكان والمرافق ، الهيئة العامة للتخطيط العمراني، المخطط العمراني الإرشادي لقرية ساقية أبو شعرة مركز أشمون محافظة المنوفية ، 0. . ب .

ثانياً: المراجع العربية: - مانه

إبراهيم علي غانم، الاتجاهات الحديثة في جغرافية الصناعة، سلسلة بحوث جغرافية،

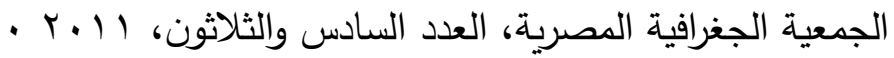

أحمد حبيب رسول، جغرافية الصناعة، دار النهضة العربية، بيروت ، 1910 . حسن عبد القادر صالح، مدخل إلى جغرافية الصناعة، دار الثروق للنشر والتوزيع،

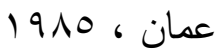
دولت صادق، الصناعات الريفية وأثرها في التتمية الاقتصادية، في بحوث المؤتمر الجغرافي العربي الأول، المجلد الثاني، القاهرة 1970 ـ رشدي علي عيد، محمد السيد حسن ، خطة مقترحة للنهوض بالصناعات النسيجية اليدوية بجمهورية مصر العربية، مجلة الاقتصاد المنزلي، كلية الاقتصاد المنزلي جامعة

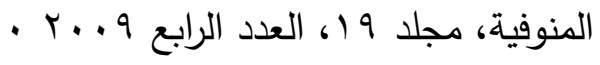

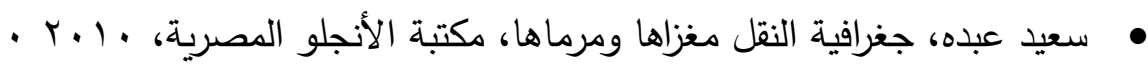
شوهدي عبد الحميد الخواجة، الصناعات الصغيرة في مركز أجا ودورها في التتمية دراسة جغرافية، المؤتمر السنوي لقسم الجغرافيا ونظم المعلومات الجغرافية ، بدون تاريخ • صلاح عبد الجابر عيسى، نماذج تطبيقية من إسهامات المرأة الريفية في الصناعات الحرفية الصغيرة بمحافظة المنوفية، المؤتمر القومي الثالث للمرأة ، محافظة المنوفية

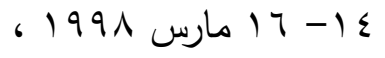

• صلاح عبد الجابر عيسى، جغرافية الريف منهجيات وقضايا متطورة، ع ا ب . 
واقع الصناعات الحرفية ومستقبلها بمحافظة المنوفية ـ مصر

عبد الستار حسين أبو هاشم، فن صناعة السجاد والكليم اليدوي، مكتبة ابن سينا ،

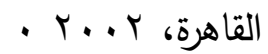

عبير محمود عبد الحكم محمد ، اقتصاديات صناعـة السجاد في مصـر ، رسالة ماجستير غير منشورة، قسم الاقتصاد كلية التجارة جامعة عين شمس، ه . . ب . علي محمد حلوه، استخدام المزيج التسويقي في تتشيط الصناعات الحرفية بالتطبيق على صناعة السجاد بمحافظة المنوفية، مجلة آفاق جديدة، كلية التجارة جامعة المنوفية،

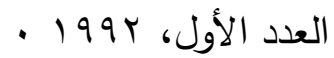

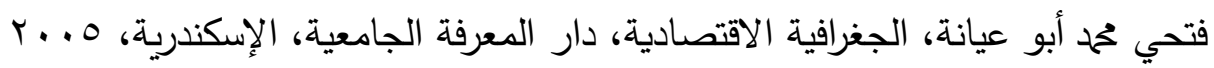
فتحي محم مصيلحي، المنوفية ، طاقات بشرية متجددة وسقوف تتموية متغيرة، مطابع جامعة المنوفية، ب ... ب . فؤاد محمد الصقار ، الجغرافية الصناعية في العالم، منشأة المعارف، ، ـ191 • محمد إبراهيم رمضان، جغرافية الصناعة في ضوء المتغيرات العالمية المعاصرة، مجلة

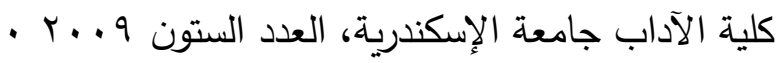
محمد الفتحي بكير، الجغرافيا الاقتصادية ، أسس وتطبيقات، دار المعرفة الجامعية،

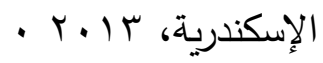
محمد خميس الزوكة، جغرافية المعادن والصناعة، دار المعرفة الجامعية، الإسكندرية، . r... موسى فتحي عتلم، خريطة التعليم العام قبل الجامعي في مركز أشمون - دراسة في

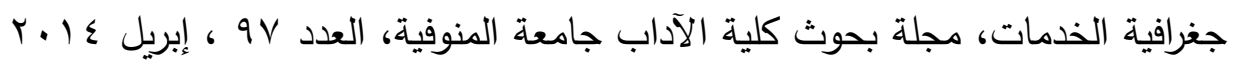

نانسي سعيد سعد حبل، العوامل المؤثرة في تتمية الصناعات الحرفية اليدوية، دراسة حالة محافظة المنوفية، رسالة ماجستير في الهندة المعمارية تخصص تخطيط

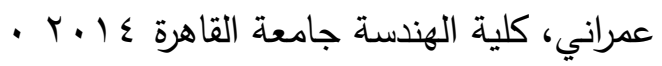




\section{د/ موسى فتحي موسى عتلم}

• نيفين فرج إبراهيم، دور الصناعات الصغيرة في الاقتصاد المصري مع إثارة خاصة

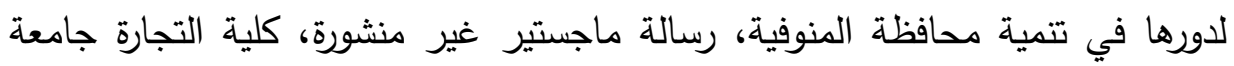

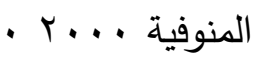

ثالثاً : المراجع غير العربية:

- Storper,M, Toward A structural Theory of Industrial Location, in Industrial Location and Regional Systems, Bergin publishers, New York, 1981 .

- Watts. H, Industrial Geography, Longman Scientific \& Technical, New York, 1987.

- Wheeler,J, et al, Economic Geography, Third Edition, John Wiley, New York, 1998 . 